\title{
The Role of Smoothened-Dependent and -Independent Hedgehog Signaling Pathway in Tumorigenesis
}

\author{
Jian Yi Chai ${ }^{1}$, Vaisnevee Sugumar ${ }^{2}$, Mohammed Abdullah Alshawsh ${ }^{3, *} \mathbb{C}$, Won Fen Wong ${ }^{4}{ }^{\oplus}$, Aditya Arya ${ }^{5}$, \\ Pei Pei Chong $1,6(1)$ and Chung Yeng Looi $1,6, *$
}

1 School of Biosciences, Faculty of Health \& Medical Sciences, Taylor's University, 1 Jalan Taylors, Subang Jaya 47500, Malaysia; jianyi.chai@sd.taylors.edu.my (J.Y.C.); PeiPei.Chong@taylors.edu.my (P.P.C.)

2 School of Medicine, Faculty of Health \& Medical Sciences, Taylor's University, 1 Jalan Taylors, Subang Jaya 47500, Malaysia; vaisneveesugumar@sd.taylors.edu.my

3 Department of Pharmacology, Faculty of Medicine, University of Malaya, Kuala Lumpur 50603, Malaysia

4 Department of Medical Microbiology, Faculty of Medicine, University of Malaya, Kuala Lumpur 50603, Malaysia; wonfen@um.edu.my

5 School of Biosciences, Faculty of Science, Building 184, The University of Melbourne, Melbourne, VIC 3010, Australia; aditya.arya@unimelb.edu.au

6 Centre for Drug Discovery and Molecular Pharmacology (CDDMP), Faculty of Health \& Medical Sciences, Taylor's University, 1 Jalan Taylors, Subang Jaya 47500, Malaysia

* Correspondence: alshaweshmam@um.edu.my (M.A.A.); chungyeng.looi@taylors.edu.my (C.Y.L.)

check for updates

Citation: Chai, J.Y.; Sugumar, V.; Alshawsh, M.A.; Wong, W.F.; Arya,

A.; Chong, P.P.; Looi, C.Y. The Role of

Smoothened-Dependent and

-Independent Hedgehog Signaling

Pathway in Tumorigenesis.

Biomedicines 2021, 9, 1188. https://

doi.org/10.3390/biomedicines9091188

Academic Editor: Dawn

Elizabeth Quelle

Received: 3 August 2021

Accepted: 1 September 2021

Published: 10 September 2021

Publisher's Note: MDPI stays neutral with regard to jurisdictional claims in published maps and institutional affiliations.

Copyright: () 2021 by the authors Licensee MDPI, Basel, Switzerland. This article is an open access article distributed under the terms and conditions of the Creative Commons Attribution (CC BY) license (https:/ / creativecommons.org/licenses/by/ $4.0 /)$.
Abstract: The Hedgehog (Hh)-glioma-associated oncogene homolog (GLI) signaling pathway is highly conserved among mammals, with crucial roles in regulating embryonic development as well as in cancer initiation and progression. The GLI transcription factors (GLI1, GLI2, and GLI3) are effectors of the Hh pathway and are regulated via Smoothened (SMO)-dependent and SMOindependent mechanisms. The SMO-dependent route involves the common Hh-PTCH-SMO axis, and mutations or transcriptional and epigenetic dysregulation at these levels lead to the constitutive activation of GLI transcription factors. Conversely, the SMO-independent route involves the SMO bypass regulation of GLI transcription factors by external signaling pathways and their interacting proteins or by epigenetic and transcriptional regulation of GLI transcription factors expression. Both routes of GLI activation, when dysregulated, have been heavily implicated in tumorigenesis of many known cancers, making them important targets for cancer treatment. Hence, this review describes the various SMO-dependent and SMO-independent routes of GLI regulation in the tumorigenesis of multiple cancers in order to provide a holistic view of the paradigms of hedgehog signaling networks involving GLI regulation. An in-depth understanding of the complex interplay between GLI and various signaling elements could help inspire new therapeutic breakthroughs for the treatment of Hh-GLI-dependent cancers in the future. Lastly, we have presented an up-to-date summary of the latest findings concerning the use of $\mathrm{Hh}$ inhibitors in clinical developmental studies and discussed the challenges, perspectives, and possible directions regarding the use of SMO/GLI inhibitors in clinical settings.

Keywords: GLI1 protein; hedgehog pathway; mutations; epigenetic regulation; glioma-associated oncogene; noncanonical; cancer; clinical trial; hedgehog inhibitors

\section{Introduction}

The hedgehog $(\mathrm{Hh})$ signaling pathway was first discovered in Drosophila melanogaster's embryonic cell [1]. Its evolution across various species is relatively conserved; however, duplication of the Hh gene in mammals revealed the involvement of three other members of the Hh family, namely the Sonic (Shh), Desert (Dhh), and Indian hedgehog (Ihh) [2]. Each of these genes has a diverse function in developing various tissues and organs; nevertheless, they utilize a similar pathway to be activated. In mammals, the Hh signaling is a rather complex relay mechanism that occurs in the primary cilium. Without the binding of 
Hh ligands to the Patched (PTCH), a 12-pass transmembrane protein receptor, the pathway remains suppressed due to the inhibitory effect of PTCH on the seven-pass transmembrane protein Smoothened (SMO) [3]. The binding of Hh ligands to PTCH relieves the inhibition of SMO protein, allowing its translocation into the primary cilium, where it rapidly accumulates [4]. Subsequently, activated SMO interferes with the proteolytic processing of glioma-associated oncogene homolog (GLI) proteins and promotes their dissociation from Suppressor of Fused (SUFU), allowing their translocation into the nucleus [5]. Through their DNA-binding domains, GLI activators (GLIAs) then bind to the GLI-binding consensus sequence $5^{\prime}$-GACCACCCA-3' residing within promoters of target genes to initiate their gene transcription, such as cyclins (CCND1, CCND2), antiapoptotic factors (BCL2, BCLX), migratory genes (SNAI1, ZEB1), and its own pathway genes (PTCH1, GLI1) [6,7].

However, the diverse response of GLI in tissues is very dependent on the delicate balance between GLIAs and GLI repressors (GLIRs) combined. The negative regulation of GLI protein (Figure 1A) is regulated by its interaction with SUFU by virtue of its SUFU-binding domain. In the absence of the Hh ligand, SMO remains inactivated, which allows the tight association of SUFU with GLI [8]. GLI bound to SUFU is susceptible to phosphorylation events that promote its processing into repressors. G-protein coupled receptor 61 (Gpr161) localizes to the primary cilia to maintain high cyclic adenosine monophosphate (CAMP) levels and protein kinase A (PKA) activity [9], which phosphorylate P1-6 clusters located on GLI2/3 [10]. Their phosphorylation by PKA primes their subsequent phosphorylation by glycogen synthase kinase 3 beta (GSK3 $\beta$ ) and casein kinase I (CKI) [11]. Phosphorylated GLI2/3 are recognized by the Cul1/ $\beta$-TrCP complex, promoting their ubiquitination and subsequent proteasomal-dependent processing into GLIRs $[12,13]$. GLIRs then bind to the promoters of target genes to repress their transcription. In the presence of an $\mathrm{Hh}$ ligand, however, activation of SMO leads to the dephosphorylation of GLI2/3 P1-6 clusters and their dissociation from SUFU [10], favoring the translocation of GLIAs into the nucleus to initiate the transcription of target genes (Figure 1B). The expression of GLI1, a primary Hh target gene, serves to amplify $\mathrm{Hh}$ transduction at the transcriptional level further [14].

Typically, Hh signaling activation is classified into two general models: ligandindependent (Type I) and ligand-dependent (Type II and III) Hh signaling. This model centers around the various Hh pathway components leading to GLI activation, which can occur either through mutations in PTCH or SMO (ligand independent) or Hh ligand stimulation (ligand dependent); however, the transcriptional or epigenetic dysregulation of Hh pathway-related genes (e.g., aberrant methylation or excessive transcription factor activation) leading to GLI activation and the regulation of GLI beyond SMO transduction are often overlooked in this model. In this review, we describe a Hh signaling model that focuses on two different GLI regulation levels relevant to carcinogenesis: SMO-dependent and SMO-independent GLI activation. Arguably, these models provide a holistic view of the paradigms of hedgehog signaling networks involving GLI regulation at the SMO level or beyond and may be more relevant to current therapeutic strategies involving the development of SMO and GLI inhibitors for treating Hh-dependent cancers. Additionally, we present the latest clinical trial findings for the recent development of Hh inhibitors in cancer treatment and provide a comprehensive review concerning the relevance, limitations, and future perspective of SMO/GLI inhibitors as targeted cancer therapy. Importantly, GLI inhibitors have shown superior anticancer activity compared to inhibitors targeting upstream (Hh and SMO) of GLI in preclinical studies [15,16]. Furthermore, GLI inhibitors effectively suppress cancer growth in many GLI-dependent cancers that utilize an SMOindependent route of GLI regulation, of which treatment with upstream inhibitors has proven ineffective [17]. Thus, understanding GLI regulation paradigms is fundamental to developing novel GLI inhibitors worthy of moving forward to clinical settings, which may help set a new stage for Hh therapy in the future. 

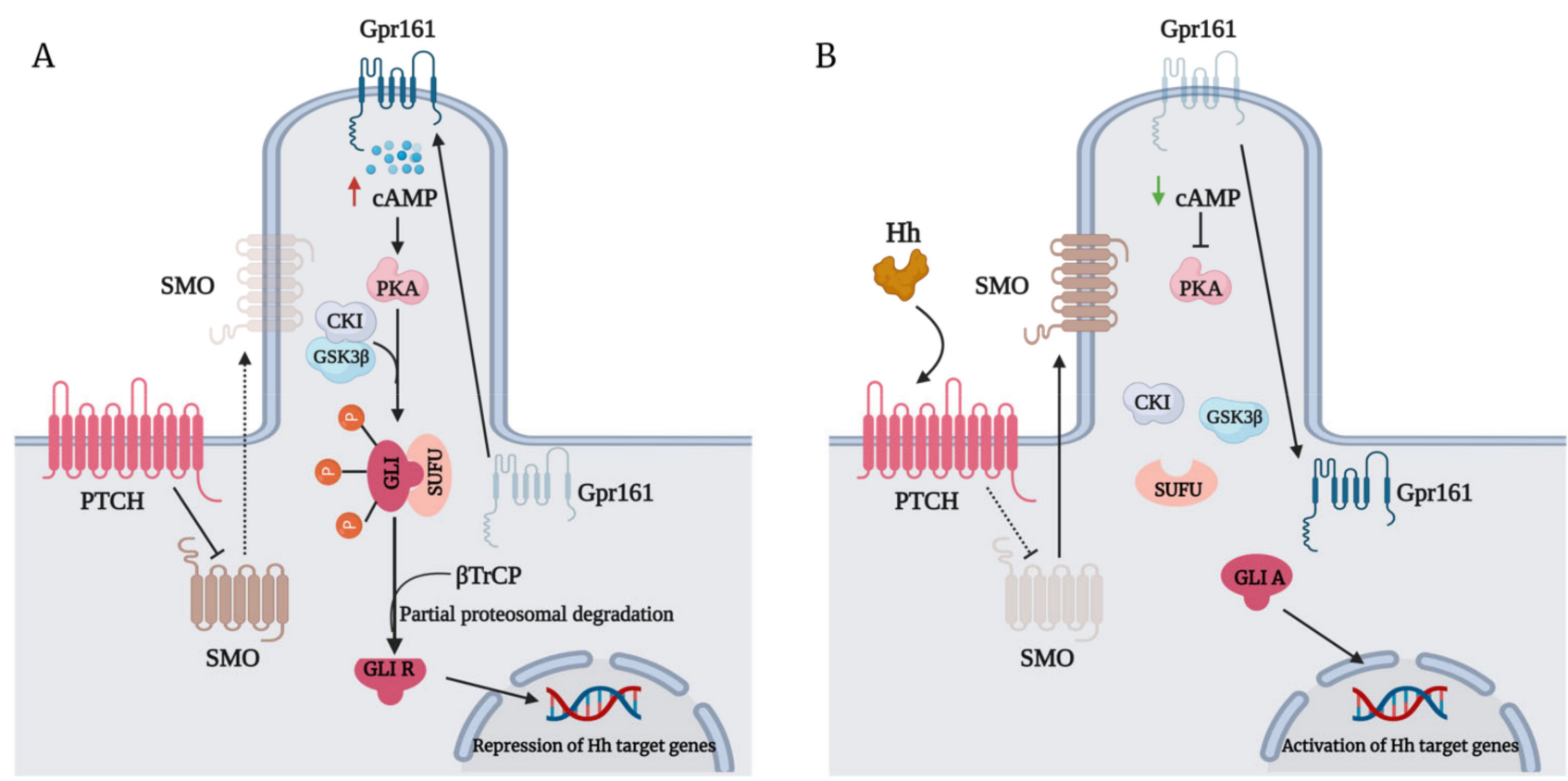

Figure 1. (A) The repression of Smoothened (SMO) by the Patched (PTCH) receptor in the absence of hedgehog (Hh) ligands promotes the interaction of Suppressor of Fused (SUFU) and glioma-associated oncogene homolog (GLI). G-protein coupled receptor 61 (GPR161) translocates to the primary cilium, which triggers high levels of cyclic adenosine monophosphate (CAMP). Elevated ciliary levels of CAMP maintain high levels of protein kinase A (PKA) activity, which phosphorylate GLI at P1-6 clusters. Consequently, phosphorylation of GLI by PKA prime its phosphorylation by casein kinase I (CKI) and glycogen synthase kinase 3 beta (GSK3 $\beta$ ) further. Phosphorylated GLI is recognized by the $\beta$-TrCP, promoting its ubiquitination and partial proteasomal processing into a repressor. GLI repressor (GLIR) then translocates into the nucleus to repress target gene transcription. (B) The binding of the Hh ligand to the PTCH receptor alleviates its repression of SMO, allowing SMO translocation to the primary cilium. Activated SMO inhibits SUFU, allowing the dissociation of GLI from SUFU. Additionally, Gpr161 is removed from the primary cilium, causing low CAMP levels and PKA activity. The release of GLI from SUFU and low PKA activity results in the dephosphorylation of GLI, preventing its proteasomal processing into a repressor. Full-length GLI or GLI activator (GLIA) then translocates into the nucleus to transcribe target genes. Red upward triangle-headed arrow: upregulation; green downward triangle-headed arrow: downregulation; dotted black triangle-headed arrow: inactivation; bar-headed arrow: inhibition; dotted bar-headed arrow: loss of inhibition.

\section{GLI Proteins and Their Domains}

GLI is a part of the GLI-Kruppel family, characterized by the presence of C2H2Kruppel-type zinc-finger (ZF) motifs [18]. Three homologs exist in vertebrates, namely GLI1, GLI2, and GLI3 (Figure 2). These proteins consist of overlapping domains, including a repressor and transactivation domain, and possess distinct but partially redundant functions. Since GLI1 lacks the repressor domain, it acts as a sole transcriptional enhancer. By contrast, GLI2 protein possesses both a repressor and two transactivation domains (TADs), $\mathrm{A} 1$ and A2, and acts as both a repressor and an activator. However, GLI2 mostly behaves as a transcriptional activator due to the inefficient processing of GLI2 into GLI2 repressor (GLI2R) [19]. Likewise, GLI3 protein possesses both repressor and activation domains but serves primarily as a transcriptional repressor due to an active processing determinant domain (PDD) that allows efficient processing of GLI3 into GLI3 repressor (GLI3R) [19,20]. Of note, GLI2 also contains a PDD but is inefficiently processed due to differences in amino residues critical for preventing complete degradation by the proteasome [20]. 

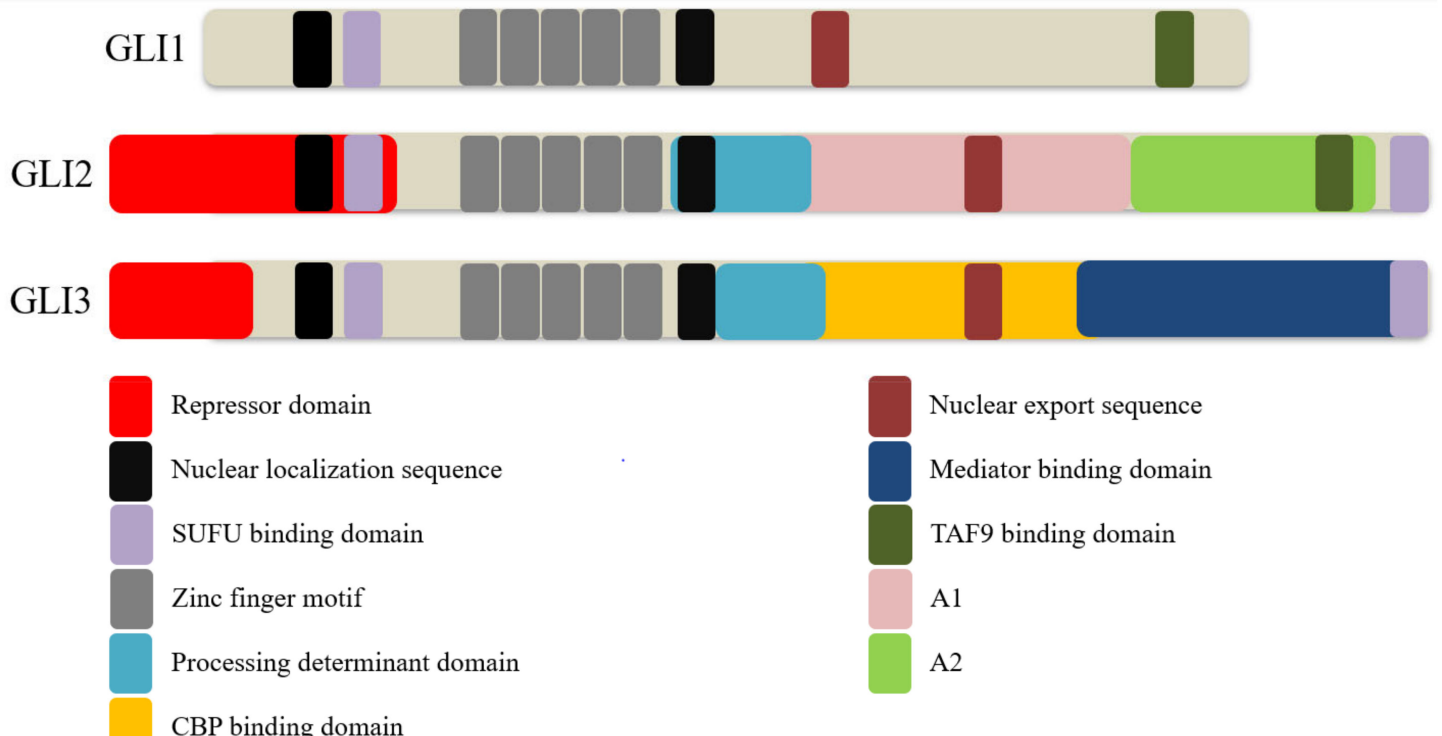

Figure 2. Schematic representation of the domains and motifs in glioma-associated oncogene homolog (GLI) proteins. All GLI proteins contain a well-conserved Supressor of Fused (SUFU)-binding domain, zinc finger motifs, nuclear localization sequences, and a nuclear export sequence. GLI2 and GLI3 contain both an N-terminal repressor and several C-terminal transactivation domains, unlike GLI1, which contains only a single transactivation domain reported so far. Additionally, GLI2 and GLI3 contain a second SUFU-binding domain at the C-terminal end critical for regulating nuclear GLI function. Both GLI2 and GLI3 contain a processing determinant domain that contributes to the proteolytic processing of these proteins into their repressor form with a more active role in GLI3 than GLI2. GLI2 contains two major transactivation domains, termed A1 and A2, while the GLI3 transactivation domain includes a CREB-binding protein (CBP)-binding domain and mediator-binding domain. Both GLI1 and GLI2 contain an $\alpha$-helical herpes simplex viral protein 16-like activation domain that binds to TATA-box binding protein associated factor 9 (TAF9) due to the presence of a highly conserved FXX $\Phi \Phi$ ( $\mathrm{F}=$ phenylalanine; $\mathrm{X}=$ any residue; $\Phi=$ any hydrophobic residue) motif in the domain. The FXX $\Phi \Phi$ motif is also conserved in GLI3 but does not bind to TAF9.

All three GLI homologs contain five Krüppel-like ZF motifs that recognize and bind to a nine base-pair DNA consensus motif 5'-GACCACCCA-3'. ZF4 and ZN5 mediate the binding of GLI proteins to the conserved DNA motif, while ZNF1-3 stabilizes the DNA domain through interaction with the phosphate backbone [21,22]. All three GLI homologs also contained a highly conserved SUFU-binding domain and two putative nuclear localization sequences (NLSs), including NLS1 and NLS2. NSL2 is a canonical bipartite NLS containing two basic clusters mapped to the fifth ZF motif in Ci and Cterminal side of GLI proteins, while NLS1 has features of both a canonical monopartite NLS and a noncanonical proline-tyrosine (PY)-NLS located just upstream of the SUFUbinding domain [23]. Both NLSs play a cooperative functional role in regulating the nuclear localization of GLI proteins, likely through importin (Imp)- $\alpha / \beta 1$ mediated nuclear import classic of canonical NLSs [24].

Mutations in either the NLS1 or NLS2 have been shown to partially impair the nuclear transportation of both GLI1 and GLI2, while the loss of both NLSs results in a drastic increase in cytoplasmic localization of both GLI proteins $[25,26]$. The function of NLS2 is also heavily regulated by a Thr374 residue adjacent to the first basic cluster of the bipartite motif. Phosphorylation of Thr374 residue by PKA enhanced the local negative charge nearby the NLS2, thus inhibiting NLS2 function and consequently inhibiting GLI1 nuclear accumulation [27]. The noncanonical PY-NLS feature of NLS1 has also been shown to mediate GLI2 and GLI3 nuclear transport by cooperating with karyopherin- $\beta 2$ (Kap $\beta 2)$ known to recognize PY-NLSs [28]. Besides regulating nuclear transportation, the interaction of PY-NLS and Kap $\beta 2$ also plays a major role in regulating the ciliary localization of all three GLI proteins independently of the Imp- $\alpha / \beta 1$ nuclear import system $[25,29]$. 
A leucine-rich nuclear export sequence (NES) is also found in all three mammalian GLI proteins, and their functional coordination with NLSs plays a major role in regulating the nuclear-cytoplastic shuttling of GLI proteins. The nuclear export of GLI1 and GLI2 is chromosomal region maintenance 1 (CRM1)-dependent, and inactivation of CRM1 with Leptomycin B (LMB) or the substitution of conserved leucine residues within the GLI1/GLI2 NES was shown to enhance the nuclear accumulation and transcriptional activities of both GLI proteins [26,30]. Interestingly, the shuttling of the SUFU-GLI1 complex between the cytoplasmic and nuclear compartments was found to depend on functional NES and CRM1, whereby the loss of either function led to an impaired cytoplasmic sequestration of GLI1 by SUFU and enhanced colocalization of SUFU and GLI1 in the nucleus [26].

SUFU binds to SUFU-binding domains located at N- and C-terminals of GLI proteins to regulate their activities through various mechanisms. Firstly, SUFU sequesters GLI proteins in the cytoplasm by binding to the SYGH core motif within the $\mathrm{N}$-terminal domain of GLI proteins [31]. This interaction facilitates the phosphorylation of GLI proteins by PKA, GSK $3 \beta$, and CK1, leading to their proteasomal degradations or processing into repressors $[8,12]$. Secondly, SUFU prevents the nuclear translocation of GLI proteins by masking their NLSs. The binding of SUFU to the SYGH core motif within the Nterminal domain of GLI proteins blocks the binding of $\operatorname{Imp} \beta 1$ and Kap $\beta 2$ to NLSs, which impedes the nuclear import of GLI proteins [24,28]. Thirdly, SUFU has been shown to regulate $\mathrm{Ci} / \mathrm{GLI}$ transcriptional activity inside the nucleus. The binding of SUFU to a second conserved C-terminal SUFU-binding domain of Ci masked the Drosophila CREBbinding protein (CBP)-binding domain (dCBD) located near the SUFU-binding domain, impeding the recruitment of the transcriptional coactivator CBP. In turn, the loss of CBP recruitment inhibited the transcriptional activity of $\mathrm{Ci}$; the C-terminal SUFU-binding site was also conserved in GLI2 and GLI3, and deletion of this site partially blocked the SUFU-mediated inhibition of GLI2 transcriptional activity [31], recapitulating the effect of SUFU-binding at the C-terminal SUFU-binding domain in the impediment of CBP recruitment and suppression of $\mathrm{Ci}$ transcriptional activity.

SUFU also negatively regulates the transcriptional activity of GLI1 in the nucleus despite the loss of CRM1-dependent nuclear export (inhibited by LMB), suggesting that the repressive activity of SUFU can still occur in the nucleus independent of cytoplasmic sequestration [26]. In further support of this finding, SUFU was also shown to interact directly with GLI1 bound to DNA, raising the possibility that this interaction may hinder the binding of other transcription activators with GLI1 [30]. By contrast, Zhang et al. argued that SUFU does not serve merely as a negative regulator but rather as a chaperone protein with a unifying role in regulating the function of GLI proteins [32]. Evidently, SUFU accompanied the translocation of GLI1 into and GLIR out of the nucleus. Furthermore, SUFU also accompanied GLI1 but not GLIR to the ciliary tip, a necessary step that precedes the translocation of GLI1 into the nucleus. Importantly, SUFU facilitates the binding of GLI1 to GLI-binding sites on the chromatin, while concomitantly reducing GLI3 binding, and intact SUFU expression is required for maximal Shh signaling output needed for the specification of the most ventral neurons [32].

The Drosophila CBP (dCBP) has been shown to bind to the $\mathrm{dCBD}$ of $\mathrm{Ci}$ as a coactivator, while the loss of dCBP abolished Hh signaling [33]. Sequence alignment revealed a motif fairly well conserved between the dCBP-binding domain of $\mathrm{Ci}$ and the A1 domain of GLI2 [34], but the role of CBP in GLI2 activity has yet to be elucidated. Like Ci, GLI3 also possesses a CBP-binding domain (CBD) and utilizes $C B P$ as a coactivator for its transcriptional activity [35]. By contrast, Zhou et al. reported that CBD showed weak transactivation in vivo, but CBP could bind efficiently to the Mediator-binding domain (MBD) located upstream of CBD to promote GLI3 transactivation, suggesting a concerted functional interaction between CBP and RNA polymerase II transcriptional mediator complex [36]. Besides binding CBP, MBD also physically targeted and inhibited the MED12 interface in the mediator complex, which in turn reversed the mediator-dependent suppression of 
GLI3 transactivation activity [36]. By contrast, CBP does not bind to GLI1 [35], suggesting the lack of a CBD or MBD in GLI1.

The C-terminal end of the GLI1 contains an $\alpha$-helical herpes simplex viral protein 16-like activation domain, including a highly conserved FXXФФ (F = phenylalanine; $\mathrm{X}=$ any residue; $\Phi=$ any hydrophobic residue) motif recognizing TAFII31/TATA-box binding protein associated factor 9 (TAF9) subunit of general transcription factor II D [37]. This motif is fairly conserved in the A2 domain of GLI2 and the C-terminal end of GLI3 [37,38]. However, TAF9 binds only to GLI1 and GLI2 but not GLI3 to promote their transcriptional activities, suggesting a redundancy of the FXX $\Phi \Phi$ motif in GLI3. Conversely, binding interference between GLI proteins and TAF9 by mutating the FXX $\Phi \Phi$ motif resulted in the loss of transcriptional activities of GLI proteins [37-39].

Both GLI2 and GLI3 contain an N-terminal repressor domain (RD) that exerts repressive transcriptional activity upon proteolytic removal of their C-terminal TADs. In contrast to the TAD of GLI proteins, their RDs are less well characterized in terms of their motifs and binding partners. The RD is most well defined for its interaction with the histone deacetylase (HDAC) complex. Ski was shown to interact directly with the Nterminal domain of both GLI3R and full-length GLI3 and to form a complex with HDAC1 to promote GLI3-mediated transcriptional repression. Additionally, a Ski-binding site was also mapped to the N-terminal RD of GLI2. Conversely, Ski-deficient mouse embryonic fibroblast (MEF) efficiently abrogated GLI3 and GLI2 transcriptional repressive activities. Ski forms complexes with corepressors such as N-CoR/SMRT, mSin3, and Sno to recruit HDACs necessary to mediate transcriptional repression activities of other repressors [40]. Mouse SUFU has been shown to interact with SAP18, a member of the mSin3-HDAC corepressor complex, to enhance GLI3-mediated transcriptional repression and impaired GLI1 transcriptional activity. Functionally, mouse SUFU interacted with GLI1, possibly via the SYGF motif in the N-terminal SUFU-binding domain and recruited the mSin3-HDAC complex through interaction with SAP18 to impede GLI1 transcriptional activity. It is conceivable that the same process may also occur in GLI3 to potentiate GLI3 transcriptional repressive activity, as both GLI1 and GLI3 interact with SUFU via the same SYGH motif at the N-terminal end. Furthermore, the Ski binding site overlaps the SUFU-binding domain at the N-terminal region of GLI3, suggesting a possible functional cooperative role between SUFU and Ski in recruiting the HDAC corepressor complex to promote GLI3-mediated transcriptional repression activity [41].

\section{The Mechanism of GLI Regulation in Human Cancers}

Aberrant GLI activation can occur via SMO-dependent or SMO-independent routes. SMO-dependent activation of GLI can result from two mechanisms: mutations that lead to the loss-of-function of the major negative regulator protein PTCH1 and gain-of-function of the SMO protein or dysregulated expression of the Hh/PTCH1/SMO caused by aberrant transcriptional and epigenetic regulations. This route of GLI activation includes both liganddependent and ligand-independent Hh signaling. On the other hand, the noncanonical SMO-independent activation of GLI can occur in the absence of Hh ligand binding to the PTCH receptor, as GLI activation is regulated by various other oncogenic pathways and signaling proteins external to the Hh pathway; this route of GLI activation is exclusively ligand independent. Accumulating evidence has implicated both routes of GLI regulation in the development of many known cancers. Because GLI plays such a crucial role in regulating developmental and cellular processes such as embryogenesis, differentiation, stem cell maintenance, and proliferation, it is understandable that its unregulated activation plays a big part in cancer tumorigenesis. Thus, this section highlights the SMO-dependent and SMO-independent mechanisms by which GLI is regulated to induce tumorigenesis.

Due to the vast amount of proto-oncogenes they regulated, GLI proteins are closely associated with alterations of cancer hallmarks, including sustained proliferative signals, evading growth suppressors, resisting cell death/apoptosis, avoiding immune destruction, activating migration/invasion and metastasis, genomic instability and mutations, 
tumor-promoting inflammation, and inducing angiogenesis [42]. For instance, the transcriptional upregulation of D-type cyclins, CCND1 and CCND2, by GLI proteins facilitates the bypass of mitotic cellular checkmarks, leading to enhance cell cycling and uncontrolled proliferation [43]. In the presence of cytotoxic drugs, GLI proteins can transcriptionally upregulate the expression of $B C L 2$ or transporter proteins to inhibit the activation of apoptotic signaling cascades and promote drug efflux, thus resisting drug-induced cell death [44]. The upregulation of GLI proteins in cancers is also associated with the downregulation of p53, which impairs cell cycle arrest and enhances genetic instability [45]. GLI proteins upregulate the expression of invasion-related and mesenchymal proteins, such as matrix metalloproteinases, N-cadherin, vimentin, and SNAI1, to activate cancer migration, invasion, and metastasis [46].

A new but notable cancer hallmark involving the dedifferentiation of noncancer stem cells to stem cell- or tumor-initiating-like cells has also been proposed by Senga and Grose [47] and poses great relevance to Hh-GLI signaling. Evidently, activation of GLI proteins has been associated with the acquisition of cancer stem cell (CSC)-like traits through upregulation of genes involved in dedifferentiation, self-renewal, and pluripotency, leading to enhanced tumorigenicity and drug resistance [48]. Thus, understanding the complex regulatory network of GLI activation can assist the development of more than one therapeutic approach in overcoming the hallmarks of cancer. In the next part, we focused on the SMO-dependent and -independent mechanisms by which GLI is activated and their relevance to cancer hallmarks (Figure 3, Table 1).

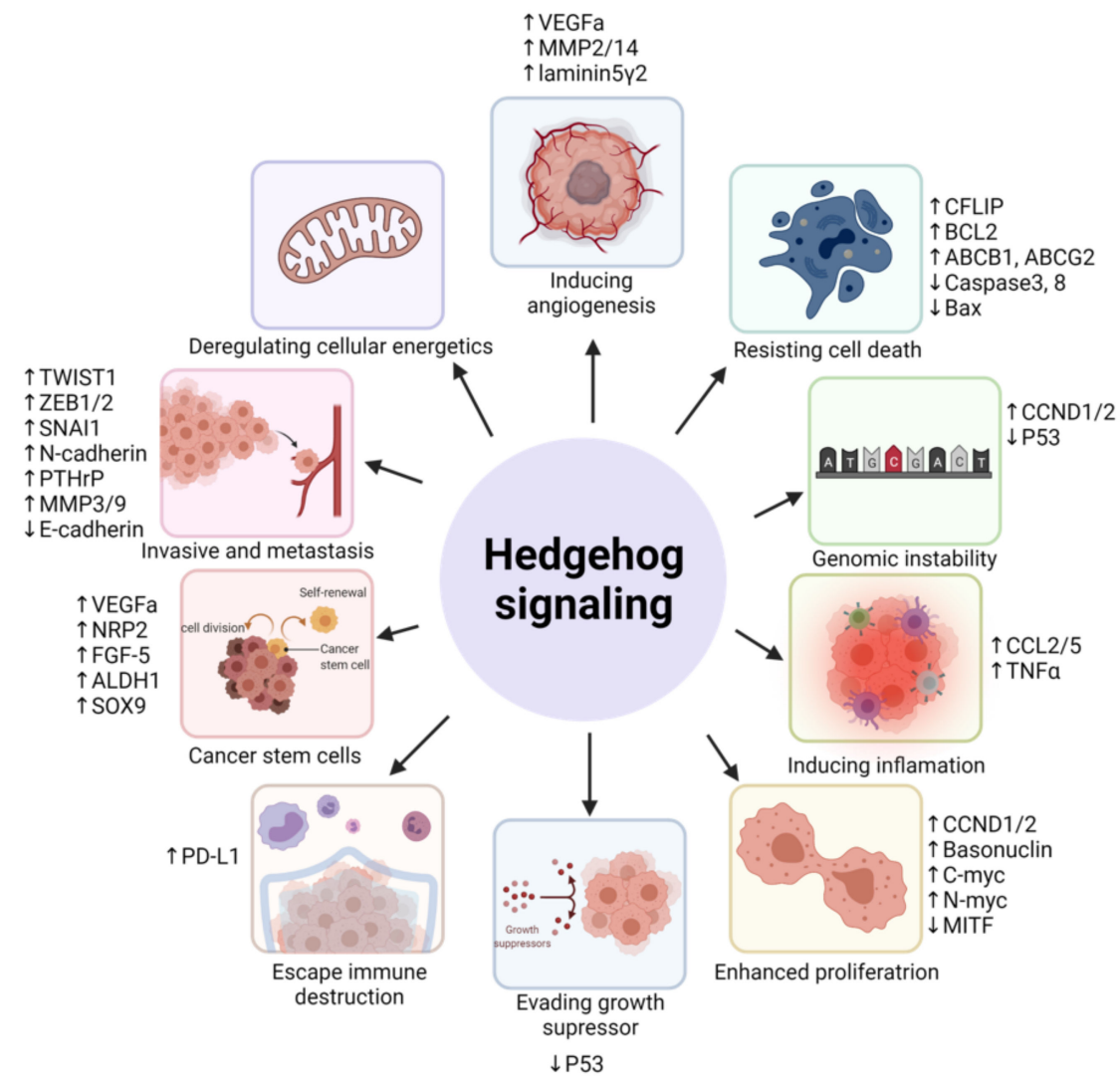

Figure 3. A simplified diagram on the role of $\mathrm{Hh}$ signaling activation in driving cancer hallmarks. Upward triangle-headed arrow: upregulation; downward triangle-headed arrow: downregulation. 
Table 1. Summary of the described SMO-dependent and SMO-independent mechanisms of GLI activation in cancers and the cancer hallmarks involved.

\begin{tabular}{|c|c|c|c|c|c|c|}
\hline GLI Activation & Dysregulation & Regulators & Mechanism of Action & Cancer/Cell Type & Cancer Hallmarks & References \\
\hline \multirow{12}{*}{ SMO-dependent } & \multirow{8}{*}{ Mutations } & \multirow{5}{*}{ PTCH1 } & \multirow{5}{*}{$\begin{array}{l}\text { Inactivating PTCH1 mutation leads to SMO } \\
\text { derepression and GLI1/2 activation }\end{array}$} & Basal cell carcinoma & $\begin{array}{l}\text { Proliferation, resisting cell death, } \\
\text { angiogenesis, genomic instability, } \\
\text { invasion, metastasis, evading } \\
\text { growth suppressor }\end{array}$ & $\begin{array}{l}{[44,45,49-} \\
52]\end{array}$ \\
\hline & & & & Medulloblastoma & Proliferation & {$[53,54]$} \\
\hline & & & & $\begin{array}{l}\text { Odontogenic keratocystic } \\
\text { tumors }\end{array}$ & $\begin{array}{l}\text { Proliferation, tumor-promoting } \\
\text { inflammation }\end{array}$ & {$[55]$} \\
\hline & & & & Breast cancer & Stemness, resisting cell death & {$[57,58]$} \\
\hline & & & & Cervical carcinoma & $\begin{array}{l}\text { Resisting cell death, invasion and } \\
\text { metastasis }\end{array}$ & [59-61] \\
\hline & & \multirow{3}{*}{$\mathrm{SMO}$} & $\begin{array}{l}\text { SMO mutants constitutively activate } \\
\text { GLI1/2 in the presence of vismodegib and } \\
\text { are resistant to PTCH catalytic inhibition }\end{array}$ & Basal cell carcinoma & $\begin{array}{l}\text { Proliferation, resisting cell death, } \\
\text { angiogenesis, genomic instability, } \\
\text { invasion and metastasis, and } \\
\text { evading growth suppressor }\end{array}$ & $\begin{array}{c}{[44,49-} \\
52,62-66]\end{array}$ \\
\hline & & & $\begin{array}{l}\text { SMO mutant constitutively activate GLI1 in } \\
\text { the presence of vismodegib }\end{array}$ & Medulloblastoma & Resisting cell death & {$[67]$} \\
\hline & & & $\begin{array}{l}\text { SMO mutant leads to enhance GLI1 } \\
\text { expression and is more resistant to } \\
\text { cyclopamine }\end{array}$ & Hepatocellular carcinoma & Proliferation & {$[68]$} \\
\hline & \multirow{4}{*}{ Transcriptional } & \multirow[t]{2}{*}{ NFkB } & \multirow{2}{*}{$\begin{array}{l}\text { Transcriptionally upregulates Shh at the } \\
\text { promoter level, leading to canonical } \\
\text { Shh-GLI activation }\end{array}$} & Pancreatic cancer & $\begin{array}{l}\text { Proliferation, resisting cell death, } \\
\text { tumor-promoting inflammation }\end{array}$ & [69-73] \\
\hline & & & & Breast cancer & Stemness, activating migration & {$[74,75]$} \\
\hline & & $\begin{array}{l}\mathrm{CREB}, \mathrm{AP} 1, \mathrm{AP} 2 \alpha, \\
\text { and } \mathrm{SP} 1\end{array}$ & $\begin{array}{l}\text { Transcriptionally upregulates SMO at the } \\
\text { promoter level, leading to GLI activation }\end{array}$ & Prostate and breast cancer & NS & [76] \\
\hline & & $\beta$-catenin/TCF-4 & $\begin{array}{l}\text { Transcriptionally upregulates both SMO } \\
\text { and GLI at the promoter level }\end{array}$ & Foreskin fibroblast & Proliferation & [77] \\
\hline
\end{tabular}


Table 1. Cont.

\begin{tabular}{|c|c|c|c|c|c|c|}
\hline GLI Activation & Dysregulation & Regulators & Mechanism of Action & Cancer/Cell Type & Cancer Hallmarks & References \\
\hline \multirow{4}{*}{ SMO-dependent } & \multirow{4}{*}{ Epigenetic } & \multirow{4}{*}{$\begin{array}{l}\text { DNA } \\
\text { methyltransferase }\end{array}$} & $\begin{array}{l}\text { Hypomethylation of Shh promoter leads to } \\
\text { improve NFkB-induced Shh transcription } \\
\text { and GLI1 expression }\end{array}$ & Breast cancer & Stemness, migration & [74] \\
\hline & & & $\begin{array}{l}\text { Hypomethylation of SMO promoter leads } \\
\text { to improve SMO transcription and } \\
\text { subsequent GLI2 expression }\end{array}$ & $\begin{array}{c}\text { prostate, kidney, } \\
\text { glioblastoma, and ovarian } \\
\text { cancer }\end{array}$ & NS & [76] \\
\hline & & & $\begin{array}{l}\text { Hypermethylation of PTCH1 promoter } \\
\text { leads to decrease PTCH1 expression, } \\
\text { causing enhance SMO-GLI1/2 activation } \\
\text { and GLI1/2 nuclear translocation }\end{array}$ & Leiomyosarcoma & $\begin{array}{l}\text { Proliferation, activating migration, } \\
\text { resisting dell death }\end{array}$ & [83] \\
\hline & & & $\begin{array}{l}\text { Hypermethylation of PTCH1 and HHIP } \\
\text { lead to increase Hh-GLI signaling }\end{array}$ & Gastric cancer & $\begin{array}{l}\text { Resisting cell death, proliferation, } \\
\text { invasion and metastasis }\end{array}$ & [84-90] \\
\hline \multirow{6}{*}{ SMO-independent } & \multirow{6}{*}{$\begin{array}{l}\text { Oncogenic } \\
\text { pathways }\end{array}$} & \multirow{3}{*}{ MAPK/ERK } & $\begin{array}{c}\text { Stimulation of NRP2 by VEGFa activates } \\
\text { ERK, which phosphorylates GLI1 to } \\
\text { promote its activation }\end{array}$ & Lung adenocarcinoma & $\begin{array}{l}\text { Stemness, resisting cell death, } \\
\text { angiogenesis }\end{array}$ & {$[91,92]$} \\
\hline & & & $\begin{array}{l}\text { Stimulation of NRP2 by VEGF induced } \\
\alpha 6 \beta 1 \text { integrin-mediated activation of } \\
\text { RAS/MEK signaling through focal } \\
\text { adhesion kinase FAK activation and } \\
\text { consequently GLI1 expression }\end{array}$ & Breast cancer & Stemness, resisting cell death & {$[58,93]$} \\
\hline & & & $\begin{array}{c}\text { Oncogenic mutant KRAS enhances GLI1 } \\
\text { expression via RAF-MEK1-ERK }\end{array}$ & $\begin{array}{l}\text { Pancreatic ductal } \\
\text { adenocarcinoma }\end{array}$ & $\begin{array}{l}\text { Resisting cell death, proliferation, } \\
\text { invasion and metastasis }\end{array}$ & {$[94,95]$} \\
\hline & & \multirow{3}{*}{ TGF- $\beta /$ SMAD } & \multirow[t]{2}{*}{ TGF- $\beta$ enhances GLI1 expression } & Hepatocellular carcinoma & $\begin{array}{l}\text { Stemness, proliferation, migration, } \\
\text { and invasion }\end{array}$ & [96] \\
\hline & & & & $\begin{array}{l}\text { Pancreatic ductal } \\
\text { adenocarcinoma }\end{array}$ & Resisting cell death, proliferation & [94] \\
\hline & & & $\begin{array}{l}\text { TGF- } \beta / \text { SMAD3 enhances GLI1 and GLI2 } \\
\text { expression }\end{array}$ & Melanoma & $\begin{array}{l}\text { Resisting apoptosis, proliferation, } \\
\text { and invasion }\end{array}$ & [97] \\
\hline
\end{tabular}


Table 1. Cont

\begin{tabular}{|c|c|c|c|c|c|c|}
\hline GLI Activation & Dysregulation & Regulators & Mechanism of Action & Cancer/Cell Type & Cancer Hallmarks & References \\
\hline \multirow{14}{*}{ SMO-dependent } & \multirow{14}{*}{$\begin{array}{l}\text { Oncogenic } \\
\text { pathways }\end{array}$} & Cooperative & $\beta$-catenin/TCF- 4 and SMAD cooperatively & Breast cancer & \multirow{2}{*}{ Invasion and metastasis } & [98] \\
\hline & & $\begin{array}{l}\text { integration of } \\
\text { TGF- } \beta / \text { SMAD and } \\
\text { Wnt } / \beta \text {-catenin }\end{array}$ & $\begin{array}{l}\text { bind to the GLI2 promoter and enhance its } \\
\text { transcription }\end{array}$ & $\begin{array}{l}\text { Oral squamous cell } \\
\text { carcinoma }\end{array}$ & & [99] \\
\hline & & Wnt/ $\beta$-catenin & $\begin{array}{c}\beta \text {-catenin/TCF- } 4 \text { upregulates CRD-BP, } \\
\text { which binds and stabilizes GLI1 transcripts }\end{array}$ & Colorectal cancer & Proliferation & {$[100,101]$} \\
\hline & & \multirow{9}{*}{ PI3K/AKT } & p-AKT enhances GLI1 expression & Gastric cancer & $\begin{array}{l}\text { Proliferation, migration, invasion, } \\
\text { metastasis, resisting cell death, } \\
\text { avoiding immune destruction }\end{array}$ & [102-104] \\
\hline & & & PI3K/mTOR regulates GLI1 expression & $\begin{array}{l}\text { Lung squamous cell } \\
\text { carcinoma }\end{array}$ & Proliferation & [105] \\
\hline & & & $\begin{array}{l}\text { ErbB2 enhances GLI1 expression via } \\
\text { PI3K/AKT/mTOR activation }\end{array}$ & $\begin{array}{c}\text { Esophageal } \\
\text { adenocarcinoma }\end{array}$ & Proliferation, resisting cell death & [106] \\
\hline & & & $\begin{array}{l}\text { PI3K/AKT regulates the nuclear } \\
\text { translocation of GLI1 }\end{array}$ & Osteosarcoma & Resisting cell death & [107] \\
\hline & & & $\begin{array}{l}\text { DYRK1B activates PI3K/AKT/mTOR } \\
\text { pathway to promote GLI1 stabilization }\end{array}$ & $\begin{array}{l}\text { Pancreatic and ovarian } \\
\text { cancer }\end{array}$ & Proliferation & {$[108]$} \\
\hline & & & $\begin{array}{l}\text { PI3K/AKT enhances GLI1/2 expression } \\
\text { and nuclear translocation }\end{array}$ & Renal cell carcinoma & Proliferation, resisting cell death & [109] \\
\hline & & & $\begin{array}{l}\text { TNF } \alpha \text { induces S6K1 phosphorylation and } \\
\text { GLI1 expression }\end{array}$ & Prostate cancer & Proliferation & [110] \\
\hline & & & $\begin{array}{l}\text { TNF } \alpha / m \text { mOR activation of S6K1 induces } \\
\text { phosphorylation of GLI1, promoting its } \\
\text { stability }\end{array}$ & $\begin{array}{c}\text { Esophageal } \\
\text { adenocarcinoma }\end{array}$ & Proliferation and invasion & [111] \\
\hline & & & $\begin{array}{l}\text { p70S6K2 phosphorylates and inhibits } \\
\text { GSK3 } \beta \text { function, promoting GLI1 stability }\end{array}$ & Non-small cell lung cancer & Proliferation, resisting cell death & [112] \\
\hline & & RAS-MEK/AKT & $\begin{array}{l}\text { Endogenous RAS-MEK and AKT signaling } \\
\text { regulate GLI1 transcription and nuclear } \\
\text { localization }\end{array}$ & Melanoma & $\begin{array}{c}\text { Proliferation, resisting cell death, } \\
\text { metastasis }\end{array}$ & [113] \\
\hline & & NFKB & $\begin{array}{l}\text { P65 transcriptionally upregulates GLI1 } \\
\text { expression by binding to GLI1 promoter }\end{array}$ & Breast cancer & $\begin{array}{l}\text { Cell proliferation, stemness, } \\
\text { migration }\end{array}$ & {$[114]$} \\
\hline
\end{tabular}


Table 1. Cont.

\begin{tabular}{|c|c|c|c|c|c|c|}
\hline GLI Activation & Dysregulation & Regulators & Mechanism of Action & Cancer/Cell Type & Cancer Hallmarks & References \\
\hline \multirow{11}{*}{ SMO-dependent } & \multirow{5}{*}{$\begin{array}{l}\text { Oncogenic } \\
\text { proteins }\end{array}$} & SOX-9 & $\begin{array}{l}\text { SOX9 binds and inhibits } \beta \text {-TrCP, promoting } \\
\text { GLI1 stability }\end{array}$ & $\begin{array}{l}\text { Pancreatic ducal } \\
\text { adenocarcinoma }\end{array}$ & $\begin{array}{l}\text { Stemness, proliferation, and } \\
\text { resisting cell death }\end{array}$ & [115] \\
\hline & & FOXC1 & $\begin{array}{l}\text { FOXC1 binds to GLI2 and enhance its DNA } \\
\text { binding }\end{array}$ & Breast cancer & $\begin{array}{l}\text { Stemness, proliferation, resisting } \\
\text { cell death }\end{array}$ & [116] \\
\hline & & Nestin & $\begin{array}{l}\text { Nestin binds to GLI3 to prevent } \\
\text { phosphorylation by PKA, thereby } \\
\text { enhancing GLI3 stability }\end{array}$ & Medulloblastoma & Proliferation & [117] \\
\hline & & \multirow[t]{2}{*}{ Gal-1 } & $\begin{array}{l}\text { Gal-1 enhance GLI1 expression by binding } \\
\text { and activating } \beta 1 \text { integrin }\end{array}$ & Gastric cancer & $\begin{array}{l}\text { Invasion, metastasis, vasculogenic } \\
\text { mimicry, avoiding immune } \\
\text { destruction }\end{array}$ & [118-121] \\
\hline & & & Gal-1 enhances GLI1 expression & $\begin{array}{l}\text { Pancreatic ductal } \\
\text { adenocarcinoma }\end{array}$ & Proliferation, angiogenesis & [122] \\
\hline & \multirow{6}{*}{$\begin{array}{l}\text { Tumor } \\
\text { suppressors }\end{array}$} & \multirow{3}{*}{ SPOP } & $\begin{array}{l}\text { Downregulation of SPOP enhance GLI1/2 } \\
\text { expression }\end{array}$ & Ovarian cancer & Proliferation, resisting cell death & [123] \\
\hline & & & \multirow{2}{*}{$\begin{array}{l}\text { Downregulation of SPOP prevents } \\
\text { proteasomal-dependent degradation of } \\
\text { GLI2, thus promoting its stability }\end{array}$} & Gastric cancer & $\begin{array}{l}\text { Proliferation, migration, and } \\
\text { resisting cell death }\end{array}$ & [124] \\
\hline & & & & С3H10T1/2 & NS & [125] \\
\hline & & ASPP2 & $\begin{array}{l}\text { Downregulation of ASPP2 enhances } \\
\text { aPKC-t-mediated phosphorylation of GLI1 } \\
\text { to promote its nuclear translocation }\end{array}$ & Gallbladder cancer & $\begin{array}{l}\text { Invasion, metastasis, and } \\
\text { tumor-promoting inflammation }\end{array}$ & [126] \\
\hline & & GSK3 $\beta$ & $\begin{array}{c}\text { Deregulated GSK3 } \beta \text { function as a result of } \\
\text { imbalance activating and inactivating } \\
\text { phosphorylation impaired its ability to } \\
\text { phosphorylate GLI3, promoting GLI3 } \\
\text { stabilization }\end{array}$ & Colon cancer & $\begin{array}{l}\text { Proliferation and resisting cell } \\
\text { death }\end{array}$ & [127] \\
\hline & & MED12 & $\begin{array}{l}\text { Downregulation of MED12 relieve its } \\
\text { constraint on GLI3, promoting its } \\
\text { hyperactivation }\end{array}$ & Prostate cancer & Proliferation & [128] \\
\hline
\end{tabular}

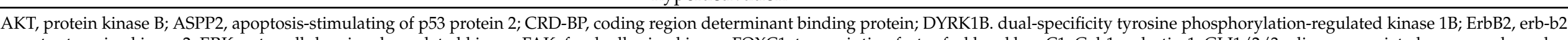

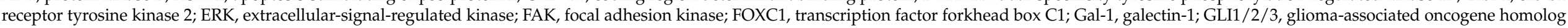

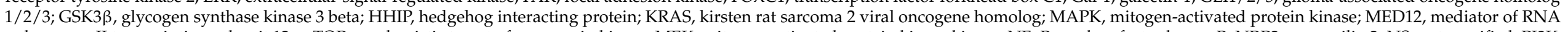

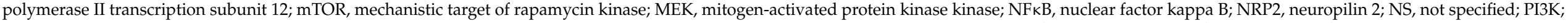

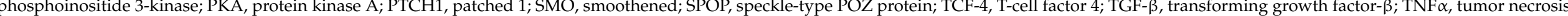
factor-alpha; and VEGFa, vascular endothelial growth factor A. 


\subsection{SMO-Dependent GLI Activation}

\subsubsection{Mutations of Hh Pathway Genes Upstream of GLI}

SMO protein represents the key positive regulator of GLI function. However, the mutation or dysregulation of SMO or any of the components such as Hh, PTCH1 leading to its activation leads to the aberrant activation of GLI and consequently oncogenesis (Figure 4). The majority of mutations in Hh signaling components have been mostly reported in cases of nevoid basal cell carcinoma syndrome (NBCCS) or Gorlin syndrome and basal cell carcinoma (BCC). The majority of PTCH1 mutations result in prematurely truncated PTCH1 proteins that are inactivated, thus promoting constitutive activation of the Hh pathway. In people with Gorlin syndrome, they carry an inactivating germline mutation of one allele of the PTCH1 gene that predisposes them to multiple developmental abnormalities such as odontogenic keratocysts and skeletal anomalies. Consequently, when the second wild-type allele is inactivated, usually by somatic events such as UV or ionizing radiation exposures, it results in the loss of heterozygosity $(\mathrm{LOH})$ of the PTCH1 gene, which in turn promotes carcinogenesis in the form of multiple BCCs [129]. Similarly, in sporadic $\mathrm{BCC}$, inactivation of both alleles is required to kickstart the development of BCCs, but unlike hereditary BCCs, both alleles are inactivated as a result of somatic events [130]. As PTCH1 functions by repressing SMO, the loss of PTCH1 alleviates its repression of SMO and promotes the onset of GLI-mediated expression of $\mathrm{Hh}$ target genes and tumorigenesis. For instance, the loss of PTCH1 in mutant skin resulted in BCC development in nude mice, associated with compromised epidermal differentiation and ectopic expression of $\mathrm{Hh}$ target genes, GLI1 and PTCH1, in the interfollicular epidermis (IFE). Furthermore, the loss of PTCH1 in mutant skin resulted in aberrant expression of CCND1 and CCND2 and impaired expression of p53 tumor suppressor, resulting in increased cell cycling and impaired p53 response to cell-cycle-driven DNA damage, which enhanced genomic instability [45].

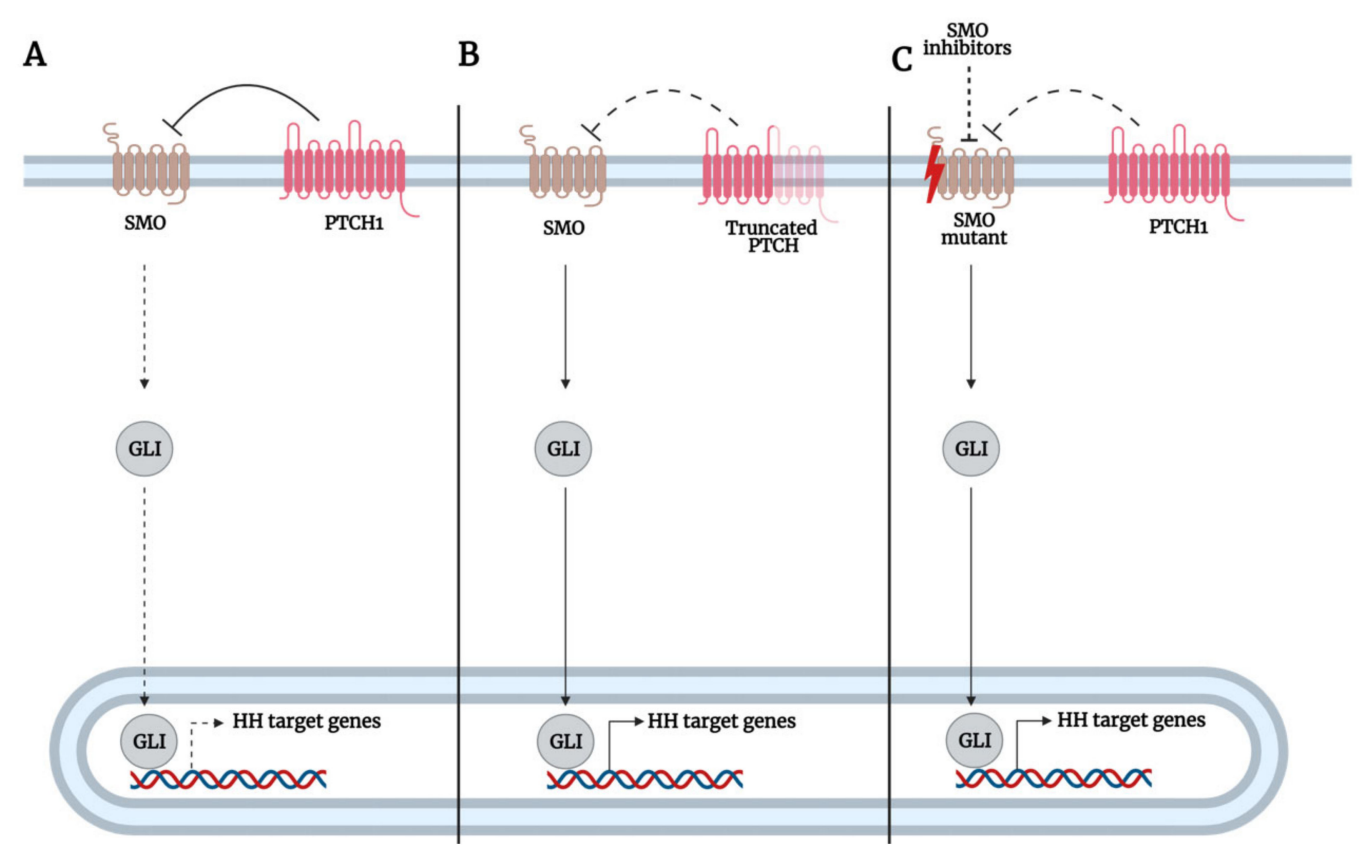

Figure 4. A simplified illustration of Smoothened (SMO)-dependent glioma-associated oncogene homolog (GLI) regulation in the context of hedgehog $(\mathrm{Hh})$ pathway mutations. (A) Under physiological conditions in adult tissues, Patched1 (PTCH1) functions by inhibiting SMO, which represses GLI function and prevents its translocation into the nucleus to activate target genes transcriptionally. (B) However, in cancer cells, loss of heterozygosity (LOH) of PTCH1 alleles results in the formation of a nonfunctional truncated PTCH1 protein. Consequently, this results in the constitutive activation of $\mathrm{SMO}$, which promotes GLI activation and its translocation into the nucleus to activate Hh target genes transcriptionally. (C) Alternatively, constitutively active SMO M1/M2 mutants resistant to PTCH1 inhibition or inhibition by SMO inhibitors promote the sustained activation of GLI and its subsequent translocation into the nucleus to transcriptionally activate Hh target genes. Bar-headed arrow: inhibition; dotted bar-headed arrow: loss of inhibition; triangle-headed arrow: activation; dotted triangle-headed arrow: inactivation. 
BCCs are also shown to overexpress GLI1 and GLI2 transcription factors, and oncogenic mutations in genes encoding these proteins are uncommon, suggesting that the mutation of PTCH1 is sufficient to drive GLI1 activation and tumorigenesis. Evidently, transgenic mice overexpressing GLI1 developed tumors that closely resemble human BCCs. Additionally, GLI1-overexpressing transgenic mouse tumors showed differentiated marker expression similar to that of human BCCs [49]. GLI2 gene silencing of nude mice injected with BCC-like K5-Gli2DN2 cell line resulted in a marked increase in apoptosis and decreased vascularization of BCC-like tumors that led to their retarded growth [50], as conditional GLI2 expression is required for the sustained growth of established BCCs [51]. In transgenic mice overexpressing GLI2 driven by the keratin 5 (K5) promoter, CCND1 and CCND2 were significantly upregulated in BCC biopsies, promoting sustained tumor growth and expansion of BCC [62]. In human BCC tumors, GLI1 and GLI2 were shown to be significantly elevated biopsy tissues, and GLI1 and GLI2 transcriptionally upregulated basonuclin and cFlip, respectively, to promote cancer cell survival [44,52].

Basonuclin functions by enhancing the transcription of rRNA, a common feature in tumorigenesis. Notably, basonuclin expression was significantly higher in human BCC tissues than in unaffected epidermis. Moreover, BCC tissues expressing high levels of basonuclin were also elevated for their GLI1 expression. Mechanistically, GLI1 binds to GLI-binding sites within the BNC1 (encoding for basonuclin protein) promoter to induce basonuclin transcription. Importantly, high levels of basonuclin correlated with elevated levels of $47 \mathrm{~S}$ pre-rRNA expression, and both proteins were more common in infiltrative type BCC than nodular-type BCC. Moreover, elevated levels of $47 \mathrm{~S}$ pre-rRNA were more common in a subset of BCC cells expressing high Ki67 cell cycle regulator levels, suggesting that basonuclin and 47S pre-rRNA may promote cell cycling and unrestricted growth of BCC. Notably, infiltrative-type BCCs are clinically more invasive and have greater growth potential as assessed by lesion size and proliferative Ki67 markers [131]. With regards to the above, GLI proteins could upregulate basonuclin and consequently enhance BCC cell proliferation by increasing rRNA transcription, which may lead to the development of a more aggressive subtype of BCC [52]. Indeed, Marceline et al. also reported that higher levels of PTCH1, which is among the main target genes of GLI, were more frequently detected in infiltrative rather than nodular-type BCC [132]

Immunohistochemical analysis of human BCC biopsies excised from different patients revealed that high expression of GLI2 was positively correlated with high expression of cFlip and BCL2. The silencing of GLI2 or cFlip was shown to increase the number of apoptotic cells induced by tumor necrosis factor-related apoptosis-inducing ligand (TRAIL) in BCC tissue ex vivo. Of note, cFlip functions as a master antiapoptotic regulator by inhibiting caspase 8 activation, a downstream target of TRAIL. Indeed, GLI2 expression in $\mathrm{HaCaT}$ keratinocytes cells was found to render them resistant to TRAIL-induced apoptosis by enhancing BCL2 expression and reducing caspase 8 activation [44]. Overall, the frequent loss of PTCH1 and the frequent activation of GLI in the absence of GLI mutations strongly suggest a role of SMO derepression by the loss of PTCH1 in mediating GLI activation in BCC.

To a smaller extent, mutations in SMO have also been reported in sporadic BCCs, leading to the Hh pathway's constitutive activation $[129,133]$. Often, SMO mutations affecting ligand-binding pockets (LBPs) lead to the development of drug resistance toward SMO inhibitors. For instance, SMO missense mutation (G497W and D473Y) have been shown to contribute to primary and secondary resistance to vismodegib in BCC patients, respectively, by interfering with the binding of vismodegib to SMO LBP [63]. Interestingly, when treated with vismodegib, vismodegib-resistant tumors of BCC patients with SMO mutations (D473H, D473G, and W535L) had significantly higher levels of GLI1 compared to vismodegib-sensitive tumors. Moreover, inhibition of GLI function by GLI kinase atypical Protein Kinase $C \iota / \lambda(a P K C-\iota / \lambda) / G L I$ inhibitor PSI and GLI2 inhibitor arsenic trioxide effectively suppressed $\mathrm{Hh}$ pathway activation in $\mathrm{Smo}^{-/-}$MEFs expressing SMO with LBP mutations (D473G, W281C, H231R, and Q477E), suggesting that the SMO LBP mutant that 
constitutively promotes GLI expression and consequently Hh pathway activation in the presence of vismodegib can be circumvented with the use of GLI antagonists. Conversely, treatment of these cells with vismodegib or Shh-N (active fragment of Shh) did not affect Hh pathway activity [64]. A D473H SMO mutant was also found to confer resistance to vismodegib in a medulloblastoma patient and induced GLI1 luciferase reporter activity in C3H10T1/2 cells [67]. Thus, as SMO mutants can constitutively activate Hh signaling by GLI activation to promote cancer cell survival, targeting GLI may serve as a promising second-line therapy for the treatment of SMO-inhibitor-resistant tumors.

The constitutively active SMOM2 mutant (W535L) was also found to be overexpressed in some sporadic and vismodegib-resistant BCCs. Notably, the SMOM2 mutant strongly induced Hh pathway activation in the absence of Hh ligand through GLI modulation and is able to resist the inhibitory catalytic signal of PTCH1. Furthermore, several other SMO mutants (F460, W535L, V321M, and L412F), including SMOM2, conferred resistance to vismodegib in $\mathrm{Smo}^{-/-}$MEF cells, suggesting a dual role of SMO mutants in tumorigenesis by promoting a constitutive $\mathrm{Hh}$ pathway activation and endowing resistance [63].

To further support the oncogenic role of SMO mutants, transfection of embryonic fibroblast REF52 cells with SMOM1 (R562Q) and -M2 mutant was found to enhance GLI1 transcript levels and confer cells' ability to grow in soft agar. Furthermore, overexpression of the SMOM2 mutant in transgenic mice led to the development of abnormal skin features similar to BCC [65]. In the adult IFE cells, SMOM2 expression drove the formation of invasive-type BCC in transgenic mice, which was associated with enhanced expression of Hh pathway genes (GLI1/2, PTCH1/2, and HHIP) and embryonic hair follicle progenitor markers (P-cadherin, LHX2, and CUX1). The loss of PTCH1 in IFE cells also yielded similar results compared to SMOM2-expressing IFE cells. Furthermore, SMOM2 induced upregulation of Wnt/ $\beta$-catenin signaling, as shown by increased nuclear $\beta$-catenin and lymphoid enhancer-binding factor-1 (LEF1) expression, which led to mice BCC and human BCC tumor initiation [66]. Besides BCC, follicular hamartomas, a rare benign tumor with the potential to develop into BCC, developed as a result of overexpressing the constitutive active SMOM2 mutant in transgenic mice revealing high levels of GLI1 and GLI2 transcripts in both in situ hybridization and northern blot analysis [62]. Taken together, these results confirm an SMO-dependent role of GLI regulation in BCC tumorigenesis.

Mutations in PTCH1 and SMO, although to a lesser degree than BCC, have also been detected in other cancers such as medulloblastoma [54], mesothelioma [134], cervical cancer [61], breast cancer [57], odontogenic keratocystic tumors [55], acute lymphoblastic leukemia [56], and hepatocellular carcinoma (HCC) $[68,135]$. Similar to BCC, GLI proteins are commonly overexpressed in these cancers. Undoubtedly, mutation of Hh pathway upstream genes leads to the constitutive activation of GLI proteins, which is vital to the development and growth of these tumors. For instance, treating medulloblastoma cell lines and primary malignant pleural mesothelioma cultures with the SMO inhibitor cyclopamine significantly inhibited GLI1 expression and in vivo xenograft growth in nude mice $[136,137]$, suggesting the importance of SMO-dependent GLI activation in the tumorigenesis of these cancers.

In human HCC tumors, expression of SMO positively correlated with tumor size, while an inverse relationship was reported for PTCH1, suggesting overaction of Hh signaling as a result of SMO derepression. Notably, a novel SMO point mutation (A to $\mathrm{T}$ transversion at position 1723) was identified and associated with enhanced GLI1 expression in human HCC. Like human HCC tumor specimens, Hep3B had significantly higher levels of SMO than PTCH1, and treatment of Hep3B with KAAD-cyclopamine (antagonist of oncogenic mutant SMO) but not cyclopamine (antagonist of wild-type SMO) markedly repressed GLI1 activity, suggesting that genetic alteration of SMO can promote HCC carcinogenesis through GLI1 activation. Furthermore, KAAD-cyclopamine treatment suppressed the expression of the c-Myc proto-oncogene, a key oncogenic factor in hepatocarcinogenesis and a major regulator of cell proliferation, and inhibited Hep3B cell 
growth which suggests a role of SMO-mediated upregulation of c-Myc in enhancing HCC growth [68].

PTCH1 LOH has been associated with enhanced medulloblastoma formation as a result of increased SMO and GLI activation [54], and the loss of GLI1 markedly suppressed spontaneous medulloblastoma formation in $\mathrm{Ptcl}^{+/-}$mice. Interestingly, in a subset of $\mathrm{Ptc1}^{+/-}$mice with the loss of GLI1 that still develop medulloblastoma, GLI2 expression was significantly upregulated and correlated with the levels of n-Myc, a regulator of D-type cyclins in neuronal cells, suggesting a compensatory GLI2/n-Myc expression in promoting medulloblastoma formation and proliferation [53]. These results suggest that dual inhibition of GLI1 and GLI2 is required to completely terminate all aspects of $\mathrm{Hh}$ signaling to inhibit medulloblastoma tumorigenesis.

Kadlub et al. reported that germline PTCH1 mutations in one allele were found in all keratocystic odontogenic tumors of patients, except in one syndromic keratocystic odontogenic tumor that resulted from a somatic silent mutation. Based on the pathological findings, the authors proposed that mutation-harboring keratocystic odontogenic tumors contain a chorionic epithelial structure that serves as a germinal center that gives rise to new daughter cysts following the course of local inflammation, suprabasal proliferation, epithelial budding, chorionic epithelial island formation, and daughter cyst formation, leading to tumor recurrence [55].

Burns et al. reported Hh pathway mutations in 16\% of childhood T-cell acute lymphoblastic leukemia (T-ALL), of which the majority of mutations were reported in the PTCH1 gene [56]. Furthermore, Hh pathway mutations were associated with primary chemotherapy failure and increased incidence of relapse. Notably, transfection of the mutant PTCH1 alleles identified in T-ALL specimens into the PTCH1-mutant T-ALL cell line Jurkat did not suppress growth in six out of seven of the tested mutant PTCH1 alleles. Additionally, these mutants were impaired in their ability to suppress GLI1 mRNA, while wild-type PTCH1 induced apoptosis and suppressed GLI1 expression. Furthermore, transduction of wild-type PTCH1 into the PTCH1-mutant cells downregulated the expression of $M Y C N$, which has been reported in approximately $20 \%$ of human T-ALL to drive oncogenic T-cell transformation [56].

To further corroborate these findings in vivo, coinjection of CRISPR/Cas9 cassettes targeting the exon 13 of PTCH1 was shown to accelerate the onset of Notch1-induced T-ALL in a zebrafish model. Furthermore, treating zebrafish engrafted with T-ALL blasts harvested from the PTCH1-mutant zebrafish with the SMO inhibitor cyclopamine led to marked tumor regression, while no tumor growth inhibition was noted in zebrafish engrafted with T-ALL harvested from aavs1-control fish. Notably, treating primary leukemic cells from patient T-ALL D15 harboring the pathogenic PTCH1 T1106M mutation with the FDA-approved SMO inhibitor vismodegib also effectively suppressed their viability and GLI1 expression [56]. These results confirm that PTCH1 mutants must transduce Hh signals to GLI through SMO to induce tumorigenesis in T-ALL.

PTCH1 mutations have also been reported in breast cancer patients, which were associated with poor prognosis and increased tumor recurrence rate [57]. Notably, high levels of Shh and GLI1 have been associated with the enhanced acquisition of CSC traits and chemoresistance in breast cancer, which can be attenuated with SMO inhibitors [58]. Thus, increased SMO-dependent GLI activation due to PTCH1 mutation or Shh induction might promote tumor recurrence by supporting the formation of chemoresistant CSC niches in breast tumors.

Deletion of PTCH1 was also associated with the progression from early to advanced stages of cervical carcinoma and predicted poorer overall survival (OS) in patients. Additionally, lower expression of PTCH1 was positively correlated with increased nuclear GLI1 in both normal epithelium and tumor samples [60]. In a different study by Chaudary et al., high expression of $S M O$, as well as upregulation of more than 3 Hh genes, including Shh, PTCH1, and GLI1, was associated with increased incidence of local recurrence after chemoradiation [60]. A different study by Chen et al. also demonstrated that Shh and 
PTCH1 were significantly correlated with pathological tumor grade, as shown by enhanced expression of these proteins in poorly differentiated tissues [61]. Similarly, GLI1 was also expressed more in poorly differentiated tissues and was strongly correlated with tumor invasion and lymph node metastasis. Like GLI1, SMO was also strongly correlated with tumor invasion, although no association was found with the pathological tumor grade [61].

Of note, according to the TCGA pancancer atlas database, the frequency of SMO, GLI1, GLI2, and GLI3 mutations and copy number variations (CNVs) is $2 \%, 3 \%, 3 \%$, and $4 \%$, respectively. Despite the lower frequency of mutations and CNVs reported in SMO compared to GLI proteins, SMO has the highest number of oncogenic driver somatic mutations reported at $4.8 \%$, followed by GLI1 $(1.9 \%)$, GLI2 $(0.3 \%)$, and GLI3 (none). Nevertheless, oncogenic driver mutations in any upstream Hh components inevitably converge at GLI proteins, leading to the constitutive activation of GLI proteins.

\subsubsection{Transcriptional and Epigenetic Regulation of Hh Pathway Genes Upstream of GLI}

Mutations in the Hh upstream elements are uncommon in many other tumors, indicating the existence of other dysregulated mechanisms affecting Hh-GLI signaling. Indeed, many of the mechanisms resulting in overactivation of SMO and subsequent activation of GLI result from the dysregulated expression of the upstream Shh/PTCH/SMO components of the Hh signaling pathway (Figure 5). Transcription factors bind to specific DNA consensus sequences within target gene promoters to initiate their transcription; however, when aberrantly activated, they lead to uncontrolled activation of target genes.

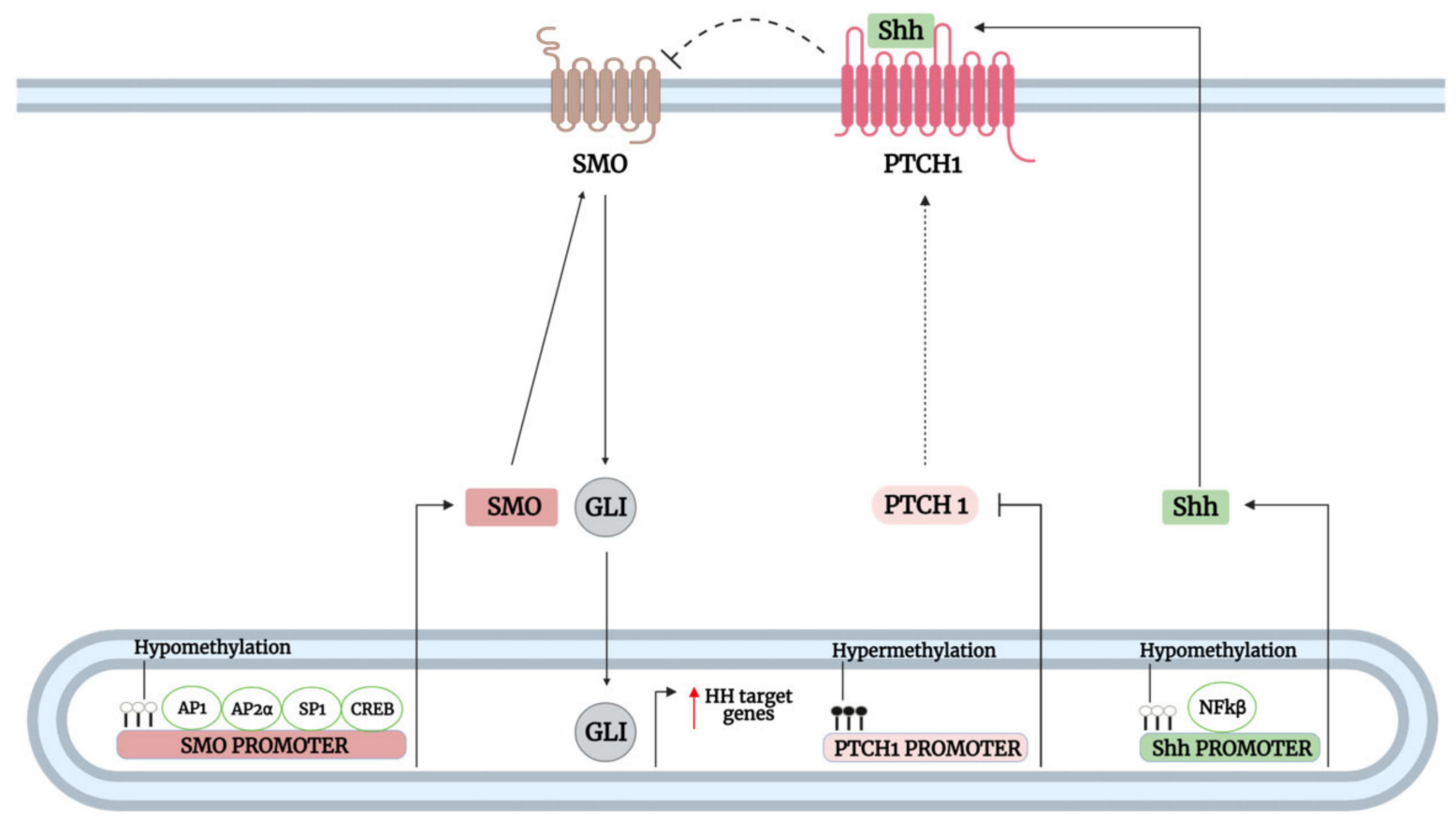

Figure 5. A simplified illustration of SMO-dependent GLI regulation in the context of transcriptional regulation. The binding of transcription factors $\mathrm{AP} 1, \mathrm{AP} 2 \alpha, \mathrm{SP} 1$, and $\mathrm{CREB}$ to promoter regions of SMO kickstarts the onset of its transcription. Similarly, the binding of NFKB to the NFKB binding site located within the Shh promoter induced the transcriptional upregulation of Shh. Furthermore, the increased transcriptional output of SMO and Shh can also occur as epigenetic events through hypomethylation of $\mathrm{CpG}$ islands that reside within promoters, which further promotes the binding of transcriptional machinery to promoters. Conversely, hypermethylation of the PTCH1 promoter leads to decreased transcriptional expression and consequently decreased production of PTCH1 protein. Together, these molecular events work in concert to further enhanced Hh pathway activity and promote tumorigenesis. Dotted triangle-headed arrow: inactivated function; dotted bar-headed arrow: loss of inhibition; red upward triangle-headed arrow: upregulation.

There is a lack of conclusive evidence to support Shh expression regulation by GLI transcription factors, but transcription factors external to the Hh pathway have been shown 
to regulate Shh expression at the promoter level. For instance, NFKB, a proinflammatory transcription factor, binds to the putative NFKB binding site in the Shh gene promoter to initiate its transcription in pancreatic carcinoma cell lines [69]. Increased Shh expression can promote the autocrine Hh-GLI pathway activation of cancer cells and stromal cells through repression of PTCH1 and increase SMO activation, thus leading to transcriptional activation of Hh target genes and carcinogenesis [72]. NFKB-mediated Shh upregulation was found to promote ASPC1 pancreatic cancer cell proliferation and protection against TRAIL-induced apoptosis/caspase 3 activation. Furthermore, ectopic induction of NFKB/IKK2 enhanced the expression of Shh in in vivo genetic mouse model and promoted pancreatic tumor growth in an in vivo chorioallantoic membrane tumor model, which can be reversed upon Shh silencing [69].

In further support of the findings above, Nakashima et al. also revealed a positive correlation between $\mathrm{p} 65$, the functional component of $\mathrm{NFkB}$, and Shh expression in human PDAC tumor specimens [70]. Abundant amounts of $\mathrm{p} 65$ and Shh were also positively correlated in chronic pancreatitis specimens, suggesting a role of Shh signaling in promoting persistent inflammation that predisposes the development of cancer. By contrast, few to no detectable levels of p65 and Shh were found in normal pancreas specimens. In vitro study using cell lines revealed that NFKB upregulates Shh to induce the proliferation of ASPC1 and SUIT2 pancreatic cancer cells. Additionally, enhanced NFKB DNA-binding ability in these cell lines was associated with the constitutive expression of Shh, PTCH1, and GLI1 at both transcript and protein levels [70], suggesting an active Shh-GLI signaling axis.

Shh produced by pancreatic ductal epithelium can also upregulate GLI1 mRNA in fibroblasts of the stromal compartment in a paracrine manner [71], and activation of canonical Hh-GLI signaling in stromal cells leads to paracrine feedbacks to the epithelial compartment, which, in turn, promotes pancreatic ductal adenocarcinoma (PDAC) progression and chemoresistance [72,73]. Notably, treating KrasG12D/+;LSL-Trp53R172H/+;Pdx-1-Cre (KPC) mice model with the SMO inhibitor IPI-926 enhanced stromal depletion and consequently improved gemcitabine delivery to PDAC tumor sites as a result of increased blood vessel perfusion [73]. Thus, high levels of NFKB in pancreatic epithelium may potentially enhance Shh expression to promote paracrine activation of Hh-GLI signaling in stromal cells, which in turn leads to desmoplastic stromal depletion, and decrease vascularization, which reduces gemcitabine delivery to tumor sites; however, this notion remains to be elucidated.

In 33 tumor cell lines, SMO gene expression was highest among all $\mathrm{Hh}$ members, and its expression was significantly and positively correlated with GLI2 transcript levels. Key functional binding sites for CREB, AP1, AP2 $\alpha$, and SP1 transcription factors were identified in $S M O$ promoter elements through luciferase reporter and electrophoretic mobility shift assay (EMSA), suggesting an important role of these transcription factors in SMO transcriptional activity and subsequent GLI2 activation in PC3 prostate cancer and MCF7 breast cancer cell lines [76]. Interestingly, Wnt3a treatment of human foreskin fibroblast cells induced the accumulation of cellular SMO and GLI proteins and the upregulation of SMO, PTCH, GLI1, GLI2, and GLI3 expression. Mechanistically, the $\beta$-catenin/T-cell factor 4 (TCF-4) complex directly binds to T/AC/GAAAG motifs residing in SMO and GLI1 promoters, and the suppression of $\beta$-catenin downregulated SMO and GLI1 expression as well as foreskin fibroblast cell proliferation [77]. Whether this mechanism of SMO regulation is translatable to cancer cells remains to be explored.

Epigenetic mechanisms, such as DNA methylation, play a significant role in regulating the expression of genes, including members of the Hh pathway. For instance, hypomethylation of CpG islands on Shh promoter has been shown to facilitate the binding of NFKB to its site, in which its increased transcriptional activity led to enhanced self-renewal/colony formation and migration of breast cancer cell lines and could be inhibited by SMO inhibition with cyclopamine. Importantly, high levels of Shh expression in human breast cancer tissues were positively correlated with positive NFKB nuclear staining score, promoter hypomethylation, and worse OS, corroborating the oncogenic role of Shh in breast cancer [74]. 
Similarly, Cui et al. also reported hypomethylation of the Shh promoter region in more than half of the breast cancer carcinomas tissues, which was positively associated with nuclear GLI1 and NFKB expression [75]. Taken together, these results suggest hypomethylation of the Shh promoter facilitates the binding of NFKB to induce its transcription, and Shh upregulation leads to increased canonical Hh-GLI signaling by which enhanced SMO activation as a result of PTCH1 repression promotes breast carcinogenesis through GLI1 activation.

Interestingly, Benvenuto et al. reported that SMO and GLI1 heavily regulated NFKB nuclear translocation [138], and together with the previous findings, suggested a positive feedback loop between Hh-GLI signaling and NFKB. Furthermore, treating BALB/c mice inoculated with mouse breast cancer cells with the SMO inhibitor GDC-0449 or GLI inhibitor GANT61 inhibited tumor growth in vivo by inhibiting Hh pathway activation, reducing cancer cell survival, and inducing apoptosis [138], confirming an oncogenic role of SMO-dependent GLI signaling in breast cancer tumorigenesis.

Hypomethylation of SMO promoter has also been reported to promote tumorigenesis through enhanced SMO-dependent GLI regulation. For instance, functional SMO is required for the expression of GLI3 in colorectal carcinoma cell lines, and promoter methylation of SMO led to decreased GLI3 expression. Conversely, treating colorectal cancer cells with demethylating agents 5-aza-20-deoxycytidine (5aza-dC) and TSA restored both SMO and GLI3 expression [78]. Of note, GLI3 overexpression in colorectal cancer cells has been implicated in enhanced colony formation, proliferation, and invasion by upregulating the expression of EMT factors (TWIST1, ZEB1, VIM, ZEB2, and CDH2) via positive regulation of ERK1/2 cascade, increasing the expression of adherence-related genes (ITGA4, GDF15, and NXPH4), and downregulating p53 levels. Furthermore, the GLI3-mediated tumorigenesis in several colorectal cancer cell lines, such as LOVO, HT29, and SW480 cells, were found to be dependent on active SMO and Shh signals [79-81]. Together with the role of functional SMO in regulating GLI3 activity, it suggests an SMO-dependent GLI signaling in colon cancer tumorigenesis. Hypomethylation of $S M O$ promoter has also been detected in other cancers, including prostate, kidney, glioblastoma, and ovarian cancer cell lines, and a positive correlation was identified between SMO and GLI2 transcript levels [76].

To further corroborate the importance of SMO in colorectal cancer tumorigenesis, Magistri et al. revealed that treating HCT 116, SW480, and SW620 colon cancer cell lines with SMO inhibitors or siRNA reduced cell proliferation via upregulation of p21 and downregulation of CCND1 and suppressed migration and three-dimensional invasion via downregulation of SNAI1 and induction of epithelial markers Cytokeratin-18 and E-cadherin. Similar findings were also obtained with the use of Shh inhibitor 5E1. In the same study, the authors found that GLI1 and GLI2 expression from a data microarray from a cohort of 382 colon cancer patients were strongly correlated with reduced OS and disease-free survival (DFS) [82]. In an earlier finding from the same group, inhibiting SMO in HCT 116 cells with SMO inhibitor resulted in deregulated cellular energetic metabolism, particularly the metabolism of nucleotide sugars, pyruvate, pyrimidine, and purine, and the citrate cycle and oxidative phosphorylation, which may potentially inhibit tumor growth [82]. In two independent studies, a positive correlation between Shh and GLI3 has also been reported in colorectal cancer tissues from patients $[79,80]$. Furthermore, implanting GLI3-expressing HT29 cells into severe combined immunodeficiency mice resulted in the development and enhanced growth of subcutaneous tumors [79]. Taken together, these findings strongly suggest an important role of the intact Shh-SMO-GLI axis in promoting colorectal cancer tumorigenesis.

Hypermethylation of the major negative regulator PTCH1 gene also contributes to carcinogenesis by decreasing inhibitory feedback to the Hh signaling and increasing GLI activity through SMO derepression. Inhibition of DNA methyltransferase by 5aza-dC was found to reduce PTCH1 DNA methylation, accompanied by decreased SMO and GLI1 expression and inhibition of GLI1 and GLI2 nuclear translocation in leiomyosarcoma cell lines. Consequently, decreased GLI activation resulting from increased PTCH1 inhibitory feedback led to decreased proliferation and migration while inducing apoptosis in the cell 
lines. Additionally, the blocking of SMO (LDE225) and GLI (GANT61) function by Hh inhibitors effectively reduced proliferation, migration, and invasion of leiomyosarcoma cell lines [83], and together with the previous results, suggested that PTCH1 downregulation can promote carcinogenesis of leiomyosarcoma cells through SMO derepression and subsequent GLI activation.

In a different study by Song et al., PTCH1 and hedgehog interacting protein (HHIP) transcript and protein levels were significantly downregulated in gastric cancer tissues, and subsequent analysis revealed significant promoter methylation of both genes [84]. Treating gastric cancer AGC cell line with 5aza-dC effectively reduced cell viability and induced apoptosis [84], suggesting a role of canonical Hh pathway activation in gastric tumorigenesis through hypermethylation and subsequent downregulation of the PTCH1 and HHIP negative regulators. Evidence for PTCH1 hypermethylation was also reported by Du et al. in a subset of gastric cancer patients [85]. In further support of the loss of PTCH1 in gastric tumorigenesis, Lee et al. reported that negative staining of PTCH1 in gastric cancer tissues of patients was positively correlated with reduced OS, while GLI2 was correlated with lymphovascular invasion [86].

In a study by Zuo et al., HHIP was hypermethylated in primary gastric cancer cells derived from two independent gastric cancer patients, and reversal of this methylation status or ectopically expressing HHIP inhibited their survival proliferation as well as migration and invasion [87]. Song et al. also reported marked lower HHIP levels in gastric cancer tissues compared to adjacent normal tissues, which was positively associated with gastric cancer metastasis [88]. Highlighting the importance of SMO in all these findings, Yang et al. revealed significantly elevated levels of SMO and GLI1 in gastric cancer tissues compared to normal paired tissues [89]. A study by Fukuya et al. also revealed elevated expression of Shh, PTCH1, SMO, GLI1, and GLI2 in the diffuse-type gastric cancer specimens compared to the intestinal-type gastric cancers [90]. Of note, diffuse-type gastric cancers have been reported to be more aggressive and metastatic than their intestinal counterpart, which suggests an association of Hh signaling with advanced stages of gastric cancer.

\subsection{SMO-Independent GLI Activation}

Numerous studies accounted for the involvement of various noncanonical mechanisms in the over-activation of GLI proteins, which explained the ineffectiveness of SMO and upstream inhibitors in the treatment of certain GLI-overexpressing cancers. These mechanisms involve the active crosstalk between the Hh pathway with multiple signaling pathways, including kirsten rat sarcoma 2 viral oncogene homolog (KRAS)/mitogenactivated protein kinase (MAPK)/extracellular-signal-regulated kinase (ERK), transforming growth factor- $\beta$ (TGF- $\beta$ )/SMAD, Wnt/ $\beta$-catenin, phosphoinositide 3-kinase (PI3K)/ protein kinase $\mathrm{B}(\mathrm{AKT}) /$ mechanistic target of rapamycin kinase (mTOR), and nuclear factor kappa B (NFkB) signaling (Figure 6). Additionally, interacting proteins (e.g., kinases and transcription factors) can also regulate GLI noncanonically, independent of SMO (Figure 7).

\subsubsection{Active Crosstalk of GLI with Oncogenic Pathways}

The interplay between GLI and oncogenic pathways is vital for the proper development and progression of cancers. For instance, it was shown that the KRAS/MAPK/ERK/ GLI1 activation could be mediated by either oncogenic KRAS mutation or stimulation of neuropilin 2 (NRP2) by vascular endothelial growth factor (VEGF) in lung adenocarcinoma (LAC) of non-small cell lung cancer (NSCLC). In the latter, Shh paracrine crosstalk between the epithelial and stromal compartment of the LAC tumor triggers the canonical activation of the stroma Hh pathway. Consequently, this led to the increased production of VEGFa ligands by stromal cells, which interacted with the NRP2 receptor of the epithelial compartment to mediate noncanonical activation of GLI1 via the initiation of MAPK/ERK cascade. Mechanistically, in vitro kinase assay revealed that ERK1 phosphorylated GLI1 to regulate its transcriptional-activating ability. Furthermore, GLI1 inhibition by GANT61 or 
siRNA-mediated silencing inhibited LAC proliferation, attenuated CSC stemness feature and markers (OCT4 and ABCG2) and induced apoptosis in vitro and in vivo [91].

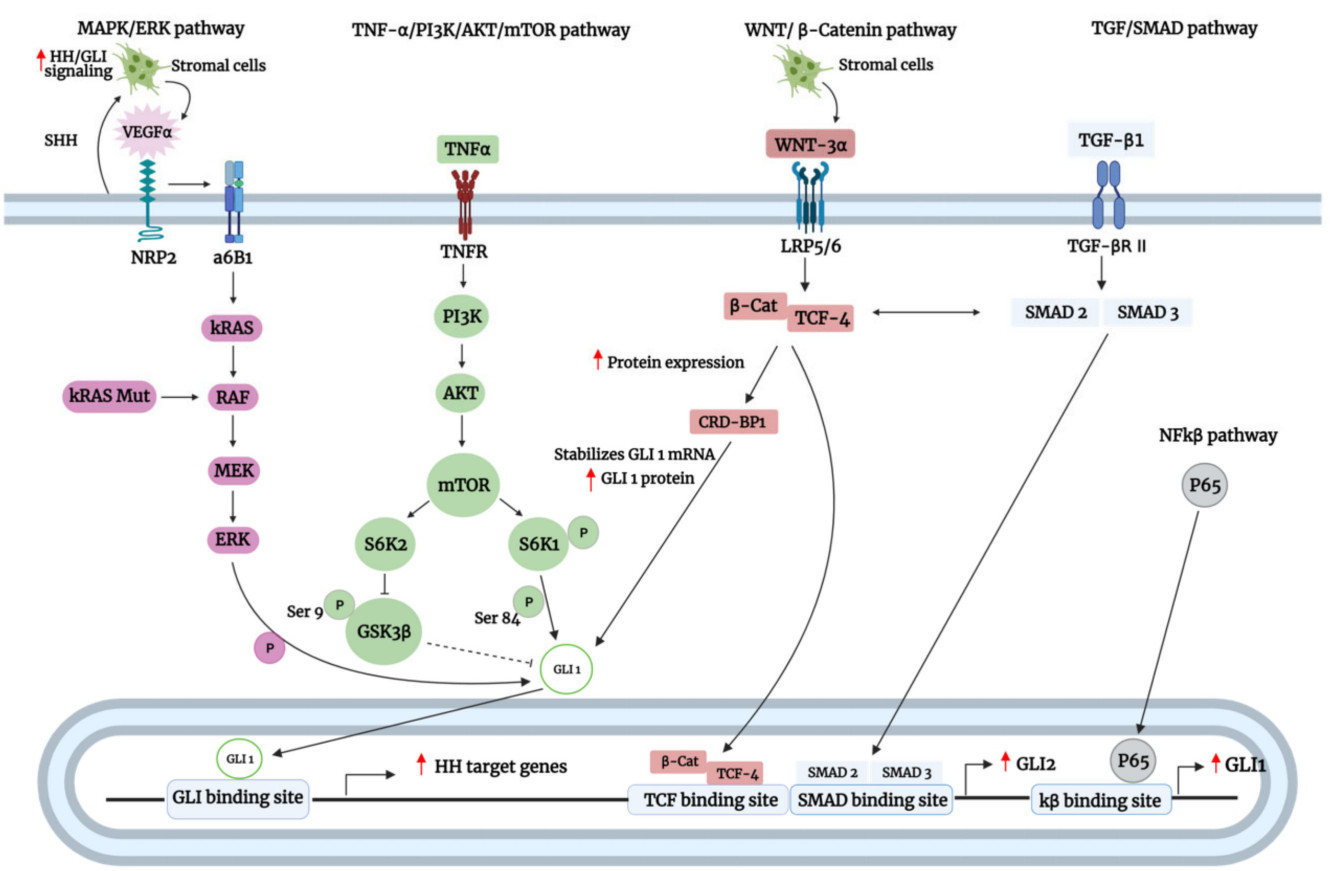

Figure 6. A schematic representation of the Smoothened (SMO)-independent regulation of gliomaassociated oncogene homolog (GLI) transcription factors by oncogenic pathways. As shown above, GLI transcription factors can be regulated at the protein or transcriptional level depending on the oncogenic pathway involved. In the mitogen-activated protein kinase (MAPK)/ extracellular-signalregulated kinase (ERK) pathway, sonic hedgehog (Shh) produced by tumor cells activates hedgehog (Hh)/GLI signaling in the stromal cells, leading to the upregulation of vascular endothelial growth factor A (VEGFa). Paracrine feedback of VEGFa to tumor cells is initiated upon binding of the VEGFa to neuropilin 2 (NRP2), which induces $\alpha 6 \beta 1$ integrin-mediated activation of kirsten rat sarcoma 2 viral oncogene homolog (KRAS) / mitogen-activated protein kinase kinase (MEK)/ERK cascade. Active ERK1 then phosphorylates GLI1 protein, leading to its activation. Oncogenic KRAS mutations also lead to the constitutive activation of the MAPK/MEK/ERK pathway, consequently promoting GLI1 phosphorylation and activation. In the phosphoinositide 3-kinase (PI3K)/protein kinase B (AKT)/mechanistic target of rapamycin kinase (mTOR)pathway, tumor necrosis factor-alpha $(\mathrm{TNF} \alpha)$ stimulation results in the activation of the mTOR complex, which in turn activates S6K2. Consequently, activated S6K2 phosphorylates glycogen synthase kinase 3 beta (GSK3 $\beta$ ) at serine 9, leading to its inactivation. Inactivated GSK3 $\beta$ is not able to phosphorylate GLI1, relieving the inhibition of GSK3 $\beta$ on GLI1. Activation of the mTOR complex also activates S6K1 by phosphorylation, and activated S6K1, in turn, phosphorylate GLI1 at Ser9 to promote its activation. In the Wnt/ $\beta$-catenin pathway, stromal cells produced Wnt3a that binds to the LRP5/ 6 receptor. The signal is then transduced to $\beta$-catenin, which forms a complex with T-cell factor 4 (TCF-4). The $\beta$-catenin-TCF-4 complex upregulates the protein expression of coding region determinant binding protein (CRD-BP), which stabilizes GLI1 mRNA and consequently enhances GLI1 protein levels. In the transforming growth factor- $\beta$ (TGF-B)/SMAD pathway, stimulation by TGF- $\beta$ results in the activation of SMAD2/3. SMAD2/3 cooperates with the $\beta$-catenin-TCF- 4 complex to upregulate the expression of GLI2 by binding to the SMAD and TCF binding site within the GLI2 promoter. In the nuclear factor kappa B (NFkB) pathway, the p65 subunit of the NFkB complex binds to the $\mathrm{kB}$ binding site within the GLI1 promoter to initiate its transcription. Red upward triangle-headed arrow: upregulation.

Importantly, this noncanonical route of GLI activation was frequently detected in patient-derived LAC CSCs. Notably, SMO was expressed at low levels in LAC cell lines 
and patient-derived LAC CSCs as a result of epigenetic silencing by hypermethylation, and together with the previous results, enforced a noncanonical role of MAPK/ERK in GLI1 regulation. Interestingly, the MAPK/ERK/GLI1 pathway could be further amplified by a positive feedback autocrine loop in which activation of the GLI1 resulted in the enhanced VEGFa expression and subsequent NRP2 function [91]. The lack of SMO expression in CSCs may partly explain the lack of benefit in lung cancer associated with the addition of SMO inhibitor to chemotherapy regimens, but there is yet to be a study to elucidate the importance of SMO/GLI in promoting chemoresistance in the context of CSC in lung cancer. Besides promoting stemness acquisition, high expression of VEGFa and NRP2 is associated with enhanced neovascularization of NSCLC tumors [92], which may suggest a role of GLI1 in mediating angiogenesis.

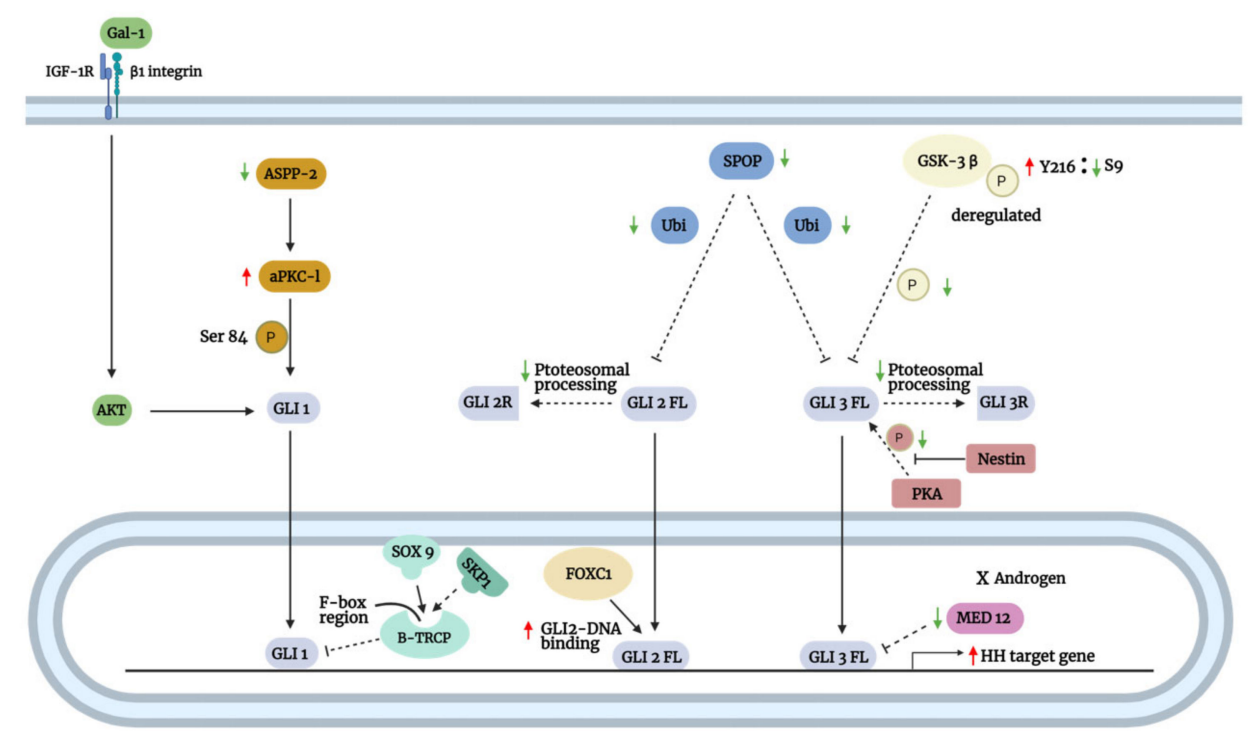

Figure 7. A schematic representation of the Smoothened (SMO)-independent regulation of gliomaassociated oncogene homolog (GLI) transcription factors by their interacting proteins. Apoptosisstimulating of p53 protein 2 (ASPP2) deficiency enhanced the binding of atypical Protein Kinase C $\iota$ (aPKC-ı) with GLI1, which allows aPKC-ı to phosphorylate GLI1 at Ser84. The phosphorylated GLI1 is, in turn, activated, promoting its translocation into the nucleus to transcribe target genes. Galectin-1 (Gal-1) binds to $\beta 1$ integrin to promote GLI1 activation. Mechanistically, activated $\beta 1$ integrin forms a complex with insulin-like growth factor 1 receptor (IGF-1R) to promote protein kinase B (AKT) activation, leading to an increase in GLI1 activity. In the nucleus, SOX9 binds to the F-box region of $\beta$-TrCP, interfering with its binding to SKP1. The binding of SOX9 to $\beta-\operatorname{TrCP}$ tethers it within the nucleus, thus protecting GLI1 from degradation. Speckle-type POZ protein (SPOP) downregulation results in decreased ubiquitination of full-length GLI2/3 proteins, favoring their activation and nuclear translocation over their proteasomal processing into repressors. In the nucleus, the N-terminal domain (aa 1-68) of transcription factor forkhead box C1 (FOXC1) binds to the internal region (aa 898-1168) of GLI2, enhancing its DNA-binding and transcriptional-activating ability. The imbalance between Tyr216 and Ser9 phosphorylation of glycogen synthase kinase 3 beta (GSK3 $\beta$ ) leads to its dysregulated function, thereby impairing its ability to phosphorylate fulllength GLI3 proteins. Unphosphorylated full-length GLI3 proteins are not subjected to proteasomal processing into their repressors, allowing their translocation into the nucleus to transcribe target genes. Under androgen-deprived conditions, the downregulation of MED12 relieves its constraint on the full-length GLI3 proteins, resulting in their hyperactivation. Green downward triangle-headed arrow: downregulation; red upward triangle-headed arrow: upregulation; dotted bar-headed arrow: loss of inhibition.

In further support of the findings above, Hh-GLI signaling in breast cancer can also be activated in a similar fashion. GLI activation upregulated the expression of VEGF 
and NRP2 in transgenic tumors of mouse models, which in turn induced $\alpha 6 \beta 1$ integrinmediated activation of RAS/MEK signaling through focal adhesion kinase (FAK) activation to enhance GLI1 expression and promote tumor-initiating or CSC-like properties [93]. Interestingly, enhanced FAK signaling in tumor epithelium as a result of cancer-associated fibroblasts (CAF)-induced extracellular matrix (ECM) remodeling has been shown to confer CSC traits in in vitro and in vivo, which in turn enhanced chemoresistance to docetaxel. In the M6-Hh (Hh expressing murine triple-negative breast cancer) tumors, Shh expressed from tumor epithelium cells induced expression of GLI1 in CAFs of the surrounding stroma, resulting in their activation. In turn, activated CAFs remodel ECM to promote CSC traits in tumor epithelium via activation of their FAK signaling. SMO inhibition of the CAF cells reduced FAK signaling, FGF-5 expression, and CSC markers in M6-Hh tumors and patient-derived xenografts implanted in $\mathrm{Rag}^{-} /^{-}$and NOD-scid IL2r $\gamma$ null mice, which in turn resensitized them to docetaxel. Moreover, in the phase-I EDALINE study, tumor specimens of high responders to docetaxel were cotreated with sonidegib and characterized by elevated Hh ligand expression, GLI1 expression, ECM remodeling, FAK signaling, phosphor-FGFR (receptor of FGF-5), and ALDH1 (CSC marker)-positive cells [58]. Taken together, these results suggest a cooperative role of SMO-dependent (stromal compartment) and SMO-independent (epithelial compartment) GLI activation in the activation of FAK signaling in breast tumor cells to confer CSC traits and consequently to enhance chemoresistance.

In another study, mutant KRAS drives PDAC tumorigenesis by regulating GLI1 expression independent of SMO. KRAS mutations are found in nearly all PDAC and are crucial drivers of PDAC growth [139]. The depletion of KRAS via siRNA-mediated knockdown led to the downregulation of GLI1 expression and the induction of mouse PDAC cell line apoptosis by caspase 3 activation. Similarly, GLI1 knockdown also significantly induced human PDAC cell line apoptosis upon challenging it with cycloheximide, an inducer of programmed apoptotic cell death. However, inhibition of anchorage-independent cell growth was less profound in PDAC cells expressing wild-type KRAS compared to mutant KRAS, suggesting that GLI1 regulation is more accurately represented in the context of mutant KRAS. In support of this, the transfecting of oncogenic KRAS construct into PDAC cell lines expressing wild-type KRAS markedly enhanced their sensitivity to GLI1 knockdown. Moreover, the depletion of SMO had no impact on PDAC formation and GLI1 expression of PDAC transgenic mice model, and the stimulation with recombinant Shh did not affect GLI reporter activity, proving an SMO-independent mechanism of GLI regulation. Interestingly, downregulation of KRAS resulted in a significant reduction in the expression of GLI1 protein and vice versa, implying the existence of a self-sustaining loop between KRAS and GLI1 protein [94]. An in vitro study by Han et al. also revealed that an intact RAF-MEK1-ERK pathway was required for KRAS-mediated GLI1/2 activation in pancreatic cancer cells [140].

Rajurkar et al. have also shown a cooperative role between KRAS and GLI1 in promoting pancreatic tumorigenesis using in vivo mice models [95]. The authors demonstrated that GLI1 is required to mediate KRAS-induced survival and proliferation of primary pancreatic cells and KRAS-induced pancreatic intraepithelial neoplasia (PanIN) lesion and PDAC formation in vivo. Notably, KRAS-induced tumors with a loss of p53 were characterized by aggressive PDA cells that were more proliferative and metastatic with evidence of dissemination to lymph nodes, liver, lungs, peritoneal cavity, and adjacent intestine. Conversely, conditional Rosa26 knock-in allele of GLI3T, which was proven to downregulate GLI1 and GLI2 expression in NIH 3T3 cells, resulted in reduced PANIN lesion formation, reduced proliferative pancreatic cells (absence of Ki67 staining), and delayed PDAC tumor formation. Ectopic GLI1 expression in KRAS-expressing mice increased PanIN lesions' formation, enhanced pancreatic cell proliferation as indicated by Ki67 staining, and promoted escape from growth arrest/senescence. Interestingly, ectopic GLI1 expression in KRAS-expressing mice enhanced IKBKE expression and nuclear RelA staining, and the knockdown of IKBKE expression in pancreatic cancer cell lines impaired 
their ability to grow in soft agar and induced apoptosis by caspase 3 cleavage [95]. Similar findings in a pancreatic cancer mouse model were also reported by Mills et al., who identified an additional IL-6/STAT3 axis regulated by GLI1 that was shown to be a crucial driver of KRAS-induced transformation [141].

TGF- $\beta$ /SMAD signaling was also positively correlated with GLI1 and GLI2 protein expression across 26 types of tumors and did not share any prognostic value with other Hh-related genes, suggesting a role of noncanonical crosstalk between TGF- $\beta$ /SMAD and GLI proteins [142]. TGF- $\beta 1$ is a potent inducer of EMT in cancer, and treatment of hepatocellular carcinoma cell lines with TGF- $\beta 1$ enhanced EMT acquisition via a GLISNAI1 dependent mechanism, which can be reversed by GLI1 knockdown. Furthermore, enhanced GLI1 expression was associated with enhanced colony formation, cell proliferation, viability, migration, and invasion in vitro, as well as enhanced vascular invasion in HCC biopsies [96]. Similarly, TGF- $\beta 1$ can also induce Hh-GLI1 signaling to promote EMT phenotype and promote migration and metastatic characteristics in mesenchymal A549 LAC cells [143], which further supports the role of GLI in mediating TGF- $\beta 1$-driven EMT in cancer. Such crosstalk between TGF- $\beta$ and GLI protein has also been observed in other cancers, including melanoma [97] and PDAC [94].

Faião-Flores et al. reported a role of GLI1/2 in conferring resistance to BRAF inhibitor vemurafenib in melanoma [97]. Examination of melanoma patient specimens failing vemurafenib revealed that all were positive for GLI1 expression, while $40 \%$ were positive for GLI2 expression. Similarly, the induction of vemurafenib resistance in melanoma cell lines was associated with frequent elevated expression of GLI1, while expression of GLI2 was elevated but to a lesser extent. Further investigation revealed that TGF- $\beta 1 /$ SMAD3 was directly involved in the noncanonical regulation of GLI1/2 activation in vemurafenibresistant melanoma cell lines. Inhibition of GLI1/2 by GANT61 significantly blocked the ability of TGF- $\beta 1$ to enhance colony formation of vemurafenib-resistant cells. Using a 3D reconstructed human melanoma skin model, both untreated naïve and resistant melanoma cells had elevated levels of MMP2/9 and were highly invasive, but treatment with GANT61, which downregulated GLI1/2 expression, reversed these effects. Both GANT61 and SIS3 (SMAD3 inhibitor) but not cyclopamine effectively suppressed GLI1/2 expression and decreased cell viability of vemurafenib-resistant cells by induction of apoptosis, as shown by the decreased $\mathrm{Bcl} 2 / \mathrm{Bax}$ ratio. The downregulation of GLI1/2 was associated with increased microphthalmia transcription factor (MITF) expression and decreased epidermal growth factor receptor (EGFR) expression [97].

In an effort to determine the clinical relevance of the findings above in vivo, the relationship between GLI1/2, MITF, and EGFR was determined in the TCGA melanoma cohort. Indeed, GLI2 was found to play a major role in suppressing MITF expression in human melanoma specimens, and the expression of GLI1/2 was correlated with EGFR/AXL signatures. These findings were consistent with those of vemurafenib-resistant cells, which showed strong upregulation of GLI1/2 and EGFR and downregulation of MITF that can be reversed with GANT61. Importantly, inhibition of GLI1/2 could not only restore sensitivity to vemurafenib but also delay the onset of vemurafenib resistance and induce senescence in melanoma cells [97]. Taken together, TGF- $\beta 1 /$ SMAD3 activates GLI1/ 2 via an SMOindependent mechanism to promote chemoresistance, enhance invasive potential, and promote the proliferation of melanoma.

Wnt $/ \beta$-catenin and TGF- $\beta$ /SMAD signaling have been reported to cooperatively induce GLI2 promoter activity by virtue of $\beta$-catenin/TCF-4 and SMAD binding sites found within the TGF- $\beta$ responsive region (29-119 bp) of the GLI2 promoter [144]. Interestingly, in highly metastatic MDA-MB-231 breast cancer cells, $\beta$-catenin/TCF-4 was shown to stimulate GLI2 promoter activity by binding to TCF-binding element (TBE) within the promoter but only in the presence of active functioning TGF- $\beta$ /SMAD signaling. Notably, when the SMAD binding site was mutated, overexpression of the $\beta$-catenin pathway failed to stimulate GLI2 promoter activity, indicating Wnt and TGF- $\beta$ signaling codependent 
regulation of GLI2. Similarly, TGF- $\beta$ type II receptor (TGFBRII) deletion also reduced GLI2 transcript levels [98].

Upon metastasis to bone, osteolytic tumors secrete parathyroid hormone-related protein (PTHrP) to induce bone resorption, triggering the release of TGF- $\beta$ that promotes tumor growth. Indeed, human bone marrow HS5 and primary bone marrow stromal cells were found to be paracrine sources of Wnt3a ligands, and treatment of breast cancer MDA-MB-231 cells with conditioned media derived from these stromal cells enhanced GLI2 levels, which was also associated with an increase in PTHrP (osteolysis mediator) levels and bone destruction. Physiologically, primary bone marrow stromal cells markedly enhanced osteolytic lesion in vivo when coinoculated with MDA-MB-231 cells. Moreover deletion of $\beta$-catenin in MDA-MB-231 cells or Wnt3a in HS5 cells reduced the ability of HS5 cells to enhance bone destruction by MDA-MB-231 cells. Conversely, inhibition of LRP5/ 6 (receptor of Wnt3a ligand) with sclerotin reduced basal GLI2 transcript levels in MDA-MB-231 cells, proving the existence of a paracrine Wnt signaling crosstalk between bone marrow stromal cells and tumor cells [98].

Not long after, a separate study revealed that GLI2 upregulated PTHrP expression and consequently bone invasion in oral squamous cell carcinoma (OSCC). Using an in vivo orthotopic model, human OSCC cell lines expressing higher levels of PTHrP were associated with enhanced bony invasion and bone destruction. Similarly, $\beta$-catenin overexpression and TGF- $\beta$ treatment were also found to upregulate GLI2 promoter activity and PTHrP levels, which in turn enhanced bone invasion and destruction. Conversely, the silencing of GLI2 in bony invasive human OSCC cells resulted in significantly lower expression of PTHrP and reduced bony invasion and bone destruction in vivo when injected into mice. In further support of these findings, higher levels of GLI2 in OSCC specimens of patients were associated with bony invasion in both qRT-PCR and immunohistochemistry analysis. Additionally, analysis of a cohort of 279 head-and-neck carcinoma datasets from cBioPortal also revealed significant coexpression of GLI2 and TGF- $\beta 1$, which are of clinical relevance to the findings above [99]. Taken together, these studies suggest a cooperative role of Wnt/TGF- $\beta 1$ signaling that converges on GLI2 to induce PTHrP expression and consequently bony invasion in cancer.

Wnt signaling has also been reported to affect the expression of GLI proteins indirectly via an intermediate. For instance, the $\beta$-catenin/TCF- 4 complex upregulates the expression of RNA-binding protein, the coding region determinant binding protein (CRD-BP). CRD$\mathrm{BP}$ can bind to the coding region of GLI1 mRNA, thereby stabilizing its steady-state transcript and protein levels. Furthermore, GLI1 contributed to Wnt/ $\beta$ catenin-dependent proliferation of human colorectal cancer cells, and GLI1 transfection into cancer cells could rescue colony formation when Wnt/ $\beta$-catenin signaling was inhibited. Notably, a PCR analysis of primary human colorectal tumor samples that were previously shown to activate $\beta$-catenin and express high levels of CRD-BP was characterized by high levels of GLI1, which was consistent with those in a panel of established colorectal cancer cell lines [100].

Additionally, c-Myc, a key target of $\beta$-catenin, can both positively and negatively regulate the expression of GLI1A and GLI3R, respectively, which subsequently enhance Hh signaling in colon carcinoma cell lines. Interestingly, endogenous $c-M y c$ can also be upregulated by endogenous GLI1 expression, suggesting a positive transcriptional regulatory loop between c-myc and GLI1. Furthermore, GLI1 overexpression rescued the inhibition of $c-M y c$ and colony formation by a dominant-negative TCF-4 [101]. Astonishingly, other studies have also reported an antagonistic effect between the $\mathrm{Hh}$ and $\mathrm{Wnt} / \beta$-catenin signaling. For instance, the overexpression of $\beta$-catenin reduced butyrate-induced GLI1 overexpression in gastric cancer cells [145], making their crosstalk in cancers more perplexing than it seems.

Numerous studies have implicated a noncanonical role of PI3K/AKT/mTOR signaling in regulating GLI proteins in multiple cancers. For instance, GLI expression in gastric cancer was shown to be heavily modulated by phospho-AKT (p-AKT) activity. Notably, 
the expression of p-AKT was positively correlated with GLI1 expression in human gastric cancer tissues, with a stronger correlation in advanced gastric cancer stages; higher levels of p-AKT and GLI1 were also detected in advanced stages of gastric cancer. Additionally, high expression of both p-AKT and GLI1 was significantly associated with the following clinicopathological factors: tumor size, lymph node metastasis, invasion depth, venous invasion, degree of differentiation, and TNM staging. Evidently, p-AKT knockdown decreased GLI1 protein expression without affecting SMO levels, and this was associated with depressed growth and migration and enhanced cisplatin sensitivity of gastric cancer cell lines. Consistent findings were also revealed upon further investigation in vivo, where the concurrent inhibition of GLI and PI3K/AKT/mTOR signaling in mouse subcutaneous xenograft model enhances tumors' sensitivity to cisplatin, as indicated by reduced tumor burden [102].

Interestingly, Chakrabarti et al. demonstrated that GLI2 promoted the expression of programmed death ligand-1 (PD-L1) to inhibit CD8+ cytotoxic T lymphocyte (CTL) cells' effector function in gastric cancer [103]. Treatment of iLgr5; GLI2A mice with GANT61 resulted in the loss of tumor formation, reduced proliferation of the gastric epithelium as indicated by decreased PCNA staining, and reduced CD8+ CTL cells infiltration within tumors. Coculturing of iLgr5; GLI2A mice-derived organoids with CTLs and dendritic cells revealed that tumor antigens secreted from the cancer organoids are presented by dendritic cells to induce PD-1 expression on CTL cells. However, significant CTL-induced organoid apoptosis could only occur when cocultures were pretreated with PD-L1 inhibitors, indicating that PD-L1 expressed on cancer organoids inactivated CTL cells' effector function by interacting with PD-1 expressed on CTL cells. Additionally, patient-derived gastric cancer organoids expressing high levels of GLI2 were found to be highly resistant to chemotherapeutic drugs epirubicin, oxaliplatin, and 5-fluorouracil compared to those without GLI2 expression in both in vitro and in vivo, while treatment with GANT61 resensitized the organoids to chemotherapy [103]. Further study by the same group revealed that the $\mathrm{PI} 3 \mathrm{~K} / \mathrm{AKT} / \mathrm{mTOR}$ pathway activated in patient-derived organoids noncanonically upregulated GLI1 and GLI2 to induce PD-L1 expression, which could be effectively suppressed with rapamycin [104]. Taken together, GLI1/2 mediates mTOR-induced PD-L1 expression to promote immune evasion of cancer cells, as well as promotes chemoresistance.

Kasiri et al. reported a trend where high GLI1 transcript expression in NSCLC patients was associated with worse OS [105]. Additionally, the loss of GLI1 by shRNA-mediated knockdown significantly suppressed cell proliferation of subcutaneous SCC xenograft tumors in vivo. In vitro study demonstrated that inhibition of PI3K/mTOR signaling effectively diminished GLI1 expression and inhibited clonogenicity and proliferation of lung squamous cell carcinoma cell lines. Likewise, regulation of GLI1 was also independent of canonical Hh signaling, as neither SMO inhibition by GDC-0449 nor induction by SAG had a significant impact on both GLI1 transcript and protein levels; SMO inhibition also did not affect colony formation and cell proliferation. The concurrent inhibition of GLI and $\mathrm{PI} 3 \mathrm{~K} / \mathrm{AKT} / \mathrm{mTOR}$ signaling demonstrated a synergistic effect in inhibiting in vivo cancer cell growth, evident by reduced tumor burden of xenografts compared to treatment with any of the agents alone [105]. GLI1 expression has also been reported to be regulated by $\mathrm{PI} 3 \mathrm{~K} / \mathrm{AKT} / \mathrm{mTOR}$ signaling in several other cancers to promote tumorigenesis, including esophageal adenocarcinoma [106], melanoma [113], osteosarcoma [107], pancreatic cancer, ovarian cancer [108], and renal cancer [109].

$\mathrm{S} 6 \mathrm{~K} 1 / 2$, members of the ribosomal S6 kinase family, are downstream targets of $\mathrm{PI} 3 \mathrm{~K} / \mathrm{AKT} / \mathrm{mTOR}$ and are involved in protein synthesis and cell proliferation. Notably, their activation has been linked to increased GLI1 expression and activity in multiple cancers. Tumor necrosis factor-alpha (TNF $\alpha$ ) induced SK61 phosphorylation, which was associated with enhanced GLI1 expression and GLI1 target genes, including cell cycle regulators CCND1 and $n-M y c$, in prostate cancer PC 3 cells. Consistent with the upregulation of these genes, GLI1 depletion by either GANT61- or siRNA-mediated knockdown effectively suppressed PC3 cell viability, liquid colony formation, and cell proliferation. Conversely, 
genetic and pharmacological inhibition of PI3K/mTOR inhibited TNF $\alpha$-induced SK61 phosphorylation and consequently GLI1 expression, which led to decreased PC3 cell viability [110]. Interestingly, a study by Wang et al. reported that in esophageal adenocarcinoma cell lines, TNF $\alpha$ stimulation and ectopic SK61 expression regulate GLI1 activity by phosphorylation of its Ser84 residue, thereby dissociating GLI1 from SUFU and allowing GLI1 translocation into the nucleus [111]. Conversely, inhibition of SK61 activation by PI3K/mTOR inhibitor rapamycin and RAD-001 enhanced HH inhibitor GDC-0449 cytotoxic effect in both in vitro and in vivo models. Additionally, GLI1 was required for TNF3/mTOR/S6K1-mediated cell proliferation, as GLI1 knockdown abrogated TNF $\alpha$ and S6K1-induced cell viability, proliferation, and invasion. Of note, SMO inhibition with cyclopamine or siRNA-mediated knockdown does not interfere with TNF $\alpha$-induced GLI activity, suggesting an SMO-independent regulation of GLI1 activity by TNF $\alpha$ [111].

P70S6K2, another known downstream effector of the PI3K pathway, was also reported by Mizuarai and colleagues to regulate GLI1 expression through modulation of GSK3 $\beta$, a negative regulator of GLI activation. Evidently, p70S6K2 inhibited GSK3 $\beta$ function by phosphorylating its Ser9 residue, which in turn stabilized GLI1 protein levels and enhanced cell viability/proliferation of non-small cell lung cancer cell lines, and this effect can be reversed upon p70S6K2 silencing. The G1/S cell-cycle-regulator gene CCND1 and apoptosis-inducer gene $\gamma$-catenin were markedly downregulated and upregulated, respectively, by siRNA-mediated knockdown of p70S6K2 in a dose-dependent manner, mirroring that of GLI1 inhibition [112].

Lastly, other routes of noncanonical GLI regulation also include NFKB signaling. In claudin-low breast cancer and EMT cell lines, the p65 subunit of the NFKB act as a transcriptional regulator of GLI1 expression by binding to the $\mathrm{KB}$ binding site located within the GLI1 promoter. Indeed, $N F \kappa B$ knockdown resulted in a significant decrease in GLI1 expression, and GLI1 knockdown resulted in decreased claudin-low breast cancer and EMT cell lines' tumorigenicity. Additionally, GLI1 knockdown in claudin-low breast cancer cell lines significantly attenuated cell proliferation, migration, anchorage-independent growth, self-renewal, and reduced tumor xenograft growth in vivo. By contrast, treatment with several SMO inhibitors does not affect GLI1 transcript levels or proliferation of EMT cell lines, indicating SMO-independent activation of GLI1 by the NFKB pathway [114].

Of note, osteopontin, a bone matrix protein, has been shown to noncanonically activate GLI1 in breast cancer to promote the acquisition of mesenchymal phenotype via upregulation of mesenchymal (N-cadherin, vimentin, TWIST, and SLUG) and downregulation of epithelial (E-cadherin and keratin-18) markers, as well as promote drug resistance to doxorubicin, paclitaxel, and cisplatin via upregulation of ABC transporters (ABCB1 and ABCG2). Interestingly, inhibition of both SMO and osteopontin resulted in greater suppression of the expression of $A B C$ transporters [146], which suggests a cooperative role of both SMO-dependent and SMO-independent axis in promoting breast cancer chemoresistance. As mentioned previously, $\mathrm{NF} \kappa \mathrm{B}$ has also been shown to transcriptionally enhance Shh expression to promote breast cancer tumorigenesis in two independent studies [74,75], and Shh induction promoted chemoresistance of breast cancer by forming CSC niches [58]. Thus, GLI1 activation by SMO-dependent or -independent mechanisms in breast cancer cells could promote EMT-like changes and stemness acquisition, resulting in enhanced metastatic potential and chemoresistance.

\subsubsection{Active Crosstalk of GLI with Oncogenic and Tumor Suppressor Proteins}

Apoptosis-stimulating of p53 protein 2 (ASPP2), a haploinsufficient tumor suppressor of the ASPP family, is frequently downregulated in multiple types of cancers, leading to increased tumor metastasis. In gallbladder cancer, ASPP2 deficiency was found to mediate tumor invasion and metastasis through the aPKC-ı/GLI1 pathway. Clinically, reduced expression of ASPP2 was positively correlated with advanced TNM stages, poor tumor differentiation, and lymph node metastasis [126]. aPKC-ı has been shown to regulate GLI activity in BCC and function downstream of SMO [147]. Similarly, ASPP2 depletion 
in gallbladder cancer cell lines was shown to enhance the expression and binding of aPKC-ı with GLI1. Consequently, aPKC-ı phosphorylated GLI1 Ser84, which, in turn, promoted its nuclear translocation to activate cytokine genes (CCL2, CCL5, and TNF $)$ involved in the recruitment of tumor-associated macrophages (TAMs). Consequently, increased TAMs recruitment promoted EMT-like changes in gallbladder cancer tissues and enhanced their tumor lung metastases in vivo. Furthermore, coculture of gallbladder cancer cells with macrophages or a macrophage-derived conditioned medium enhanced cell migration with a concomitant increase in mesenchymal $\mathrm{N}$-cadherin and vimentin and a decrease in epithelial marker E-cadherin. Interestingly, GLI1 can also regulate PRKCI (gene encoding aPKC- $\iota$ ) by directly binding to its promoter region, implying the existence of a positive feedback loop. Of note, SMO inhibition by both cyclopamine and siRNAmediated knockdown had no significant effect on GLI1 expression in gallbladder cancer cells, suggesting SMO-independent, aPKC-ı-mediated GLI1 activation [126].

Transcription factor SOX-9, a novel cancer stem cell marker, expression was shown to be regulated by GLI1 to promote CSC features in PDAC PANC-1 cells. The CSC spheroids were enriched for GLI1 regulatory genes (GLI1, GLI2, SOX9, and SNAI1) and pancreatic CSC markers (CD24, CD44, ESA, CD133 and CXCR4, OCT4, and KLF4). The suppression of either SOX-9 or GLI1 impaired CSC markers' expression with very similar profiles. Additionally, SOX9 suppression significantly impaired spheroid formation and side population cells. SOX9 suppression also significantly attenuated PDAC cell proliferation, anchorage independence, and survival. Conversely, restoring GLI1 expression by siRNA-mediated knockdown of $\beta$-TrCP, a negative regulator of GLI1, rescued cell death induced by SOX9 deficiency. Conversely, cosuppression of GLI1 and SOX9 further enhanced cell death [115].

Mechanistically, SOX9 inhibited the function of $\beta-\operatorname{TrCP}$, a negative regulator of GLI, by binding to specific protein motifs (F-box region) present in the $\beta-\operatorname{TrCP}$ subunit, thereby disrupting its interaction with GLI protein. Additionally, SOX9 interfered with the $\beta-\operatorname{TrCP}$ function by blocking its interaction with SKP1, an essential subunit of the SCF $\beta-\operatorname{TrCP}$ complex, and tethering it within the nucleus of PDAC cells to protect nuclear GLI1 from degradation. Notably, a positive feedback loop between SOX9 and GLI1 has been reported. To provide greater clinical relevance to human physiology, the authors assessed the expression of SOX9 and $\beta-\operatorname{TrCP}$ expression in primary human PDAC specimens by utilizing Oncomine microarray data, and as seen in their studies, SOX9 mRNA upregulation was accompanied by downregulation of $B T R C$ (encodes for $\beta-\operatorname{TrCP}$ ), suggesting a potential for SOX9-mediated GLI1 upregulation via downregulation of $\beta$-TrCP [115].

Transcription factor forkhead box C1 (FOXC1), a known inducer of oncogenesis in breast cancer, has been reported to be overexpressed in basal-like breast cancer (BLBC) to promote CSC traits. Notably, increased levels of FOXC1 were associated with the upregulation of GLI2 protein accompanied by an increased BLBC stem-like phenotype. FOXC1-mediated upregulation of ALDH1 activity and mammosphere formation capacity was significantly attenuated by GLI2 knockdown in MDA-MB-231 cells. Interestingly, the ectopic expression of mouse GLI2, whose expression was not affected by GLI2 shRNA, could rescue the GLI2-knockdown-induced decrease in ALDH activity and mammosphere growth in GLI2 knockdown FOXC1-overexpressing MDA-MB-231 cells. Mechanistically, it was shown that the internal region (aa 898-1168) of GLI2 was a direct-binding site for the FOXC1 N-terminal domain (aa 1-68), which contributed to GLI2-enhanced transcriptionalactivating capacity. In support of this, FOXC1 enhanced the DNA-binding ability of GLI2, evident by enhanced binding of GLI2 at the promoter of FAM38B gene, which is also markedly upregulated in breast cancer cells as a result of FOXC1 overexpression. Moreover, GLI1 (GANT61) but not SMO (GDC-0449 and LDE225) inhibition significantly reduced FOXC1-induced GLI-BS-luciferase activity in both SMO-positive and SMO-negative breast cancer cell lines, suggesting an SMO-independent activation of GLI [116].

To confirm the findings above in vivo, the authors injected FOXC1-overexpressing MDA-MB-231 cells orthotopically into the fourth mammary glands of BALB/c nude mice, which led to tumor development. Conversely, injected FOXC1-knockdown cells halted 
tumorigenesis. Additionally, FOXC1-overexpressing BLBC cells were less sensitive to the inhibitory effect of SMO inhibitor GDC-0449 compared to vector-overexpressing BLBC cells both in vitro and in vivo. Notably, establishing GD-0449-resistant BLBC sublines by long-term culturing of parental cells in the presence of escalating dose of GDC-0449 was accompanied by enhanced FOXC1 expression, suggesting a compensatory FOXC1mediated upregulation of GLI that was independent of SMO activity. In clinical samples of BLBC patients, most were evident for the expression of FOXC1 and GLI2, and a strong correlation was noted between the expression of the two proteins. Similarly, an analysis of breast cancer samples from the TCGA database and Curtis dataset also revealed a strong correlation between FOXC1 and GLI2. Importantly, upregulation of Hh pathway-associated genes in patients was significantly correlated with FOXC1 expression and decreased DFS compared to patients not enriched for Hh pathway-associated genes [116].

Speckle-type POZ protein (SPOP), an E3 ubiquitin ligase substrate-binding adaptor protein, was markedly downregulated in human ovarian cancer tissues, and its lower expression levels were associated with advanced cancer stages and malignancy. SPOP transfection was associated with decreased proliferation, colony formation, and enhanced apoptosis of OVCAR-3 ovarian cancer cells, while SPOP knockdown produced the opposite effects. Additionally, SPOP transfection downregulated proliferating cell nuclear antigen (PCNA) and antiapoptotic protein BCL2 and upregulated proapoptotic proteins cleavedcaspase 3 and Bax expression, while SPOP knockdown produced the opposite effects. Interestingly, low SPOP levels contributed to enhanced Hh signaling by modulating GLI1/2 expression, resulting in decreased apoptosis in ovarian cancer cell lines [123].

In a separate study by Zeng et al., SPOP was also significantly depleted in gastric cancer tissues compared to adjacent gastric mucosa tissues [124]. An analysis of clinicopathological features revealed a negative correlation between SPOP and lymph node metastasis, poor tissue differentiation, and advanced TNM stages. SPOP transfection of gastric cancer cell lines inhibited cell proliferation, migration, and colony formation. Mechanistic studies revealed that SPOP inhibited Hh pathway activation by promoting the proteasomal-dependent degradation of GLI2 in the cytoplasm. Likewise, SPOP repression enhanced GLI1/2 levels, which consequently promoted gastric cancer cell proliferation and migration as well as attenuated apoptosis. The transfection of SPOP was associated with upregulation of GLI1 regulatory targets, including caspase 3, cleaved caspase 3, and PARP, while GLI1 knockdown downregulated caspase-3, cleaved caspase-3, tumor suppressor PTEN, and cyclin-dependent kinase inhibitors p16, p21, and p27 and upregulated pro-proliferative proteins, including cyclin B1 (CCNB1), PCNA, p-ERK, and Daxx [124]. In support of the findings from Zend et al., Wang and colleagues have also demonstrated that SPOP interacted with the C-terminal region of GLI2 to promote its proteasomal-dependent degradation in C3H10T1/2 cells, and SPOP knockdown restored the levels of GLI2 [125].

Nestin, an important biomarker of stem cells, has been used to identify cells with cancer stem-like phenotype in a CSC population. Nestin was shown to play a crucial role in medulloblastoma-like tumor formation in transgenic mice with deleted PTCH1 in cerebellar granule neuron precursor cells, and its knockdown markedly impaired proliferation and induced differentiation in vitro, but unlike the function of Nestin, no stem cell properties were observed. Furthermore, Nestin knockdown in medulloblastoma cells significantly inhibited proliferation in vitro and in vivo, independent of apoptosis. Mechanistically, Nestin promoted tumorigenesis by modulating GLI3 activity and consequently Hh pathway activity. Nestin interacted with the C-terminal region of GLI3 to prevent its phosphorylation (presumably by PKA) and proteolytic processing into repressor form, thereby impairing its role as a negative regulator of the Hh pathway [117].

GSK3 $\beta$ is an established inhibitor of full-length activator GLI and is known to promote GLI2/3 processing into their repressors via phosphorylation of serine residues residing in GLI proteins. Interestingly, Trnski et al. reported high levels of GSK3 $\beta$ and GLI3 in colon cancer tissue specimens, while SMO and PTCH1 were only detected in less than half the samples [127]. GSK3 $\beta$ expression was significantly associated with higher 
DUKES' stage and lymph node involvement, with a similar trend observed for GLI3. In vitro study revealed that GSK3 $\beta$ was positively correlated with colon cancer cells survival, and their higher expression levels were unexpectedly associated with enhanced Hh-GLI signaling. Reduced GLI1 expression due to inhibition of GSK3 $\beta$ activity with lithium chloride significantly inhibited cell proliferation and induced apoptosis, which was associated with enhanced caspase 3 and PARP cleavage. Unlike GLI, SMO inhibition with cyclopamine had no effect on cell proliferation and had a minimal effect on GLI1 expression [127].

Further investigations revealed that the inhibitory Ser9 phosphorylation of GSK3 $\beta$ was largely absent in colon cancer cell lines, whereas the activating Tyr216 phosphorylation remains, suggesting deregulated GSK3 $\beta$ function. Intriguingly, treating colon cancer cell lines with lithium chloride, a GSK3 $\beta$ inhibitor, increased Ser9 phosphorylation of GSK3 $\beta$, which in turn restored the balance between the activating Tyr216 and inactivating Ser9 phosphorylation on GSK3 $\beta$ and restored its proper function. Consequently, the restoration of GSK3 $\beta$ proper function accelerated the formation of the GLI3-SUFU-GSK3 $\beta$ complex, which led to more efficient processing of GLI3 into its repressor form and consequently HhGLI signaling downregulation [127]. This study also suggests that imbalance activation and inactivation phosphorylation of GSK3 $\beta$ lead to its impaired function and, as a consequence, enhance Hh-GLI signaling and survival of colon cancer cells.

In prostate cancer cells, it was reported that the MED12 loss of function mutation promoted the androgen-independent cell growth of prostate cancer cells. Castration-resistant prostate cancer (CRPC) is known to develop as a result of androgen deprivation treatment. In this study, knockdown of MED12 was found to relieve its constraint on the GLI3-protein in the absence of androgen, leading to hyperactivation of GLI3 and consequently androgen-independent growth of LNCaP cells [128]. Notably, Zhou et al. revealed that overexpression of the GLI3-binding domain on MED12 inhibited the transactivation function of GLI3 [36], recapitulating the effect of the loss of MED12 on GLI3 hyperactivation in CRPC.

High expression of Galectin-1 (Gal-1) was associated with increased invasion and metastasis of gastric cancer cells and a poorer prognosis and survival, as well as increased lymph node metastasis and tumor invasion depth in gastric cancer patients. In human GC tissue samples, a positive correlation between Gal-1 and GLI1 was noted; it was shown that Gal-1 upregulated the expression of GLI1 through an SMO-independent manner [118]. Mechanistically, Gal-1 secreted by gastric cancer tissue-derived CAFs binds to $\beta 1$ integrin, an important regulator of cancer cell invasion, to induce GLI1 expression and gastric cancer cell invasion, while siRNA-mediated knockdown of $\beta 1$ integrin abrogated this effect [119]. In further support of this, Goel et al. reported that $\beta 1$ integrin regulated GLI1 activity through the modulation of the insulin-like growth factor 1 receptor (IGF-1R)/AKT pathway [148]. $\beta 1$ integrin forms a complex with IGF-IR to promote AKT activation, leading to an increase in GLI1 expression [148]. The siRNA-mediated knockdown of GLI1 could also abolish Gal-1-induced gastric cancer invasion and expression of mesenchymal markers, including N-cadherin, vimentin, and SNAI1, and invasion-related protein MMP9, as well as restore the expression of the epithelial marker, E-cadherin [119].

Similarly, Gal-1 was also reported to modulate the expression of GLI1 in PDAC to promote proliferation, angiogenesis, and desmoplasic reaction. In ela-myc mice model, Gal-1 was mainly restricted to the stromal compartment, and Gal-1 knockout enhanced mice survival and impaired pancreatic tumor proliferation. Furthermore, the loss of Gal-1 impaired acinar-to-ductal metaplasia, an important step that precedes the transition to PDAC. Additionally, Gal-1 could enhance the immune cell evasion of pancreatic tumors by hampering T-cell and neutrophil tumor infiltration but whether GLI1 mediated this effect remains to be elucidated. Importantly, Gal-1 could enhance GLI1 expression in both fibroblast and tumor epithelium cells. As Gal-1 is restricted to the stromal compartment as assessed in pancreatic tumor specimens, Gal-1 could potentially induce GLI1 expression in 
tumor epithelium cells via paracrine induction, recapitulating the importance of stromalderived Gal-1 in inducing GLI1 expression in the surrounding tumor [122].

Interestingly, Gal-1 was found to induce vasculogenic mimicry (VM), an endothelialindependent vascular system that allows blood transportation, through GLI1-mediated upregulation of VM-related molecules, including MMP2, MMP14, and laminin5 $\gamma 2$, in gastric cancer cell lines and tumor xenografts [120]. Immunohistochemical analysis of gastric cancer tissues revealed a significant correlation of Gal1 and GLI1 expression, and GLI1 expression was significantly correlated with VM. In an earlier study by the same group, immunohistochemical analysis of human gastric tissues revealed that Gal-1 expression was significantly correlated with vimentin, a mesenchymal marker shown to be positively correlated with VM. Further investigation revealed that Gal-1 promoted VM formation via activation of the EMT pathway to promote gastric cancer progression [121]. As Gal-1 was shown to modulate GLI1 expression to promote EMT [118,119], Gal-1 may have GLI1 as a mediator of the EMT pathway to induce VM in gastric cancer.

\section{Hh Pathway as Therapeutic Targets in Cancer Clinical Studies}

Since the discovery of the Hh pathway aberrant activation in cancers, tremendous efforts have been made to develop new Hh pathway targeting agents for the treatment of malignancies. From a wide range of $\mathrm{Hh}$ inhibitors that were developed and tested preclinically, SMO and GLI inhibitors have shown the most promise due to their improved efficacy in both in vitro and in vivo cancer models. In light of these findings, several $\mathrm{Hh}$ inhibitors, including the cyclopamine derivatives vismodegib, sonidegib, glasdegib, taladegib, saridegib, and TAK441, the antifungal itraconazole (also inhibits SMO), and the GLI inhibitor arsenic trioxide, are currently being developed in clinical studies. In particular, due to the durable objective tumor response rate (ORR) backed by Hh signaling's well-defined pathological role in BCC and acceptable toxicity in the tested populations, vismodegib and sonidegib have been recently approved by the FDA for the treatment of adults with BCC who are not candidates for surgery or radiation $[149,150]$. Clinical investigations are currently ongoing for these drugs in other solid tumors and hematologic malignancies and their utility in combination therapy. Like vismodegib and sonidegib, glasdegib has also recently been approved by the FDA for the treatment of adults with acute myeloid leukemia (AML) who are not candidates for intensive induction chemotherapy [151]. Due to its promising development in the treatment of AML, glasdegib is currently being tested in phase III, randomized (1:1) double-blind global trials (BRIGHT AML 1019; NCT03416179) for its utility in combination with intensive (glasdegib plus cytarabine and daunorubicin) or nonintensive (glasdegib plus azacitidine) chemotherapy [152].

By contrast, despite the superior pharmacological properties of GLI inhibitors, arsenic trioxide remains the sole GLI inhibitor that has been investigated clinically in Hh pathwayactive cancers such as BCC (NCT01791894, completed) [153]. Nonetheless, the frequent development of SMO inhibitor resistance (discussed in Section 3.1.1) in advanced BCC still warrants the development of new GLI inhibitors and investigation of their potential use as second-line therapy in clinical settings. Additionally, GLI inhibitors are more suitable candidates for treating noncanonical Hh pathway-associated cancers that are not dependent on SMO input for GLI activation (discussed in Sections 3.1.1 and 3.1.2). Xie et al. have described clinical trials of Hh inhibitors in cancer treatment published from 2013-2017 [154]; thus, we summarized the latest clinical findings concerning the use of Hh inhibitors in cancer treatment published from 2017-2021 (Table 2). 
Table 2. Summary of HH inhibitors' latest clinical findings in developmental clinical trials from 2017-2021.

\begin{tabular}{|c|c|c|c|c|c|}
\hline Hh Inhibitor & Clinical Trial Phase & $\begin{array}{c}\text { Cancer Type } \\
\text { (Patients Enrolled) }\end{array}$ & Treatment Interventions & Efficacy & $\begin{array}{l}\text { Clinical Trial Number } \\
\text { (Recruitment Status) }\end{array}$ \\
\hline \multirow{11}{*}{ Vismodegib } & Phase Ib [155] & Intermediate or highrisk MF $(n=10)$ & $\begin{array}{l}\text { Vismodegib } 150 \mathrm{mg} \text { daily with } \\
\text { ruxolitinib } 15 \text { or } 20 \mathrm{mg} \text { twice daily }\end{array}$ & Only symptom response $(n=5)$ & NCT02593760 (Completed) \\
\hline & Phase I [157] & Metastatic pancreatic cancer $(n=69)$ & $\begin{array}{l}\text { Erlotinib } 150 \mathrm{mg} \text { and vismodegib } \\
150 \mathrm{mg} \text { once daily }\end{array}$ & $\begin{array}{l}\text { No tumor response observed; SD }(\mathrm{n}=13) ; \\
\text { paired biopsies analysis showed reduced } \\
\text { GLI1 mRNA, phospho-GLI, and Hh target } \\
\text { genes; }\end{array}$ & NS \\
\hline & Phase II [159] & Untreated PDA $(n=71)$ & $\begin{array}{c}\text { Gemcitabine } 1000 \mathrm{mg} / \mathrm{m}^{2} \text { and } \\
\text { nab-paclitaxel } 125 \mathrm{mg} / \mathrm{m}^{2} \times \text { days } \\
1-8-15 \text {, followed by the same } \\
\text { regimen with oral vismodegib } 150 \\
\text { mg daily } \times 28 \text { days }\end{array}$ & $\begin{array}{l}\text { ORR 27\%, median OS } 9.79 \text { months, and } \\
\text { median PFS } 5.42 \text { months }\end{array}$ & NCT01088815 (Completed) \\
\hline & Phase II [160] & Multiple BCC $(n=229)$ & $\begin{array}{c}\text { Group A: vismodegib } 150 \mathrm{mg} \text { daily } \\
\times 12 \text { weeks, then placebo } \times 8 \\
\text { weeks, followed by vismodegib } 150 \\
\text { mg daily } \times 12 \text { weeks; } \\
\text { Group B: vismodegib } 150 \mathrm{mg} \text { daily } \\
\times 24 \text { weeks, then placebo } \times 8 \\
\text { weeks, followed by vismodegib } 150 \\
\text { mg daily } \times 8 \text { weeks }\end{array}$ & ORR 62.7\% (Group A) and 54.0\% (Group B) & NCT01815840 (Completed) \\
\hline & Phase II [161] & laBCC $(n=55)$ & Vismodegib $150 \mathrm{mg}$ once daily & CR $61.4 \%$ & NCT02667574 (Ongoing) \\
\hline & Phase I [162] & laBCC $(n=71)$ and $\operatorname{mBCC}(n=33)$ & $\begin{array}{l}\text { Vismodegib } 150 \mathrm{mg} \text { once daily until } \\
\text { disease progression, intolerable } \\
\text { toxicity, or study withdrawal }\end{array}$ & $\begin{array}{l}\text { ORR } 60.3 \% \text { (laBCC) and } 48.5 \%(\mathrm{mBCC}) \\
\text { median OS } 33.4 \text { months (mBCC), not } \\
\text { estimable in laBCC cohort }\end{array}$ & NCT00833417 (Completed) \\
\hline & Phase II [163] & $\begin{array}{l}\text { Infiltrative, Nodular, and Superficial } \\
\text { BCC }(n=27)\end{array}$ & Vismodegib 150 mg daily & CR $20 \%$, PR $41.5 \%$, and SD $36.9 \%$ & NCT01700049 (Completed) \\
\hline & \multirow{4}{*}{ Phase II [164-167] } & $\begin{array}{l}\text { Italian cohort: laBCC }(\mathrm{n}=159) \text { and } \\
\operatorname{mBCC}(n=23)\end{array}$ & \multirow{4}{*}{$\begin{array}{l}\text { Vismodegib } 150 \mathrm{mg} \text { daily until } \\
\text { progressive disease, unacceptable } \\
\text { toxicity, or withdrawal }\end{array}$} & ORR $61.7 \%(\mathrm{laBCC})$ and $20 \%(\mathrm{mBCC})$ & \multirow{4}{*}{ NCT01367665 (Completed) } \\
\hline & & Ocular or Periocular laBCC $(n=244)$ & & CR $28.7 \%$ and PR $38.5 \%$ & \\
\hline & & $\mathrm{laBCC}$ and $\mathrm{mBCC}(n=1232)$ & & $\begin{array}{c}\text { ORR } 68.5 \%(\mathrm{laBCC}) \text { and } 36.9 \%(\mathrm{mBCC}) ; \mathrm{SD} \\
25.1 \%(\mathrm{laBCC}) \text { and } 46.4 \%(\mathrm{mBCC})\end{array}$ & \\
\hline & & laBCC and $\mathrm{mBCC}(n=1227)$ & & ORR $64.9 \%$ & \\
\hline
\end{tabular}


Table 2. Cont.

\begin{tabular}{|c|c|c|c|c|c|}
\hline Hh Inhibitor & Clinical Trial Phase & $\begin{array}{c}\text { Cancer Type } \\
\text { (Patients Enrolled) }\end{array}$ & Treatment Interventions & Efficacy & $\begin{array}{l}\text { Clinical Trial Number } \\
\text { (Recruitment Status) }\end{array}$ \\
\hline \multirow{12}{*}{$\begin{array}{l}\text { Sonidegib/ } \\
\text { Erismodegib }\end{array}$} & Phase I [168] & $\begin{array}{l}\text { Untreated AML }(n=15), \text { rel } / \text { ref AML } \\
(n=23), \operatorname{MDS}(n=18), \text { CMML }(n=4), \\
\text { and MF }(n=2)\end{array}$ & $\begin{array}{l}\text { Sonidegib } 200-400 \mathrm{mg} \text { daily with } \\
\text { azacitidine } 75 \mathrm{mg} / \mathrm{m}^{2}\end{array}$ & $\begin{array}{l}\text { AML: ORR } 23.1 \% \text {; rel } / \text { ref AML: ORR } 7.1 \% \text {, } \\
\text { SD } 76 \% \text {, and OS } 7.6 \text { months }\end{array}$ & NCT02129101 (Completed) \\
\hline & Phase II [169] & Multiple myeloma $(n=28)$ & $\begin{array}{l}\text { Sonidegib } 400 \mathrm{mg} \text { daily with } \\
\text { Lenalidomide } 10 \mathrm{mg} \text { daily }\end{array}$ & CR 46\%, VGPR 85\%, and 24 month PFS 73\% & NCT02086552 (Ongoing) \\
\hline & Phase Ib/II [170] & $\begin{array}{l}\text { MF without prior therapy with JAKi ( } n \\
\qquad=50)\end{array}$ & $\begin{array}{l}\text { Sonidegib } 400 \mathrm{mg} \text { daily with ruxolitinib } \\
20 \mathrm{mg} \text { twice daily }\end{array}$ & $\begin{array}{l}29.6 \% \text { patients achieved }>35 \% \text { reduction in } \\
\text { spleen volume; } 26 \% \text { patients achieved } 50 \% \\
\text { reduction in MFSAF and TSS; minimal } \\
\text { change in GLI1 expression }\end{array}$ & NCT01787552 (Completed) \\
\hline & Phase II [171] & $\begin{array}{l}\text { Hypomethylating agent failure: MDS ( } n \\
=26), \text { CMML }(n=5) \text {, and AML }(n=4)\end{array}$ & Oral glasdegib 100 mg daily & $\begin{array}{l}\text { ORR 6\%, SD 56\%, median OS } 10.4 \text { months, } \\
\text { and EFS } 6.4 \text { months }\end{array}$ & NCT01842646 (Completed) \\
\hline & Phase I [172] & $\begin{array}{c}\operatorname{AML}(n=7), \operatorname{MDS}(n=4), \operatorname{CMML}(n= \\
1), \text { and } \operatorname{MF}(n=1)\end{array}$ & Glasdegib 25/50/100 mg once daily & $\begin{array}{c}\text { >80\% suppression of GLI1 expression; } \\
\text { AML: CR } 8 \% \text { and SD 31\%; MDS: CR } 8 \% \text { and } \\
\text { SD } 16 \%\end{array}$ & NCT02038777 (Ongoing) \\
\hline & Phase Ib [173] & CML-CP $(n=11)$ & $\begin{array}{l}\text { Erismodegib } 200 \mathrm{mg} \text { once daily with } \\
\text { nilotinib } 400 \mathrm{mg} \text { twice daily }\end{array}$ & $\begin{array}{l}\text { No clear clinical benefits were observed in } \\
\text { terms of MMR and CCyR }\end{array}$ & NCT01456676 (Completed) \\
\hline & I/II [174] & $\mathrm{MB}(n=55)$ and others $(n=21)$ & $\begin{array}{l}\text { Sonidegib } 800 \mathrm{mg} \text { (adult) or } 680 \mathrm{mg} / \mathrm{m}^{2} \\
\text { (pediatric) once daily }\end{array}$ & $\begin{array}{l}\text { ORR } 6.58 \% \text { ( } 50 \% \text { responses were in } \\
\text { Hh-positive MB patients); SD ( } n=11 ; 27.7 \% \\
\text { responses were in Hh-positive MB patients) }\end{array}$ & NCT01125800 (Completed) \\
\hline & Phase II [175] & $\begin{array}{c}\text { mBCC }(n=36) \text {, laBCC: aggressive }(n= \\
112) \text { and nonaggressive }(n=82)\end{array}$ & Sonidegib 200 or $800 \mathrm{mg}$ once daily & ORR $51.1 \%(\mathrm{laBCC})$ and $12.6 \%(\mathrm{mBCC})$ & NCT01327053 (Completed) \\
\hline & Phase II [176] & $\operatorname{NBCCS}(n=10)$ & Sonidegib $400 \mathrm{mg}$ or placebo & $\begin{array}{l}\text { Total BCC reduced by } 40 \% \text { and } 45 \% \text { at } \\
\text { weeks } 12 \text { and } 16 \text {, respectively, vs. zero } \\
\text { reduction for placebo }\end{array}$ & NCT01350115 (Completed) \\
\hline & Phase Ib [177] & $\begin{array}{c}\text { Metastatic pancreatic cancer: } \\
\text { Chemo-naïve }(n=17) \text { and prior-chemo } \\
(n=9)\end{array}$ & $\begin{array}{l}\text { Escalated dose of sonidegib ( } 800 \mathrm{mg} \\
\text { and } 200 \mathrm{mg} \text { for chemo-naive and } \\
\text { prior-chemo group, respectively) with } \\
\text { gemcitabine } 1000 \mathrm{mg} / \mathrm{m}^{2} \text { and } \\
\text { nab-paclitaxel } 125 \mathrm{mg} / \mathrm{m}^{2}\end{array}$ & SD $8 \%, 35 \%$ PR, and $4 \%$ CR. & \multirow[t]{2}{*}{ NCT02358161 (Completed) } \\
\hline & Phase I/II [178] & Metastatic pancreatic cancer $(n=25)$ & $\begin{array}{l}\text { Sonidegib } 200 \mathrm{mg} \text { once daily with } \\
\text { gemcitabine } 1000 \mathrm{mg} / \mathrm{m}^{2} \text { and } \\
\text { nab-paclitaxel } 125 \mathrm{mg} / \mathrm{m}^{2}\end{array}$ & PR $10 \%$, SD 53\%, and OS 6 months & \\
\hline & Phase Ib [179] & $\begin{array}{l}\text { Triple-negative advanced breast cancer } \\
\qquad(n=12)\end{array}$ & $\begin{array}{l}\text { Sonidegib } 400 / 600 / 800 \mathrm{mg} \text { with } \\
\text { docetaxel } 75 \mathrm{mg} / \mathrm{m}^{2}\end{array}$ & ORR $30 \%$ & NCT02027376 (Completed) \\
\hline
\end{tabular}


Table 2. Cont.

\begin{tabular}{|c|c|c|c|c|c|}
\hline Hh Inhibitor & Clinical Trial Phase & $\begin{array}{c}\text { Cancer Type } \\
\text { (Patients Enrolled) }\end{array}$ & Treatment Interventions & Efficacy & $\begin{array}{l}\text { Clinical Trial Number } \\
\text { (Recruitment Status) }\end{array}$ \\
\hline $\begin{array}{l}\text { Sonidegib/ } \\
\text { Erismodegib }\end{array}$ & Phase I [180] & $\begin{array}{l}\text { High-risk localized prostate cancer } \\
\qquad(n=14)\end{array}$ & $\begin{array}{c}\text { Sonidegib } 800 \mathrm{mg} \text { once daily or no } \\
\text { treatment } \times 4 \text { weeks before } \\
\text { prostatectomy }\end{array}$ & $\begin{array}{l}\text { 86\% in the Sonidegib arm achieved at least } \\
\text { two-fold GLI1 suppression; no significant } \\
\text { difference in DFS between sonidegib and } \\
\text { observation arms }\end{array}$ & NCT02111187 (Completed) \\
\hline \multirow{4}{*}{ Glasdegib } & Phase Ib/II [181] & $\begin{array}{l}\text { Primary or secondary MF treated } \\
\text { previously with ruxolitinib }(n=21)\end{array}$ & Glasdegib or placebo $100 \mathrm{mg}$ once daily & $\begin{array}{c}9.5 \% \text { and } 40 \% \text { patients had } 50 \% \text { and more } \\
\text { than } 20 \% \text { reduced in TSS at week } 12, \\
\text { respectively; SVR } 4.8 \%\end{array}$ & NCT02226172 (Terminated) \\
\hline & \multirow[t]{2}{*}{ Phase II $[183,184]$} & $\begin{array}{c}\text { AML ineligible for intensive } \\
\text { chemotherapy: de novo }(n=56) \text { and } \\
\text { secondary }(n=60)\end{array}$ & \multirow{2}{*}{$\begin{array}{l}\text { Glasdegib } 100 \mathrm{mg} \text { daily with LDAC } 20 \\
\text { mg twice daily or LDAC } 20 \mathrm{mg} \text { alone }\end{array}$} & $\begin{array}{l}\text { Median OS: de novo (6.6 vs. } 4.3 \text { months) } \\
\text { and secondary ( } 9.1 \text { vs. } 4.1 \text { months) }\end{array}$ & \multirow[t]{3}{*}{ NCT01546038 (Completed) } \\
\hline & & $\begin{array}{l}\text { AML ineligible for intensive } \\
\text { chemotherapy }(n=116)\end{array}$ & & Median OS 8.3 vs. 4.3 months & \\
\hline & Phase II [185] & $\operatorname{AML}(n=66)$ and $\operatorname{MDS}(n=5)$ & $\begin{array}{l}\text { Glasdegib } 100 \mathrm{mg} \text { once daily with } \\
\text { cytarabine } 100 \mathrm{mg} / \mathrm{m}^{2} \text { and } \\
\text { daunorubicin } 60 \mathrm{mg} / \mathrm{m}^{2}\end{array}$ & $\begin{array}{c}\text { CR } 46.4 \% \text { ( } \geq 55 \text { years old } 40 \% \mathrm{CR} \text { ), median } \\
\text { OS } 14.9 \text { months }\end{array}$ & \\
\hline \multirow[b]{2}{*}{ Saridegib/Patadegib } & Phase $\mathrm{Ib}[186]$ & Metastatic pancreatic cancer $(n=16)$ & $\begin{array}{l}\text { Saridegib }(110,130 \text {, or } 160 \mathrm{mg}) \text { once } \\
\text { daily with gemcitabine } 1000 \mathrm{mg} / \mathrm{m} 2\end{array}$ & $\begin{array}{c}\text { Radiological PR } 31 \% \text { and median PFS > } \\
\text { month }\end{array}$ & NCT01130142 (Completed) \\
\hline & Phase II [187] & Gorlin syndrome BCC $(n=17)$ & Vehicle or $2 / 4 \%$ patidegib twice daily & $\begin{array}{l}\text { ORR 25\% (patidegib) vs. } 0 \% \text { (vehicle); } \\
\text { shrinkage of SEBs was observed only in } \\
\text { patients with successful reduction in Hh } \\
\text { pathway activity. }\end{array}$ & NCT02762084 (Completed) \\
\hline \multirow{3}{*}{ Taladegib } & Phase I [188] & Advanced solid tumors $(n=19)$ & Taladegib 100/200/300 mg once daily & $\begin{array}{l}\text { All dose levels significantly inhibit GLI1 } \\
\text { transcript levels; PR 5.3\% and SD 21.1\% }\end{array}$ & NCT01919398 (Completed) \\
\hline & Phase I/Ib [189] & Advanced solid tumors $(n=16)$ & $\begin{array}{l}\text { Taladegib 50/100 mg once or } 400 \mathrm{mg} \\
\text { twice daily with paclitaxel } 80 \mathrm{mg} / \mathrm{m}^{2}\end{array}$ & $\mathrm{PR}(n=3)$ & ISRCTN15903698 (NS) \\
\hline & Phase I [190] & $\begin{array}{l}\text { Treatment-naïve and previously treated } \\
\qquad \text { BCC }(n=84)\end{array}$ & Taladegib $400 \mathrm{mg}$ once daily & $\begin{array}{c}\text { Unaffected skin biopsies GLI1 expression } \\
\text { showed an inhibition median of } 92.3 \% ; \\
\text { ORR } 46.8 \%\end{array}$ & NCT01226485 (Completed) \\
\hline
\end{tabular}


Table 2. Cont.

\begin{tabular}{|c|c|c|c|c|c|}
\hline Hh Inhibitor & Clinical Trial Phase & $\begin{array}{c}\text { Cancer Type } \\
\text { (Patients Enrolled) }\end{array}$ & Treatment Interventions & Efficacy & $\begin{array}{l}\text { Clinical Trial Number } \\
\text { (Recruitment Status) }\end{array}$ \\
\hline \multirow{3}{*}{ Itraconazole } & Phase II [191] & $\begin{array}{l}\text { stomach cancer and gastroesophageal } \\
\text { junction cancer }(n=23)\end{array}$ & $\begin{array}{c}160 \mathrm{mg} / \mathrm{m}^{2} \text { nab-paclitaxel and } 100 \\
\mathrm{mg} / \mathrm{m}^{2} \text { oxaliplatin } \times 1 \text { day, } \mathrm{S}-160 \\
\mathrm{mg} / \mathrm{m}^{2} \times 3 \text { days, and itraconazole } \\
400 \mathrm{mg} \times \text { days } 3 \text { days }\end{array}$ & $\begin{array}{c}\text { ORR } 70 \% \text {, median OS } 24 \text { months, and } \\
\text { 1-year OS rate } 95 \% \text {, }\end{array}$ & UMIN000021340 (Preinitiation) \\
\hline & Phase II [192] & $\begin{array}{l}\text { Biochemically recurrent prostate cancer } \\
\qquad(n=21)\end{array}$ & $\begin{array}{c}\text { Oral itraconazole } 300 \mathrm{mg} \text { twice } \\
\text { daily }\end{array}$ & $\begin{array}{l}>50 \% \text { PSA decline } 5 \% \text {; any PSA decline } \\
47 \% \text {; among } 10 \text { patients without a PSA } \\
\text { decline, no significant difference between } \\
\text { on-treatment and pretreatment PSADT }\end{array}$ & NCT01787331 (Completed) \\
\hline & Phase I/II [193] & $\begin{array}{l}\text { Platinum-resistant ovarian cancer }(n= \\
11)\end{array}$ & $\begin{array}{l}\text { Itraconazole } 300 \mathrm{mg} \text { twice daily } \\
\text { with hydroxychloroquine (dose } \\
\text { escalation } 200-600 \mathrm{mg} \text { twice daily) }\end{array}$ & $\begin{array}{c}\text { ORR none, SD }(n=1) \text {, and median PFS } \\
1.6 \text { months }\end{array}$ & NCT03081702 (Completed) \\
\hline Arsenic trioxide & Phase II [153] & Refractory $\mathrm{mBCC}(n=5)$ & $\begin{array}{c}\text { Arsenic trioxide } 0.3 \mathrm{mg} / \mathrm{kg} \times 5 \\
\text { days followed by itraconazole } 400 \\
\mathrm{mg} \times 23 \text { days }\end{array}$ & SD 60\%; 75\% reduction in GLI1 expression & NCT01791894 (Completed) \\
\hline
\end{tabular}

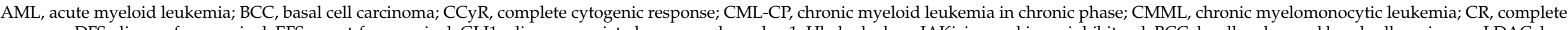

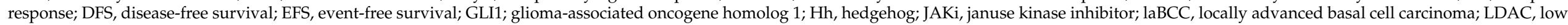

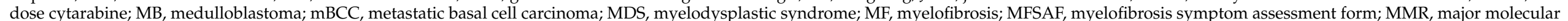

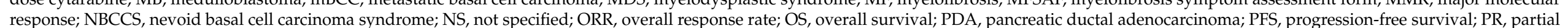

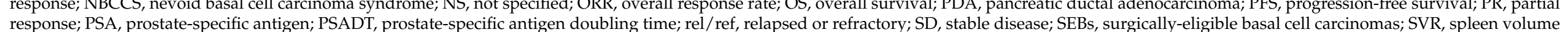
response; reduction; TSS, total symptom score; and VGPR, very good partial response.
restigen 
To date, BCC remains the most clinically relevant cancer associated with the Hh pathway. BCC is rarely fatal but, in some cases, may develop into an advanced or invasive type of BCC when left untreated. There are two categories of advanced BCC: locally advanced BCC (laBCC) and metastatic BCC (mBCC). In clinical trials, laBCC tumors are characterized by at least one histologically confirmed lesion $\geq 10 \mathrm{~mm}$ that is either inoperable or has recurred following surgery or radiotherapy, while mBCC tumors are characterized by histologically confirmed BCC that has metastasized to distant organs, such as the lung, liver, lymph nodes, or bones (NCT01367665) [163,165-167].

As most BCC exhibit mutation in the PTCH1 gene that results in SMO hyperactivation [130], they are largely amenable to treatment with SMO inhibitors. Vismodegib has been FDA approved for the treatment of laBCC and mBCC in 2012. The FDA approval was based on favorable results from a phase II clinical trial study in which vismodegib exposure led to a 30\% ORR in mBCC and 43\% ORR, including $21 \%$ complete response (CR) in laBCC [194]; the long-term follow-up reported a better ORR of $48.5 \%$ in $\mathrm{mBCC}$ and $60.3 \%$ in laBCC [162]. Not long after, sonidegib was FDA approved in 2015 for the treatment of laBCC after displaying ORR comparable to vismodegib in a phase II clinical trial [195]. Moreover, the utility of SMO inhibitors, including sonidegib and vismodegib, has proven to be clinically beneficial for the treatment of nonadvanced BCCs in NBCCS patients [176] and for the long-term intermittent treatment of multiple nonadvanced BCCs, including those with NBCCS [160], which warrants further study. In a phase II clinical trial study, topical patidegib consisting of the IPI-926/saridegib SMO inhibitor has recently shown promise in mitigating facial BCCs in Gorlin/NBCCS patients without causing systemic adverse effects commonly seen in oral Hh inhibitors [187]. A phase III confirmatory clinical trial study following this has just been recently completed in 2021, but no results have been posted so far (NCT03703310).

Like BCCs, most Shh-medulloblastomas are characterized by mutations in the PTCH1 gene, and to a smaller extent, in SUFU and SMO genes [196]. Likewise, Shh-medulloblastomas are also amenable to SMO inhibitor treatment; in particular, sonidegib has shown superior antitumor efficacy (ORR: 55\%) compared to vismodegib (ORR: 17\%) in a systemic review and meta-analysis of phase I and phase II clinical trials of pediatric and adult medulloblastoma patients treated with sonidegib and vismodegib [197]. Currently, a phase I clinical trial evaluating the safety and tolerability of sonidegib in combination with ribociclib (NCT03434262) and a phase II clinical trial evaluating the feasibility and tolerability of vismodegib as maintenance therapy after conventional adjuvant chemotherapy (NCT01878617) are ongoing.

For other cancer types where mutations in Hh pathway genes are mostly absent, the utility of SMO inhibitors as monotherapy is less profound. Notably, glasdegib, in combination with low-dose cytarabine (LDAC), has been FDA approved to treat newly diagnosed AML patients who are 75 years old or older or have comorbidities that preclude the use of intensive induction chemotherapy. Approval was based on a multicenter, openlabel, phase II study, which showed almost two-fold improvement in overall survival (OS) for the glasdegib + LDAC compared to LDAC alone arm [183,184]. A phase III clinical trial study is currently ongoing for the testing of saridegib in combination with intensive (glasdegib plus cytarabine and daunorubicin) or nonintensive (glasdegib plus azacitidine) chemotherapy (BRIGHT AML 1019; NCT03416179). Other hematological malignancies, such as hypomethylating agent (HMA) failure myelodysplastic syndrome (MDS) and HMA-relapsed AML, have also shown stable disease (SD) that was significantly correlated to improved OS when treated with SMO inhibitors, suggesting that SMO inhibition may add to HMA efficacy [168,171]. Additionally, lenalidomide in combination with LDE225 as post-transplant maintenance therapy in multiple myeloma patients who underwent single autologous stem cell transplant was associated with improved response depth [169].

Besides hematological-related malignancies, solid tumors such as pancreatic, gastric, breast cancer, and lung cancer may benefit from treatment with specific SMO inhibitors. In advanced pancreatic cancer, adding saridegib/IPI-926 to FOLFIRINOX (5-fluorouracil, 
leucovorin, irinotecan, and oxaliplatin) resulted in favorable ORR (67\%), improved disease stabilization, and a decline in CA19-9 tumor marker [198]. Similarly, treatment of metastatic pancreatic cancer with combined saridegib and gemcitabine showed $31 \%$ radiological partial response (PR) [186]. However, the addition of a different SMO inhibitor, vismodegib, to gemcitabine and nab-paclitaxel did not improve efficacy compared to gemcitabine alone in patients with metastatic pancreatic cancer [159].

The addition of vismodegib to FOLFOX neither improved progression-free survival (PFS), response rate (RR), nor OS in advanced gastric and gastroesophageal junction carcinoma [199]; however, a subset of gastric and gastroesophageal junction cancer patients with high CD44 median score experienced CR, better OS, and reduced disease progression [200]. By contrast, treatment of advanced and recurrent gastric cancer with combined itraconazole, S-1, oxaliplatin, and nab-paclitaxel showed a high tumor RR (70\%) and durable 1-year OS rate (81.8\%) [191].

The addition of sonidegib to docetaxel also showed antitumor activity at the recommended phase II dose (RP2D) in 3 out of 10 triple-negative breast cancer patients with measurable disease, including one CR and two long-lasting stabilization [179]. Eleven out of fourteen patients diagnosed with extensive-stage small-cell lung cancer (SCLC) develop PR when treated with sonidegib in combination with etoposide/cisplatin [201], which was higher than historical rates observed with etoposide/cisplatin alone [202,203] in extensive SCLC patients. Overall, these results should be interpreted with caution as these clinical studies are limited by small numbers and lack a placebo arm or correlative molecular analyses to assess the relationship between response and expression of Hh pathway targets. Further studies are warranted to properly denote the therapeutic significance of targeting Hh-GLI signaling in treating these cancers.

GLI proteins, especially GLI1, have demonstrated prognostic values for predicting survival among diverse cancer types, including breast cancer [204-208], liver cancer [208,209], pancreatic cancer [208,210], ovarian cancer [208,211-213], glioma [214], prostate cancer [215], colon/colorectal cancer [81,216,217] gastric cancer [218-220], AML [208], and medulloblastoma [221]. By contrast, despite the widespread use of SMO inhibitors, the value of SMO as a prognostic biomarker is less profound and has only been reported in a handful of cancer types, including bladder cancer [222], glioma [223,224], liver cancer [68], and head-and-neck cancer [209]. However, SMO mutants have shown to be significantly associated with shorter survival in malignant pleural mesothelioma [225] and olfactory groove meningioma [226] patients, suggesting that SMO mutational features defining a molecular subgroup in cancers are better indicators of poor prognosis than wild-type SMO. As GLI1 is most amenable to activation by both SMO-dependent and SMO-independent axes among the Hh pathway components, it is unsurprising that its expression is more commonly associated with poor prognosis in Hh-active cancer patients.

Although GLI1 expression has been frequently associated with poor prognosis in many known cancers, SMO inhibitors are ineffective in treating various cancers despite showing antitumor activity in preclinical studies. Indeed, most preclinical studies utilized in vitro cell lines that do not fully represent in vivo tumor biology and physiology occurring in humans. Although patient-derived xenograft models may provide more physiologically relevant results, they lack the complex interplay between tumor cells and the tumor microenvironment components, including CAFs, immune cells, soluble growth factors, extracellular matrix, and the vasculature system [227]. In actuality, a tumor bulk includes a heterogeneous pool of cells that harbor distinct molecular signatures with differential levels of treatment sensitivity.

With regards to the above, the bulk of the tumor might include a distinct group of cells that utilizes either an SMO-dependent or SMO-independent route of GLI activation, or both-with the SMO-independent one likely being the preferential route supported by the fact that mutations in Hh components upstream of GLI are largely absent in most cancer types [228]. Furthermore, the major oncogenic signaling pathways frequently activated in cancers are proven to regulate GLI transcription and activity independent 
of SMO (see Sections 3.2.1 and 3.2.2), potentially explaining why SMO inhibitors may be ineffective in producing meaningful tumor responses in most solid tumors despite the expression of GLI proteins in these tumors. In further support of this, a large-scale pancancer analysis revealed that GLI1 and GLI2 shared broad prognostic association with TGFB ligand and mesenchymal genes but not with Hh genes, potentially explaining the frequent failure of SMO inhibitors in most solid tumors [142]. Thus, targeting GLI may be a better therapeutic option in circumstances where GLI-expressing tumors do not respond well to SMO inhibitors.

Consistent with its role as a prognostic marker, GLI1 expression is commonly used as a pharmacodynamic marker in clinical studies. Additionally, GLI1 serves as an excellent biomarker for tumor response in BCC and Hh-active medulloblastoma [187,229,230]. However, decreased GLI1 levels do not always correlate with tumor response. Several clinical studies showed that the downregulation of intratumoral GLI1 levels did not correlate with tumor response in pancreatic and prostate cancer patients treated with SMO inhibitors $[157,158,180]$. In HM failure MDS patients treated with glasdegib as monotherapy, improved disease stabilization and survival did not correlate with Hh pathway expression but did halt further increase in GLI1 mRNA and its downstream targets, including MYC and CCND1 [171]. In such circumstances, correlative analyses of potential biomarkers with tumor responses may help identify a subset of patients who may derive benefit from SMO inhibitors.

However, Hh pathway components, particularly GLI1, are ideal predictive biomarkers for SMO inhibitor therapy in several cancers, including BCC and Shh-medulloblastomas. For instance, patients with BCC that responded well to sonidegib and vismodegib had upregulated GLI1 transcripts [194,230]. In patients with Hh-positive medulloblastomas, five out of ten patients showed an objective response (OR), including four CRs and one PR, associated with elevated GLI1 signature [174]. Patients with stable disease of 6 months or longer had grade 1 or 2 conventional chondrosarcomas, all of which showed overexpression of the Hh ligand [231]. An improved clinical response, including one CR, was also observed in three out of ten evaluable triple-negative advanced breast cancer patients with high paracrine Hh Pathway Activation Signature (HPAS), characterized by high tumor epithelial Hh and stromal GLI1 expression [179]. Thus, stratification of patients based on Hh biomarkers, particularly GLI1, may help identify a specific subset of patients that may benefit from $\mathrm{Hh}$ inhibitors.

\section{Current Challenges and Future Perspective for Using SMO/GLI Inhibitors in Clinical Settings}

SMO inhibitors have shown promising efficacy in treating Hh-active cancers, particularly BCC and Shh-medulloblastoma. Despite this, SMO mutations frequently emerged among these cancers, contributing to the development of acquired resistance against SMO inhibitors. The majority of acquired resistance is caused by mutations in the drug-binding pocket of SMO, impeding the binding of SMO inhibitors $[63,64,67]$. In light of this discovery, efforts are being made to develop nonredundant SMO inhibitors, such as TAK441 [232], taladegib [233], and LEQ-506 [234]. These investigational SMO inhibitors have been shown to inhibit SMO D473H mutant conferring resistance to vismodegib/sonidegib in preclinical studies [235]. Importantly, taladegib treatment has shown significant antitumor activity in Hh treatment-naïve and previously Hh-treated BCC patients of a phase I study [190], warranting further study on its utility as second-line therapy for treating SMO inhibitorresistant cancers in clinical settings. The screening of benzimidazole derivatives led to the identification of novel SMO inhibitors, $\mathrm{HH}-13$ and $\mathrm{HH}-20$, with potent inhibitory activity on SMO D473H mutant conferring resistance to vismodegib [236]. Another novel SMO inhibitor, MRT-92, was shown to bind effectively to the entire transmembrane cavity of the SMO D473H mutant, which allows for the inhibition of the SMO mutant [237]. With regards to what is above, further study and characterization of these SMO inhibitors are still required to determine their suitability for proof-of-concept in vivo testing before they can be further tested in clinical settings. 
Besides nonredundant SMO inhibitors, targeting GLI may serve as a feasible approach to overcoming SMO resistance. The FDA-approved antipinworm agent, pyrvinium, has been shown to inhibit the activity of SMO-D473H mutant and GLI activity resulting from the loss of SUFU [238]. Targeting the GLI protein function with arsenic trioxide or PSI was shown to circumvent the issue concerning SMO resistance in MEF cells, underscoring the use of GLI inhibitors as a second line of therapy [64]. Indeed, in a phase II clinical trial, the sequential treatment of metastatic BCC patients experiencing relapse after SMO inhibitor treatment with arsenic trioxide and itraconazole effectively suppressed 75\% GLI1 mRNA expression and produced SD in three out of five patients; however, the lack of tumor shrinkage may be due to suboptimal dosing or transient GLI1 suppression [153]. Moreover, targeting GLI can also serve as a promising therapeutic approach for treating cancers with intrinsic resistance to SMO inhibitors due to SUFU mutations or GLI2 amplification. Furthermore, oncogenic mutations in GLI genes have rarely been reported in cancers [239], making them a more predictable target for inhibition, but whether long-term usage of GLI inhibitors may lead to clinically acquired resistance remains a question.

Many solid tumors that have shown promise for the targeting of SMO in preclinical studies fail to translate successfully into clinical settings. Furthermore, the inferior prognostic and predictive value of SMO compared to GLI (see Section 4), the absence of SMO mutations despite the high expression of GLI [228], and the frequent report of a noncanonical arm of GLI activation in most cancers (see Sections 3.2.1 and 3.2.2) strongly suggest an SMO-independent route as the major mechanism of GLI regulation in the majority of tumors. Indeed, various preclinical reports have shown a lack of GLI suppression and antitumor efficacy following treatment with SMO inhibitors that can be circumvented with GLI inhibitors (see Section 3.2.1 and Section 3.2.2). Furthermore, GLI inhibitors have shown superior pharmacological properties compared to SMO inhibitors [15,16].

Although preclinical results are convincing, most GLI inhibitors have yet to be assessed in the clinical setting due to their nonstable pharmacokinetics/bioavailabilities. For instance, GANT61 is rapidly hydrolyzed into an inactive benzaldehyde species due to its lack of stability at physiological $\mathrm{pH}$ [240]. Ongoing efforts are being made to develop more effective and stable GLI inhibitors for their use in clinical settings. Recently, a novel GLI inhibitor, SRI-38832, has shown not only an improved efficacy but also an enhanced bioavailability in a murine xenograft model, representing the first step toward the development of a clinically viable GLI inhibitor [241]. The improved efficacy and stable pharmacokinetic/bioavailability profiles of SRI-38832 make it a novel scaffold for hit-tolead optimization, which, if successful, sets a new stage for treating Hh-dependent cancers in future clinical settings. Other potential GLI inhibitors include small chemical molecules, HPI-1 [242,243], HPI-2, HPI-3, and HPI-4 [242], and natural compounds, cynanbungeigenin C (CBC) and D (CBD) [244], physalin B [245], and glabrescione B [246]. An indirect approach of inhibiting GLI function by targeting GLI modulators has also been reported with bromodomain-4 (BRD4), CK2, aPKC, dual-specificity tyrosine phosphorylation-regulated kinase 1B (DYRK1B), and HDACs inhibitors [244,247].

Of note, the lack of efficacy with SMO inhibitors in treating solid tumors does not necessarily preclude its clinical significance in these tumors. When used in combination with chemotherapeutics, SMO inhibitors have shown antitumor activity in a specific subset of populations expressing CSC markers. For instance, in a small subset of patients with gastric cancer expressing high median CD44 scores, the addition of vismodegib to FOLFOX led to a better therapeutic response, including CR, better OS, and reduced disease progression. Furthermore, high CD44 expression was associated with decreased survival in the chemotherapy alone group. The authors' preclinical work revealed that the CD44-expressing subpopulation of gastric cancer cells exhibited enhanced chemotherapeutic resistance, which can be reversed in vitro and in xenografts with SMO shRNA or vismodegib treatment [199].

Triple-negative breast cancer patients with elevated phospho-FGFR expression, collagen deposition, and fiber linearization experienced CR or disease stabilization when 
treated with combined sonidegib and docetaxel. On the other hand, nonresponders exhibited weak phospho-FGFR expression, low collagen deposition, and minimal evidence of mechano-signaling and breast CSCs despite having high paracrine HPAS. The authors demonstrated that $\mathrm{Hh}$ ligand secreted from murine triple-negative breast cancer cells promoted the reprogramming of CAFs, which led to the extensive reshaping of ECM that fostered the development of supportive CSC niches through enhancing mechano-signaling and phosphor-FGFR activation in the tumor epithelium [58].

A patient with extensive SCLC showing high tumor-specific amplification of SOX2 and PIK3CA, both on chromosome $3 \mathrm{q} 26.3$, had the longest progression-free response for up to 27 months with maintenance sonidegib after several cycles of combined treatment with etoposide/cisplatin and sonidegib [200]. Notably, coamplification of SOX2 and PIK3CA on chromosome 3q26 has been shown to cooperatively drive stem-like phenotype in tumorderived lung squamous cell carcinoma cells by activating cell-autonomous Hh signaling axis, while treatment of these cells but not their parental counterpart with sonidegib significantly inhibited oncosphere proliferation [248]. These results support the feasibility of combining chemotherapeutics and SMO inhibitors for treating tumors, based on the notion that chemotherapeutics perform the killing of most fast-growing cancer cells, while SMO inhibitors target residual CSCs with active Hh signaling to halt tumor self-renewal and repopulation. Thus, the stratification of patients based on predictive biomarkers, such as Hh and possibly stem cell factors, may assist the identification of patients eligible for Hh-based therapies.

Despite the success of oral SMO inhibitors, their clinical use is restricted due to adverse effects frequently associated with these drugs. Adverse effects accompanied by vismodegib treatment frequently led to the discontinuation of treatment in patients with $B C C$, following which tumor recur [249]. In the open-label STEVIE trial, adverse effects were reported in $36 \%$ of advanced BCC patients treated with vismodegib, of which $22 \%$ were serious adverse effects [164]. The combined use of IPI-926 and FOLFIRINOX produced a high ORR rate of $67 \%$ in advanced PDAC patients, but detrimental effects induced by this combination in a phase II trial led to the unfortunate early termination of the study [197]. The development of a new topical Hh inhibitor, patidegib, has led to significant shrinkage of surgically eligible BCC lesions without any of the adverse effects usually seen in oral Hh inhibitors [187]; a phase III clinical trial has been conducted to confirm these findings. However, such inhibitors are only applicable to superficial cancer and do not circumvent the in vivo toxicity posed by most oral Hh inhibitors when treating nonsuperficial or invasive cancers.

Ongoing efforts are still being made to discover novel potent SMO inhibitors, such as MRT-83, MRT-92, CAT3, MK-4101, Smoothib, L-4, Nilotinib [244], and naturally derived compounds [245]. Importantly, discovering new hit compounds can provide a platform for the innovative design of new derivatives that are potentially safer yet still effective for treating SMO-dependent cancers in clinical settings. Of importance, the use of GLI inhibitors may produce less-adverse effects compared to SMO inhibitors due to their improved pharmacological properties, but intensive efforts are still needed to develop more pharmacologically stable GLI inhibitors before they can be further tested in clinical trials.

It has been recognized that combination treatment may allow for synergistic interaction that allows the administration of lower doses of the combination constituents, thereby reducing adverse reactions. With that said, simultaneous targeting of SMO and GLI has been shown to provide synergistic inhibitory effects on various cancers, including multiple myeloma [250,251], medulloblastoma [252], and glioblastoma [253]. Additionally, a combination of SMO inhibitors with inhibitors targeting other oncogenic targets, such as PI3K/AKT/mTOR [254-257], EGFR [258], DNA methyltransferases [83], and interleukin 6 [259], resulted in synergistic inhibition of cancer cell growths. Such combinations included the use of SMO or GLI inhibitors with drugs targeting oncogenic drivers of noncanonical GLI activation, which allows for the simultaneous targeting of compensatory noncanonical GLI activation and other Hh-unrelated key cancer targets. 
Recently, glasdegib added to LDAC has demonstrated improved clinical efficacy for treating AML compared to SMO inhibitors given as monotherapy $[156,172,183,184]$; such findings were also demonstrated in preclinical studies [151]. Additionally, vismodegib plus arsenic trioxide, in association with temozolomide, resulted in the marked inhibition of glioblastoma tumor growth in mice, while single-agent therapy yielded minimal efficacy [253]. Cotreatment of HT29 cells with GANT61 and 5-fluorouracil produced a synergistic and marked inhibitory effect compared to treatment with any of the agents alone [241].

Currently, ongoing efforts are being made in clinical trials to investigate the suitability of SMO inhibitors as part of a combination therapy regimen for treating various cancers (see Table 2 and Section 4). Taken together, the current preclinical and clinical data support the potential for synergistic effect when the SMO inhibitor is administered alongside conventional chemotherapeutics or other targeted drugs, representing a plausible approach for reducing adverse reactions while providing optimal clinical responses. Such an approach should be further considered for tumors such as $\mathrm{mBCC}$ and Hh-active medulloblastoma that have shown high tumor response to Hh inhibitors, which may improve the odds of therapeutic success. Furthermore, the constant emergence of SMO inhibitor-resistant tumors in monotherapy treatment points further to the need to investigate the use of SMO inhibitors as part of a combination therapy regimen.

\section{Conclusions}

This review highlighted the diverse biological roles of GLI transcriptional effectors in cancer initiation and progression. GLI proteins can be regulated through SMO-dependent and SMO-independent mechanisms, both of which have been heavily implicated in tumorigenesis. SMO-dependent GLI signaling occurs as a result of dysregulated upstream Hh components caused by mutations (e.g., loss-of-function of PTCH and gain-of-function of $\mathrm{SMO}$ ) or uncontrolled transcriptional regulation (e.g., aberrant transcription factors and epigenetic alterations), resulting in the hyperactivation of SMO by which the excessive signal is translated to GLI. Conversely, SMO-independent GLI signaling involves the noncanonical crosstalk of GLI with other signaling pathways (KRAS/MAPK/ERK, TGF$\beta / \mathrm{SMAD}, \mathrm{TNF} / \mathrm{PI} 3 \mathrm{~K} / \mathrm{AKT} / \mathrm{mTOR}, \mathrm{Wnt} / \beta$-catenin, and NF-kB) and signaling proteins. This method of GLI regulation is commonly implicated in cancers that are resistant to SMO inhibitors (e.g., cyclopamine and vismodegib).

$\mathrm{SMO}$ inhibitors have proven to be effective in treating a wide range of malignancies in clinical settings, especially in cancers such as BCC that are heavily dependent on Hh-GLI signaling. However, resistance to SMO inhibitors often arises due to mutations within the LBPs of SMO, consequently blocking the binding of inhibitors. Moreover, the noncanonical route of GLI activation has been frequently reported in many other solid tumors, such as NSCLC, PDAC, gastric adenocarcinomas, and triple-negative breast cancer, leading to SMO inhibitor resistance. Hence, we propose that targeting GLI transcription factors shows promise as a therapeutic strategy for overcoming SMO-independent cancers' growth. Firstly, oncogenic mutations are less commonly found in GLI proteins as compared to other Hh pathway components, making them a more fitting therapeutic target that is less likely to develop resistance. Secondly, inhibiting GLI protein function has proven to exert superior anticancer effects compared to targeting Hh components upstream of GLI proteins. Thirdly, in many Hh pathway overexpressing cancers, GLI proteins (especially GLI1) are the most consistently upregulated component among the Hh pathway elements and are intimately associated with poor prognosis in cancer patients, making them more practical therapeutic targets in a wide variety of tumors. Lastly, inhibiting the GLI function serves as a promising strategy for blocking both canonical and noncanonical input and may serve as an alternative therapeutic method for treating SMO inhibitor-resistant cancers.

Future efforts should focus on optimizing potential lead Hh-targeting compounds to improve their potency, stability, solubility, pharmacokinetic profiles, specificity, and safety. One such compound, GLI inhibitor SRI-38832, has shown promise as a scaffold for hit-to- 
lead optimization, as shown by its stable pharmacokinetic/bioavailability profiles and good efficacy in the xenograft murine model, representing the first step toward the development of a clinically viable GLI inhibitor. An investigational SMO inhibitor, taladegib, has demonstrated a potent inhibitory effect on SMO D473H mutant and showed promising antitumor efficacy in Hh treatment-naïve and previously Hh-treated BCC patients, showing promise as second-line therapy for SMO-inhibitor resistant cancers. Efforts can be made to identify and validate new predictive biomarkers to help select potentially responsive patients who may benefit from $\mathrm{Hh}$ therapies. Lastly, including $\mathrm{Hh}$ inhibitors as part of a combination therapy regimen may help improve clinical efficacy while minimizing the emergence of acquired resistance and reducing adverse reactions.

\begin{abstract}
Author Contributions: Conceptualization, C.Y.L. and W.F.W.; methodology, J.Y.C., V.S., and M.A.A.; writing-original draft preparation, J.Y.C., V.S., and M.A.A.; writing-review and editing, P.P.C. and A.A.; visualization, J.Y.C. and V.S.; supervision, C.Y.L. and W.F.W.; project administration, C.Y.L., W.F.W., and M.A.A.; funding acquisition, M.A.A., W.F.W., and C.Y.L. All authors have read and agreed to the published version of the manuscript.
\end{abstract}

Funding: This publication paper was funded by Ministry of Higher Education (MOE) under Fundamental Research Grant Project, FRGS grant (FP103-2019A), (Ref: FRGS/1/2019/SKK10/UM/02/3) and (FRGS/1/2020/SKK0/TAYLOR/02/6) as well as University of Malaya grant No. IIRG010C-2019.

Acknowledgments: We would like to thank Natalie Vivien Gunter from Taylor's University for proofreading the manuscript.

Conflicts of Interest: The authors declare no conflict of interest.

\title{
References
}

1. Nüsslein-volhard, C.; Wieschaus, E. Mutations Affecting Segment Number and Polarity in Drosophila. Nature 1980, 287, 795-801. [CrossRef] [PubMed]

2. Carballo, G.B.; Honorato, J.R.; De Lopes, G.P.F.; de Sampaio, E.; Spohr, T.C.L. A Highlight on Sonic Hedgehog Pathway. Cell Commun. Signal. 2018, 16, 11. [CrossRef]

3. Mastronardi, F.G.; Dimitroulakos, J.; Kamel-Reid, S.; Manoukian, A.S. Co-Localization of Patched and Activated Sonic Hedgehog to Lysosomes in Neurons. Neuroreport 2000, 11, 581-585. [CrossRef] [PubMed]

4. Rohatgi, R.; Milenkovic, L.; Corcoran, R.B.; Scott, M.P. Hedgehog Signal Transduction by Smoothened: Pharmacologic Evidence for a 2-Step Activation Process. Proc. Natl. Acad. Sci. USA 2009, 106, 3196-3201. [CrossRef]

5. Hsu, S.H.C.; Zhang, X.; Yu, C.; Li, Z.J.; Wunder, J.S.; Hui, C.C.; Alman, B.A. Kif7 Promotes Hedgehog Signaling in Growth Plate Chondrocytes by Restricting the Inhibitory Function of Sufu. Development 2011, 138, 3791-3801. [CrossRef] [PubMed]

6. Skoda, A.M.; Simovic, D.; Karin, V.; Kardum, V.; Vranic, S.; Serman, L. The Role of the Hedgehog Signaling Pathway in Cancer: A Comprehensive Review. Bosn. J. Basic Med. Sci. 2018, 18, 8-20. [CrossRef]

7. Gonnissen, A.; Isebaert, S.; Haustermans, K. Targeting the Hedgehog Signaling Pathway in Cancer: Beyond Smoothened. Oncotarget 2015, 6, 13899-13913. [CrossRef] [PubMed]

8. Jia, J.; Zhang, L.; Zhang, Q.; Tong, C.; Wang, B.; Hou, F.; Amanai, K.; Jiang, J. Phosphorylation by Double-Time/CKI $\varepsilon$ and CKI $\alpha$ Targets Cubitus Interruptus for Slimb/ $\beta$-TRCP-Mediated Proteolytic Processing. Dev. Cell 2005, 9, 819-830. [CrossRef] [PubMed]

9. Tschaikner, P.; Enzler, F.; Torres-Quesada, O.; Aanstad, P.; Stefan, E. Hedgehog and Gpr161: Regulating CAMP Signaling in the Primary Cilium. Cells 2020, 9, 118. [CrossRef] [PubMed]

10. Niewiadomski, P.; Kong, J.H.; Ahrends, R.; Ma, Y.; Humke, E.W.; Khan, S.; Teruel, M.N.; Novitch, B.G.; Rohatgi, R. Gli Protein Activity Is Controlled by Multisite Phosphorylation in Vertebrate Hedgehog Signaling. Cell Rep. 2014, 6, 168-181. [CrossRef] [PubMed]

11. Price, M.A.; Kalderon, D. Proteolysis of the Hedgehog Signaling Effector Cubitus Interruptus Requires Phosphorylation by Glycogen Synthase Kinase 3 and Casein Kinase 1. Cell 2002, 108, 823-835. [CrossRef]

12. Shafique, S.; Rashid, S. Structural Basis of BTrCP1-Associated GLI3 Processing. Sci. Rep. 2019, 9, 6865. [CrossRef]

13. Pan, Y.; Wang, C.; Wang, B. Phosphorylation of Gli2 by Protein Kinase A Is Required for Gli2 Processing and Degradation and the Sonic Hedgehog-Regulated Mouse Development. Dev. Biol. 2009, 326, 177-189. [CrossRef]

14. Sabol, M.; Trnski, D.; Musani, V.; Ozretić, P.; Levanat, S. Role of GLI Transcription Factors in Pathogenesis and Their Potential as New Therapeutic Targets. Int. J. Mol. Sci. 2018, 19, 2562. [CrossRef]

15. Zubčić, V.; Rinčić, N.; Kurtović, M.; Trnski, D.; Musani, V.; Ozretić, P.; Levanat, S.; Leović, D.; Sabol, M. GANT61 and Lithium Chloride Inhibit the Growth of Head and Neck Cancer Cell Lines Through the Regulation of GLI3 Processing by GSK3 $\beta$. Int. J. Mol. Sci. 2020, 21, 6410. [CrossRef] [PubMed]

16. Miyazaki, Y.; Matsubara, S.; Ding, Q.; Tsukasa, K.; Yoshimitsu, M.; Kosai, K.i.; Takao, S. Efficient Elimination of Pancreatic Cancer Stem Cells by Hedgehog/GLI Inhibitor GANT61 in Combination with MTOR Inhibition. Mol. Cancer 2016, 15, 49. [CrossRef] 
17. Pietrobono, S.; Gagliardi, S.; Stecca, B. Non-Canonical Hedgehog Signaling Pathway in Cancer: Activation of GLI Transcription Factors beyond Smoothened. Front. Genet. 2019, 10, 556. [CrossRef] [PubMed]

18. Zhu, H.; Lo, H.-W. The Human Glioma-Associated Oncogene Homolog 1 (GLI1) Family of Transcription Factors in Gene Regulation and Diseases. Curr. Genomics 2010, 11, 238-245. [CrossRef] [PubMed]

19. Niewiadomski, P.; Niedziółka, S.M.; Markiewicz, Ł.; Uśpieński, T.; Baran, B.; Chojnowska, K. Gli Proteins: Regulation in Development and Cancer. Cells 2019, 8, 147. [CrossRef]

20. Pan, Y.; Wang, B. A Novel Protein-Processing Domain in Gli2 and Gli3 Differentially Blocks Complete Protein Degradation by the Proteasome. J. Biol. Chem. 2007, 282, 10846-10852. [CrossRef]

21. Kinzler, K.W.; Vogelstein, B. The GLI Gene Encodes a Nuclear Protein Which Binds Specific Sequences in the Human Genome. Mol. Cell. Biol. 1990, 10, 634. [CrossRef] [PubMed]

22. Pavletich, N.; Pabo, C. Crystal Structure of a Five-Finger GLI-DNA Complex: New Perspectives on Zinc Fingers. Science 1993, 261, 1701-1707. [CrossRef] [PubMed]

23. Hatayama, M.; Aruga, J. Gli Protein Nuclear Localization Signal. Vitam. Horm. 2012, 88, 73-89.

24. Szczepny, A.; Wagstaff, K.M.; Dias, M.; Gajewska, K.; Wang, C.; Davies, R.G.; Kaur, G.; Ly-Huynh, J.; Loveland, K.L.; Jans, D.A. Overlapping Binding Sites for Importin B1 and Suppressor of Fused (SuFu) on Glioma-Associated Oncogene Homologue 1 (Gli1) Regulate Its Nuclear Localization. Biochem. J. 2014, 461, 469-476. [CrossRef]

25. Torrado, B.; Graña, M.; Badano, J.L.; Irigoín, F. Ciliary Entry of the Hedgehog Transcriptional Activator Gli2 Is Mediated by the Nuclear Import Machinery but Differs from Nuclear Transport in Being Imp- $\alpha$ /B1-Independent. PLoS ONE 2016, 11, e0162033.

26. Barnfield, P.C.; Zhang, X.; Thanabalasingham, V.; Yoshida, M.; Hui, C. Negative Regulation of Gli1 and Gli2 Activator Function by Suppressor of Fused through Multiple Mechanisms. Differentiation 2005, 73, 397-405. [CrossRef]

27. Sheng, T.; Chi, S.; Zhang, X.; Xie, J. Regulation of Gli1 Localization by the CAMP/Protein Kinase A Signaling Axis through a Site Near the Nuclear Localization Signal. J. Biol. Chem. 2006, 281, 9-12. [CrossRef]

28. Shi, Q.; Han, Y.; Jiang, J. Suppressor of Fused Impedes Ci/Gli Nuclear Import by Opposing Trn/Kapb2 in Hedgehog Signaling. J. Cell Sci. 2014, 127, 1092-1103. [PubMed]

29. Han, Y.; Xiong, Y.; Shi, X.; Wu, J.; Zhao, Y.; Jiang, J. Regulation of Gli Ciliary Localization and Hedgehog Signaling by the PY-NLS/Karyopherin-B2 Nuclear Import System. PLOS Biol. 2017, 15, e2002063. [CrossRef] [PubMed]

30. Kogerman, P.; Grimm, T.; Kogerman, L.; Krause, D.; Undén, A.B.; Sandstedt, B.; Toftgård, R.; Zaphiropoulos, P.G. Mammalian Suppressor-of-Fused Modulates Nuclear-Cytoplasmic Shuttling of GLI-1. Nat. Cell Biol. 1999, 1, 312-319. [CrossRef] [PubMed]

31. Han, Y.; Shi, Q.; Jiang, J. Multisite Interaction with Sufu Regulates Ci/Gli Activity through Distinct Mechanisms in Hh Signal Transduction. Proc. Natl. Acad. Sci. USA 2015, 112, 6383-6388. [CrossRef]

32. Zhang, Z.; Shen, L.; Law, K.; Zhang, Z.; Liu, X.; Hua, H.; Li, S.; Huang, H.; Yue, S.; Hui, C.; et al. Suppressor of Fused Chaperones Gli Proteins To Generate Transcriptional Responses to Sonic Hedgehog Signaling. Mol. Cell. Biol. 2017, 37, e00421-16. [CrossRef]

33. Akimaru, H.; Chen, Y.; Dai, P.; Hou, D.-X.; Nonaka, M.; Smolik, S.M.; Armstrong, S.; Goodman, R.H.; Ishii, S. Drosophila CBP Is a Co-Activator of Cubitus Interruptus in Hedgehog Signalling. Nature 1997, 386, 735-738. [CrossRef]

34. Hughes, D.C.; Allen, J.; Morley, G.; Sutherland, K.; Ahmed, W.; Prosser, J.; Lettice, L.; Allan, G.; Mattei, M.G.; Farrall, M.; et al. Cloning and Sequencing of the Mouse Gli2 Gene: Localization to the Dominant Hemimelia Critical Region. Genomics 1997, 39, 205-215. [CrossRef] [PubMed]

35. Dai, P.; Akimaru, H.; Tanaka, Y.; Maekawa, T.; Nakafuku, M.; Ishii, S. Sonic Hedgehog-Induced Activation of the Gli1Promoter Is Mediated by GLI3. J. Biol. Chem. 1999, 274, 8143-8152. [CrossRef] [PubMed]

36. Zhou, H.; Kim, S.; Ishii, S.; Boyer, T.G. Mediator Modulates Gli3-Dependent Sonic Hedgehog Signaling. Mol. Cell. Biol. 2006, 26, 8667. [CrossRef] [PubMed]

37. Yoon, J.W.; Liu, C.Z.; Yang, J.T.; Swart, R.; Iannaccone, P.; Walterhouse, D. GLI Activates Transcription through a Herpes Simplex Viral Protein 16-Like Activation Domain. J. Biol. Chem. 1998, 273, 3496-3501. [CrossRef]

38. Yoon, J.W.; Lamm, M.; Iannaccone, S.; Higashiyama, N.; Leong, K.F.; Iannaccone, P.; Walterhouse, D. P53 Modulates The Activity Of The GLI1 Oncogene Through Interactions With The Shared Coactivator TAF9. DNA Repair 2015, 34, 9. [CrossRef]

39. Bosco-Clément, G.; Zhang, F.; Chen, Z.; Zhou, H.M.; Li, H.; Mikami, I.; Hirata, T.; Yagui-Beltran, A.; Lui, N.; Do, H.T.; et al. Targeting Gli Transcription Activation by Small Molecule Suppresses Tumor Growth. Oncogene 2014, 33, 2087-2097. [CrossRef] [PubMed]

40. Dai, P.; Shinagawa, T.; Nomura, T.; Harada, J.; Kaul, S.C.; Wadhwa, R.; Khan, M.M.; Akimaru, H.; Sasaki, H.; Colmenares, C.; et al. Ski Is Involved in Transcriptional Regulation by the Repressor and Full-Length Forms of Gli3. Genes Dev. 2002, 16, 2843. [CrossRef]

41. Cheng, S.Y.; Bishop, J.M. Suppressor of Fused Represses Gli-Mediated Transcription by Recruiting the SAP18-MSin3 Corepressor Complex. Proc. Natl. Acad. Sci. USA 2002, 99, 5442-5447. [CrossRef]

42. Hanahan, D.; Weinberg, R.A. Hallmarks of Cancer: The Next Generation. Cell 2011, 144, 646-674. [CrossRef]

43. Kenney, A.M.; Rowitch, D.H. Sonic Hedgehog Promotes G1 Cyclin Expression and Sustained Cell Cycle Progression in Mammalian Neuronal Precursors. Mol. Cell. Biol. 2000, 20, 9055. [CrossRef]

44. Kump, E.; Ji, J.; Wernli, M.; Häusermann, P.; Erb, P. Gli2 Upregulates CFlip and Renders Basal Cell Carcinoma Cells Resistant to Death Ligand-Mediated Apoptosis. Oncogene 2008, 27, 3856-3864. [CrossRef] [PubMed] 
45. Li, Z.J.; Mack, S.C.; Mak, T.H.; Angers, S.; Taylor, M.D.; Hui, C.-C. Evasion of P53 and G 2 /M Checkpoints Are Characteristic of Hh-Driven Basal Cell Carcinoma. Oncogene 2014, 33, 2674-2680. [CrossRef] [PubMed]

46. Katoh, Y.; Katoh, M. Hedgehog Signaling, Epithelial-to-Mesenchymal Transition and MiRNA (Review). Int. J. Mol. Med. 2008, 22, 271-275. [CrossRef] [PubMed]

47. Senga, S.S.; Grose, R.P. Hallmarks of Cancer-the New Testament. Open Biol. 2021, 11, 200358. [CrossRef] [PubMed]

48. Cochrane, C.R.; Szczepny, A.; Watkins, D.N.; Cain, J.E. Hedgehog Signaling in the Maintenance of Cancer Stem Cells. Cancers 2015, 7, 1554. [CrossRef]

49. Nilsson, M. Induction of Basal Cell Carcinomas and Trichoepitheliomas in Mice Overexpressing GLI-1. Proc. Natl. Acad. Sci. USA 2000, 97, 3438-3443. [CrossRef]

50. Ji, J.; Kump, E.; Wernli, M.; Erb, P. Gene Silencing of Transcription Factor Gli2 Inhibits Basal Cell Carcinomalike Tumor Growthin Vivo. Int. J. Cancer 2008, 122, 50-56. [CrossRef]

51. Hutchin, M.E.; Kariapper, M.S.T.; Grachtchouk, M.; Wang, A.; Wei, L.; Cummings, D.; Liu, J.; Evan Michael, L.; Glick, A.; Dlugosz, A.A. Sustained Hedgehog Signaling Is Required for Basal Cell Carcinoma Proliferation and Survival: Conditional Skin Tumorigenesis Recapitulates the Hair Growth Cycle. Genes Dev. 2005, 19, 214-223. [CrossRef]

52. Cui, C.; Elsam, T.; Tian, Q.; Seykora, J.T.; Grachtchouk, M.; Dlugosz, A.; Tseng, H. Gli Proteins Up-Regulate the Expression of Basonuclin in Basal Cell Carcinoma. Cancer Res. 2004, 64, 5651-5658. [CrossRef]

53. Kimura, H.; Stephen, D.; Joyner, A.; Curran, T. Gli1 Is Important for Medulloblastoma Formation in Ptc1+/- Mice. Oncogene 2005, 24, 4026-4036. [CrossRef]

54. Romer, J.T.; Kimura, H.; Magdaleno, S.; Sasai, K.; Fuller, C.; Baines, H.; Connelly, M.; Stewart, C.F.; Gould, S.; Rubin, L.L.; et al. Suppression of the Shh Pathway Using a Small Molecule Inhibitor Eliminates Medulloblastoma in Ptc1+/-P53-/- Mice. Cancer Cell 2004, 6, 229-240. [CrossRef] [PubMed]

55. Kadlub, N.; Coudert, A.; Gatibelza, M.E.; El Houmami, N.; Soufir, N.; Ruhin-Poncet, B.; L’Hermine, A.C.; Berdal, A.; Vazquez, M.P.; Descroix, V.; et al. PTCH1 Mutation and Local Aggressiveness of Odontogenic Keratocystic Tumors in Children: Is There a Relationship? Hum. Pathol. 2013, 44, 1071-1078. [CrossRef] [PubMed]

56. Burns, M.A.; Liao, Z.W.; Yamagata, N.; Pouliot, G.P.; Stevenson, K.E.; Neuberg, D.S.; Thorner, A.R.; Ducar, M.; Silverman, E.A.; Hunger, S.P.; et al. Hedgehog Pathway Mutations Drive Oncogenic Transformation in High-Risk T-Cell Acute Lymphoblastic Leukemia. Blood 2017, 130, 367. [CrossRef] [PubMed]

57. Wang, C.-Y.; Chang, Y.-C.; Kuo, Y.-L.; Lee, K.-T.; Chen, P.-S.; Cheung, C.H.A.; Chang, C.-P.; Phan, N.N.; Shen, M.-R.; Hsu, H.-P. Mutation of the PTCH1 Gene Predicts Recurrence of Breast Cancer. Sci. Rep. 2019, 9, 16359. [CrossRef] [PubMed]

58. Cazet, A.S.; Hui, M.N.; Elsworth, B.L.; Wu, S.Z.; Roden, D.; Chan, C.L.; Skhinas, J.N.; Collot, R.; Yang, J.; Harvey, K.; et al. Targeting Stromal Remodeling and Cancer Stem Cell Plasticity Overcomes Chemoresistance in Triple Negative Breast Cancer. Nat. Commun. 2018, 9, 2897. [CrossRef]

59. Chakraborty, C.; Dutta, S.; Mukherjee, N.; Samadder, S.; Roychowdhury, A.; Roy, A.; Mondal, R.K.; Basu, P.; Roychoudhury, S.; Panda, C.K. Inactivation of PTCH1 Is Associated with the Development of Cervical Carcinoma: Clinical and Prognostic Implication. Tumour Biol. 2014, 36, 1143-1154. [CrossRef] [PubMed]

60. Chaudary, N.; Pintilie, M.; Hedley, D.; Fyles, A.W.; Milosevic, M.; Clarke, B.; Hill, R.P.; Mackay, H. Hedgehog Pathway Signaling in Cervical Carcinoma and Outcome after Chemoradiation. Cancer 2012, 118, 3105-3115. [CrossRef] [PubMed]

61. Chen, H.; Wang, J.; Yang, H.; Chen, D.; Li, P. Association between FOXM1 and Hedgehog Signaling Pathway in Human Cervical Carcinoma by Tissue Microarray Analysis. Oncol. Lett. 2016, 12, 2664-2673. [CrossRef] [PubMed]

62. Grachtchouk, V.; Grachtchouk, M.; Lowe, L.; Johnson, T.; Wei, L.; Wang, A.; De Sauvage, F.; Dlugosz, A.A. The Magnitude of Hedgehog Signaling Activity Defines Skin Tumor Phenotype. EMBO J. 2003, 22, 2741-2751. [CrossRef] [PubMed]

63. Pricl, S.; Cortelazzi, B.; Dal Col, V.; Marson, D.; Laurini, E.; Fermeglia, M.; Licitra, L.; Pilotti, S.; Bossi, P.; Perrone, F. Smoothened (SMO) Receptor Mutations Dictate Resistance Tovismodegib in Basal Cell Carcinoma. Mol. Oncol. 2015, 9, 389-397. [CrossRef] [PubMed]

64. Atwood, S.X.; Sarin, K.Y.; Whitson, R.J.; Li, J.R.; Kim, G.; Rezaee, M.; Ally, M.S.; Kim, J.; Yao, C.; Chang, A.L.S.; et al. Smoothened Variants Explain the Majority of Drug Resistance in Basal Cell Carcinoma. Cancer Cell 2015, 27, 342-353. [CrossRef]

65. Xie, J.; Murone, M.; Luoh, S.M.; Ryan, A.; Gu, Q.; Zhang, C.; Bonifas, J.M.; Lam, C.W.; Hynes, M.; Goddard, A.; et al. Activating Smoothened Mutations in Sporadic Basal-Cell Carcinoma. Nature 1998, 391, 90-92. [CrossRef]

66. Youssef, K.K.; Lapouge, G.; Bouvrée, K.; Rorive, S.; Brohée, S.; Appelstein, O.; Larsimont, J.C.; Sukumaran, V.; Van De Sande, B.; Pucci, D.; et al. Adult Interfollicular Tumour-Initiating Cells Are Reprogrammed into an Embryonic Hair Follicle Progenitor-like Fate during Basal Cell Carcinoma Initiation. Nat. Cell Biol. 2012, 14, 1282-1294. [CrossRef]

67. Yauch, R.L.; Dijkgraaf, G.J.P.; Alicke, B.; Januario, T.; Ahn, C.P.; Holcomb, T.; Pujara, K.; Stinson, J.; Callahan, C.A.; Tang, T.; et al. Smoothened Mutation Confers Resistance to a Hedgehog Pathway Inhibitor in Medulloblastoma. Science 2009, 326, 572. [CrossRef] [PubMed]

68. Sicklick, J.K.; Li, Y.X.; Jayaraman, A.; Kannangai, R.; Qi, Y.; Vivekanandan, P.; Ludlow, J.W.; Owzar, K.; Chen, W.; Torbenson, M.S.; et al. Dysregulation of the Hedgehog Pathway in Human Hepatocarcinogenesis. Carcinogenesis 2006, 27, 748-757. [CrossRef]

69. Kasperczyk, H.; Baumann, B.; Debatin, K.M.; Fulda, S. Characterization of Sonic Hedgehog as a Novel NF-KB Target Gene That Promotes NF-KB-Mediated Apoptosis Resistance and Tumor Growth in Vivo. FASEB J. 2009, 23, 21-33. [CrossRef] 
70. Nakashima, H.; Nakamura, M.; Yamaguchi, H.; Yamanaka, N.; Akiyoshi, T.; Koga, K.; Yamaguchi, K.; Tsuneyoshi, M.; Tanaka, M.; Katano, M. Nuclear Factor-KB Contributes to Hedgehog Signaling Pathway Activation through Sonic Hedgehog Induction in Pancreatic Cancer. Cancer Res. 2006, 66, 7041-7049. [CrossRef]

71. Tian, H.; Callahan, C.A.; Dupree, K.J.; Darbonne, W.C.; Ahn, C.P.; Scales, S.J.; De Sauvage, F.J. Hedgehog Signaling Is Restricted to the Stromal Compartment during Pancreatic Carcinogenesis. Proc. Natl. Acad. Sci. USA 2009, 106, 4254-4259. [CrossRef]

72. Gu, D.; Schlotman, K.E.; Xie, J. Deciphering the Role of Hedgehog Signaling in Pancreatic Cancer. J. Biomed. Res. 2016, 30, 353-360.

73. Olive, K.P.; Jacobetz, M.A.; Davidson, C.J.; Gopinathan, A.; McIntyre, D.; Honess, D.; Madhu, B.; Goldgraben, M.A.; Caldwell, M.E.; Allard, D.; et al. Inhibition of Hedgehog Signaling Enhances Delivery of Chemotherapy in a Mouse Model of Pancreatic Cancer. Science 2009, 324, 1457-1461. [CrossRef] [PubMed]

74. Duan, Z.H.; Wang, H.C.; Zhao, D.M.; Ji, X.X.; Song, M.; Yang, X.J.; Cui, W. Cooperatively Transcriptional and Epigenetic Regulation of Sonic Hedgehog Overexpression Drives Malignant Potential of Breast Cancer. Cancer Sci. 2015, 106, 1084-1091. [CrossRef] [PubMed]

75. Cui, W.; Wang, L.H.; Wen, Y.Y.; Song, M.; Li, B.L.; Chen, X.L.; Xu, M.; An, S.X.; Zhao, J.; Lu, Y.Y.; et al. Expression and Regulation Mechanisms of Sonic Hedgehog in Breast Cancer. Cancer Sci. 2010, 101, 927-933. [CrossRef] [PubMed]

76. Lou, H.; Li, H.; Huehn, A.R.; Tarasova, N.I.; Saleh, B.; Anderson, S.K.; Dean, M. Genetic and Epigenetic Regulation of the Smoothened Gene (SMO) in Cancer Cells. Cancers 2020, 12, 2219. [CrossRef] [PubMed]

77. Wang, Y.; Lin, P.; Wang, Q.; Zheng, M.; Pang, L. Wnt3a-Regulated TCF4 / $\beta$-Catenin Complex Directly Activates the Key Hedgehog Signalling Genes Smo and Gli1. Exp. Ther. Med. 2018, 16, 2101. [CrossRef] [PubMed]

78. Zhu, Y.; James, R.M.; Peter, A.; Lomas, C.; Cheung, F.; Harrison, D.J.; Bader, S.A. Functional Smoothened Is Required for Expression of GLI3 in Colorectal Carcinoma Cells. Cancer Lett. 2004, 207, 205-214. [CrossRef]

79. Iwasaki, H.; Nakano, K.; Shinkai, K.; Kunisawa, Y.; Hirahashi, M.; Oda, Y.; Onishi, H.; Katano, M. Hedgehog Gli3 Activator Signal Augments Tumorigenicity of Colorectal Cancer via Upregulation of Adherence-Related Genes. Cancer Sci. 2013, 104, 328-336. [CrossRef] [PubMed]

80. Kang, H.N.; Oh, S.C.; Kim, J.S.; Yoo, Y.A. Abrogation of Gli3 Expression Suppresses the Growth of Colon Cancer Cells via Activation of P53. Exp. Cell Res. 2012, 318, 539-549. [CrossRef]

81. Shen, M.; Zhang, Z.; Wang, P. GLI3 Promotes Invasion and Predicts Poor Prognosis in Colorectal Cancer. Biomed Res. Int. 2021, 2021, 8889986. [CrossRef] [PubMed]

82. Magistri, P.; Battistelli, C.; Strippoli, R.; Petrucciani, N.; Pellinen, T.; Rossi, L.; Mangogna, L.; Aurello, P.; D’Angelo, F.; Tripodi, M.; et al. SMO Inhibition Modulates Cellular Plasticity and Invasiveness in Colorectal Cancer. Front. Pharmacol. 2018,8 , 956. [CrossRef] [PubMed]

83. Garcia, N.; Al-Hendy, A.; Baracat, E.C.; Carvalho, K.C.; Yang, Q. Targeting Hedgehog Pathway and DNA Methyltransferases in Uterine Leiomyosarcoma Cells. Cells 2020, 10, 53. [CrossRef]

84. Song, Y.; Tian, Y.; Zuo, Y.; Tu, J.C.; Feng, Y.F.; Qu, C.J. Altered Expression of PTCH and HHIP in Gastric Cancer through Their Gene Promoter Methylation: Novel Targets for Gastric Cancer. Mol. Med. Rep. 2013, 7, 1159-1168. [CrossRef] [PubMed]

85. Du, P.; Ye, H.-R.; Gao, J.; Chen, W.; Wang, Z.-C.; Jiang, H.-H.; Xu, J.; Zhang, J.-W.; Zhang, J.-C.; Cui, L. Methylation of PTCH1a Gene in a Subset of Gastric Cancers. World J. Gastroenterol. 2009, 15, 3799. [CrossRef] [PubMed]

86. Lee, S.J.; Do, I.G.; Lee, J.; Kim, K.M.; Jang, J.; Sohn, I.; Kang, W.K. Gastric Cancer (GC) Patients with Hedgehog Pathway Activation: PTCH1 and GLI2 as Independent Prognostic Factors. Target. Oncol. 2013, 8, 271-280. [CrossRef] [PubMed]

87. Zuo, Y.; Song, Y.; Zhang, M.; Xu, Z.; Qian, X. Role of PTCH1 Gene Methylation in Gastric Carcinogenesis. Oncol. Lett. 2014, 8, 679. [CrossRef]

88. Song, Y.; Tu, J.; Cheng, Y.; Zhou, F.; Liu, P.; Zhou, S.; Gu, Y.; Sun, Y. HHIP Overexpression Suppresses Human Gastric Cancer Progression and Metastasis by Reducing Its CpG Island Methylation. Front. Oncol. 2020, 10, 1667. [CrossRef]

89. Yang, Z.; Lv, Y.; Wang, L.; Chen, Y.; Han, J.; Zhao, S.; Liu, W. Inhibition of Hedgehog Pathway Reveals the Regulatory Role of SMO in Gastric Cancer Cells. Tumour Biol. 2017, 39, 1-6. [CrossRef]

90. Fukaya, M.; Isohata, N.; Ohta, H.; Aoyagi, K.; Ochiya, T.; Saeki, N.; Yanagihara, K.; Nakanishi, Y.; Taniguchi, H.; Sakamoto, H.; et al. Hedgehog Signal Activation in Gastric Pit Cell and in Diffuse-Type Gastric Cancer. Gastroenterology 2006, 131, 14-29. [CrossRef]

91. Po, A.; Silvano, M.; Miele, E.; Capalbo, C.; Eramo, A.; Salvati, V.; Todaro, M.; Besharat, Z.M.; Catanzaro, G.; Cucchi, D.; et al. Noncanonical GLI1 Signaling Promotes Stemness Features and in Vivo Growth in Lung Adenocarcinoma. Oncogene 2017, 36, 4641-4652. [CrossRef]

92. Kawakami, T.; Tokunaga, T.; Hatanaka, H.; Kijima, H.; Yamazaki, H.; Abe, Y.; Osamura, Y.; Inoue, H.; Ueyama, Y.; Nakamura, M. Neuropilin 1 and Neuropilin 2 Co-Expression Is Significantly Correlated with Increased Vascularity and Poor Prognosis in Nonsmall Cell Lung Carcinoma. Cancer 2002, 95, 2196-2201. [CrossRef] [PubMed]

93. Goel, H.L.; Pursell, B.; Chang, C.; Shaw, L.M.; Mao, J.; Simin, K.; Kumar, P.; Vander Kooi, C.W.; Shultz, L.D.; Greiner, D.L.; et al. GLI1 Regulates a Novel Neuropilin-2/A6ß1 Integrin Based Autocrine Pathway That Contributes to Breast Cancer Initiation. EMBO Mol. Med. 2013, 5, 488-508. [CrossRef] [PubMed]

94. Nolan-Stevaux, O.; Lau, J.; Truitt, M.L.; Chu, G.C.; Hebrok, M.; Fernández-Zapico, M.E.; Hanahan, D. GLI1 Is Regulated through Smoothened-Independent Mechanisms in Neoplastic Pancreatic Ducts and Mediates PDAC Cell Survival and Transformation. Genes Dev. 2009, 23, 24-36. [CrossRef] 
95. Rajurkar, M.; De Jesus-Monge, W.E.; Driscoll, D.R.; Appleman, V.A.; Huang, H.; Cotton, J.L.; Klimstra, D.S.; Zhu, L.J.; Simin, K.; $\mathrm{Xu}$, L.; et al. The Activity of Gli Transcription Factors Is Essential for Kras-Induced Pancreatic Tumorigenesis. Proc. Natl. Acad. Sci. USA 2012, 109, E1038-E1047. [CrossRef] [PubMed]

96. Zheng, X.; Rumie Vittar, N.B.; Gai, X.; Fernandez-Barrena, M.G.; Moser, C.D.; Hu, C.; Almada, L.L.; McCleary-Wheeler, A.L.; Elsawa, S.F.; Vrabel, A.M.; et al. The Transcription Factor GLI1 Mediates TGF $\beta 1$ Driven EMT in Hepatocellular Carcinoma via a SNAI1-Dependent Mechanism. PLoS ONE 2012, 7, e49581. [CrossRef]

97. Faião-Flores, F.; Alves-Fernandes, D.K.; Pennacchi, P.C.; Sandri, S.; Vicente, A.L.S.A.; Scapulatempo-Neto, C.; Vazquez, V.L.; Reis, R.M.; Chauhan, J.; Goding, C.R.; et al. Targeting the Hedgehog Transcription Factors GLI1 and GLI2 Restores Sensitivity to Vemurafenib-Resistant Human Melanoma Cells. Oncogene 2017, 36, 1849-1861. [CrossRef]

98. Johnson, R.W.; Merkel, A.R.; Page, J.M.; Ruppender, N.S.; Guelcher, S.A.; Sterling, J.A. Wnt Signaling Induces Gene Expression of Factors Associated with Bone Destruction in Lung and Breast Cancer. Clin. Exp. Metastasis 2014, 31, 945-959. [CrossRef]

99. Cannonier, S.A.; Gonzales, C.B.; Ely, K.; Guelcher, S.A.; Sterling, J.A. Hedgehog and TGF $\beta$ Signaling Converge on Gli2 to Control Bony Invasion and Bone Destruction in Oral Squamous Cell Carcinoma. Oncotarget 2016, 7, 76062-76075. [CrossRef]

100. Noubissi, F.K.; Goswami, S.; Sanek, N.A.; Kawakami, K.; Minamoto, T.; Moser, A.; Grinblat, Y.; Spiegelman, V.S. Wnt Signaling Stimulates Transcriptional Outcome of the Hedgehog Pathway by Stabilizing GLI1 MRNA. Cancer Res. 2009, 69, 8572-8578. [CrossRef]

101. Varnat, F.; Siegl-Cachedenier, I.; Malerba, M.; Gervaz, P.; Ruiz, I.; Altaba, A. Loss of WNT-TCF Addiction and Enhancement of HH-GLI1 Signalling Define the Metastatic Transition of Human Colon Carcinomas. EMBO Mol. Med. 2010, 2, 440-457. [CrossRef] [PubMed]

102. Yao, Y.; Zhou, D.; Shi, D.; Zhang, H.; Zhan, S.; Shao, X.; Sun, K.; Sun, L.; Wu, G.; Tian, K.; et al. GLI1 Overexpression Promotes Gastric Cancer Cell Proliferation and Migration and Induces Drug Resistance by Combining with the AKT-MTOR Pathway. Biomed. Pharmacother. 2019, 111, 993-1004. [CrossRef] [PubMed]

103. Chakrabarti, J.; Holokai, L.; Syu, L.; Steele, N.G.; Chang, J.; Wang, J.; Ahmed, S.; Dlugosz, A.; Zavros, Y. Hedgehog Signaling Induces PD-L1 Expression and Tumor Cell Proliferation in Gastric Cancer. Oncotarget 2018, 9, 37439. [CrossRef] [PubMed]

104. Koh, V.; Chakrabarti, J.; Torvund, M.; Steele, N.; Hawkins, J.A.; Ito, Y.; Wang, J.; Helmrath, M.A.; Merchant, J.L.; Ahmed, S.A.; et al. Hedgehog Transcriptional Effector GLI Mediates MTOR-Induced PD-L1 Expression in Gastric Cancer Organoids. Cancer Lett. 2021, 518, 59-71. [CrossRef] [PubMed]

105. Kasiri, S.; Shao, C.; Chen, B.; Wilson, A.N.; Yenerall, P.; Timmons, B.C.; Girard, L.; Tian, H.; Behrens, C.; Wistuba, I.I.; et al. GLI1 Blockade Potentiates the Antitumor Activity of PI3K Antagonists in Lung Squamous Cell Carcinoma. Cancer Res. 2017, 77, 4448-4459. [CrossRef] [PubMed]

106. Kebenko, M.; Drenckhan, A.; Gros, S.J.; Jücker, M.; Grabinski, N.; Ewald, F.; Grottke, A.; Schultze, A.; Izbicki, J.R.; Bokemeyer, C.; et al. ErbB2 Signaling Activates the Hedgehog Pathway via PI3K-Akt in Human Esophageal Adenocarcinoma: Identification of Novel Targets for Concerted Therapy Concepts. Cell. Signal. 2015, 27, 373-381. [CrossRef]

107. Zhu, J.; Sun, Y.; Lu, Y.; Jiang, X.; Ma, B.; Yu, L.; Zhang, J.; Dong, X.; Zhang, Q. Glaucocalyxin A Exerts Anticancer Effect on Osteosarcoma by Inhibiting GLI1 Nuclear Translocation via Regulating PI3K/Akt Pathway. Cell Death Dis. 2018, 9, 708. [CrossRef]

108. Singh, R.; Dhanyamraju, P.K.; Lauth, M. DYRK1B Blocks Canonical and Promotes Non-Canonical Hedgehog Signaling through Activation of the MTOR/AKT Pathway. Oncotarget 2017, 8, 833-845. [CrossRef]

109. Zhou, J.; Zhu, G.; Huang, J.; Li, L.; Du, Y.; Gao, Y.; Wu, D.; Wang, X.; Hsieh, J.T.; He, D.; et al. Non-Canonical GLI1/2 Activation by PI3K/AKT Signaling in Renal Cell Carcinoma: A Novel Potential Therapeutic Target. Cancer Lett. 2016, 370, 313-323. [CrossRef]

110. Yang, H.; Hu, L.; Liu, Z.; Qin, Y.; Li, R.; Zhang, G.; Zhao, B.; Bi, C.; Lei, Y.; Bai, Y. Inhibition of Gli1-Mediated Prostate Cancer Cell Proliferation by Inhibiting the MTOR/S6K1 Signaling Pathway. Oncol. Lett. 2017, 14, 7970-7976. [CrossRef]

111. Wang, Y.; Ding, Q.; Yen, C.J.; Xia, W.; Izzo, J.G.; Lang, J.Y.; Li, C.W.; Hsu, J.L.; Miller, S.A.; Wang, X.; et al. The Crosstalk of MTOR/S6K1 and Hedgehog Pathways. Cancer Cell 2012, 21, 374-387. [CrossRef] [PubMed]

112. Mizuarai, S.; Kawagishi, A.; Kotani, H. Inhibition of P70S6K2 Down-Regulates Hedgehog/GLI Pathway in Non-Small Cell Lung Cancer Cell Lines. Mol. Cancer 2009, 8, 44. [CrossRef] [PubMed]

113. Stecca, B.; Mas, C.; Clement, V.; Zbinden, M.; Correa, R.; Piguet, V.; Beermann, F.; Ruiz I Altaba, A. Melanomas Require HEDGEHOG-GLI Signaling Regulated by Interactions between GLI1 and the RAS-MEK/AKT Pathways. Proc. Natl. Acad. Sci. USA 2007, 104, 5895-5900. [CrossRef] [PubMed]

114. Colavito, S.A.; Zou, M.R.; Yan, Q.; Nguyen, D.X.; Stern, D.F. Significance of Glioma-Associated Oncogene Homolog 1 (GLI1) Expression in Claudin-Low Breast Cancer and Crosstalk with the Nuclear Factor Kappa-Light-Chain-Enhancer of Activated B Cells (NFkB) Pathway. Breast Cancer Res. 2014, 16, 444. [CrossRef]

115. Deng, W.; Vanderbilt, D.B.; Lin, C.C.; Martin, K.H.; Brundage, K.M.; Ruppert, J.M. SOX9 Inhibits $\beta$-TrCP-Mediated Protein Degradation to Promote Nuclear GLI1 Expression and Cancer Stem Cell Properties. J. Cell Sci. 2015, 128, 1123-1138. [CrossRef]

116. Han, B.; Qu, Y.; Jin, Y.; Yu, Y.; Deng, N.; Wawrowsky, K.; Zhang, X.; Li, N.; Bose, S.; Wang, Q.; et al. FOXC1 Activates Smoothened-Independent Hedgehog Signaling in Basal-like Breast Cancer. Cell Rep. 2015, 13, 1046-1058. [CrossRef] [PubMed]

117. Li, P.; Lee, E.H.; Du, F.; Gordon, R.E.; Yuelling, L.W.; Liu, Y.; Ng, J.M.Y.; Zhang, H.; Wu, J.; Korshunov, A.; et al. Nestin Mediates Hedgehog Pathway Tumorigenesis. Cancer Res. 2016, 76, 5573-5583. [CrossRef] 
118. Chong, Y.; Tang, D.; Gao, J.; Jiang, X.; Xu, C.; Xiong, Q.; Huang, Y.; Wang, J.; Zhou, H.; Shi, Y.; et al. Galectin-1 Induces Invasion and the Epithelial-Mesenchymal Transition in Human Gastric Cancer Cells via Non-Canonical Activation of the Hedgehog Signaling Pathway. Oncotarget 2016, 7, 83611-83626. [CrossRef]

119. Chong, Y.; Tang, D.; Xiong, Q.; Jiang, X.; Xu, C.; Huang, Y.; Wang, J.; Zhou, H.; Shi, Y.; Wu, X.; et al. Galectin-1 from CancerAssociated Fibroblasts Induces Epithelial-Mesenchymal Transition through B1 Integrin-Mediated Upregulation of Gli1 in Gastric Cancer. J. Exp. Clin. Cancer Res. 2016, 35, 175. [CrossRef]

120. You, X.; Wu, J.; Wang, Y.; Liu, Q.; Cheng, Z.; Zhao, X.; Liu, G.; Huang, C.; Dai, J.; Zhou, Y.; et al. Galectin-1 Promotes Vasculogenic Mimicry in Gastric Adenocarcinoma via the Hedgehog/GLI Signaling Pathway. Aging 2020, 12, 21837-21853. [CrossRef]

121. You, X.; Liu, Q.; Wu, J.; Wang, Y.; Dai, J.; Chen, D.; Zhou, Y.; Lian, Y. Galectin-1 Promotes Vasculogenic Mimicry in Gastric Cancer by Upregulating EMT Signaling. J. Cancer 2019, 10, 6286-6297. [CrossRef] [PubMed]

122. Martínez-Bosch, N.; Fernández-Barrena, M.G.; Moreno, M.; Ortiz-Zapater, E.; Munné-Collado, J.; Iglesias, M.; André, S.; Gabius, H.J.; Hwang, R.F.; Coise Poirier, F.; et al. Galectin-1 Drives Pancreatic Carcinogenesis through Stroma Remodeling and Hedgehog Signaling Activation. Cancer Res. 2014, 74, 3512-3524. [CrossRef]

123. Li, Y.; Yu, Q.; Li, R.; Luo, J.; Yuan, D.; Song, J.; Sun, Y.; Long, T.; Yang, Z. SPOP Regulates the Biological Mechanism of Ovarian Cancer Cells through the Hh Signaling Pathway. Onco Targets Ther. 2019, 12, 9239-9248. [CrossRef]

124. Zeng, C.; Wang, Y.; Lu, Q.; Chen, J.; Zhang, J.; Liu, T.; Lv, N.; Luo, S. SPOP Suppresses Tumorigenesis by Regulating Hedgehog/Gli2 Signaling Pathway in Gastric Cancer. J. Exp. Clin. Cancer Res. 2014, 33, 75. [CrossRef] [PubMed]

125. Wang, C.; Pan, Y.; Wang, B. Suppressor of Fused and Spop Regulate the Stability, Processing and Function of Gli2 and Gli3 Full-Length Activators but Not Their Repressors. Development 2010, 137, 2001-2009. [CrossRef] [PubMed]

126. Tian, L.; Deng, Z.; Xu, L.; Yang, T.; Yao, W.; Ji, L.; Lu, Y.; Zhang, J.; Liu, Y.; Wang, J. Downregulation of ASPP2 Promotes Gallbladder Cancer Metastasis and Macrophage Recruitment via APKC-ı/GLI1 Pathway. Cell Death Dis. 2018, 9, 1115. [CrossRef]

127. Trnski, D.; Sabol, M.; Gojević, A.; Martinić, M.; Ozretić, P.; Musani, V.; Ramić, S.; Levanat, S. GSK3 $\beta$ and Gli3 Play a Role in Activation of Hedgehog-Gli Pathway in Human Colon Cancer - Targeting GSK3 $\beta$ Downregulates the Signaling Pathway and Reduces Cell Proliferation. Biochim. Biophys. 2015, 1852, 2574-2584. [CrossRef]

128. Muthutkumar, S.; Boyer, T.; Burleson, M.O. Med12 Mutations Promote Castration Resistant Prostate Cancer through Hyperactivated GLI3/SHH Signaling. FASEB J. 2019, 33, 647.26. [CrossRef]

129. Pellegrini, C.; Maturo, M.G.; Di Nardo, L.; Ciciarelli, V.; Gutiérrez García-Rodrigo, C.; Fargnoli, M.C. Understanding the Molecular Genetics of Basal Cell Carcinoma. Int. J. Mol. Sci. 2017, 18, 2485. [CrossRef] [PubMed]

130. De Zwaan, S.E.; Haass, N.K. Genetics of Basal Cell Carcinoma. Australas. J. Dermatol. 2010, 51, 81-92. [CrossRef] [PubMed]

131. Horlock, N.; Wilson, G.D.; Daley, E.M.; Richman, R.I.; Grobbelaar, A.O.; Sanders, R.; Foy, C. Cellular Proliferation Characteristics Do Not Account for the Behaviour of Horrifying Basal Cell Carcinoma. A Comparison of the Growth Fraction of Horrifying and Non Horrifying Tumours. Br. J. Plast. Surg. 1998, 51, 59-66. [CrossRef] [PubMed]

132. Marcelina, P.; Mappiasse, A.; Anwar, A.I.; Ganda, I.J.; Hatta, M.; Masadah, R. Expression of Patched-1 Protein in Aggressive and Nonaggressive Basal Cell Carcinoma. Am. J. Clin. Exp. Immunol. 2016, 4, 122-128. [CrossRef]

133. Reifenberger, J.; Wolter, M.; Knobbe, C.B.; Köhler, B.; Schönicke, A.; Scharwächter, C.; Kumar, K.; Blaschke, B.; Ruzicka, T.; Reifenberger, G. Somatic Mutations in the PTCH, SMOH, SUFUH and TP53 Genes in Sporadic Basal Cell Carcinomas. Br. J. Dermatol. 2005, 152, 43-51. [CrossRef]

134. Niyaz, M.; Khan, M.S.; Mudassar, S. Hedgehog Signaling: An Achilles' Heel in Cancer. Transl. Oncol. 2019, 12, 1334-1344. [CrossRef]

135. Zheng, X.; Zeng, W.; Gai, X.; Xu, Q.; Li, C.; Liang, Z.; Tuo, H.; Liu, Q. Role of the Hedgehog Pathway in Hepatocellular Carcinoma (Review). Oncol. Rep. 2013, 30, 2020-2026. [CrossRef]

136. Shi, Y.; Moura, U.; Opitz, I.; Soltermann, A.; Rehrauer, H.; Thies, S.; Weder, W.; Stahel, R.A.; Felley-Bosco, E. Role of Hedgehog Signaling in Malignant Pleural Mesothelioma. Clin. Cancer Res. 2012, 18, 4646-4656. [CrossRef]

137. De la Rosa, J.; Sánchez, M.; Enguita-Germán, M.; García-López, R.; Schiapparelli, P.; Shahi, M.H.; Meléndez, B.; Rey, J.A.; Idoate, M.A.; Castresana, J.S. Inhibition of the Sonic Hedgehog Pathway by Cyclopamine or GLI1 SiRNA Reduces In Vivo Tumorigenesis of Human Medulloblastoma Cells Xenotransplanted to Immunodeficient Nude Mice. Adv. Transl. Med. Res. 2019, 1, 1-5.

138. Benvenuto, M.; Masuelli, L.; De Smaele, E.; Fantini, M.; Mattera, R.; Cucchi, D.; Bonanno, E.; Di Stefano, E.; Frajese, G.V.; Orlandi, A.; et al. In Vitro and in Vivo Inhibition of Breast Cancer Cell Growth by Targeting the Hedgehog/GLI Pathway with SMO (GDC-0449) or GLI (GANT-61) Inhibitors. Oncotarget 2016, 7, 9250. [CrossRef] [PubMed]

139. Waters, A.M.; Der, C.J. KRAS: The Critical Driver and Therapeutic Target for Pancreatic Cancer. Cold Spring Harb. Perspect. Med. 2018, 8, a031435. [CrossRef]

140. Han, J.J.; Fernandez-Zapico, M.E. Crosstalk between kras and hedgehog pathways in the regulation of gli function in pancreatic cancer cells. Pancreas 2006, 33, 466. [CrossRef]

141. Mills, L.D.; Zhang, Y.; Marler, R.J.; Herreros-Villanueva, M.; Zhang, L.; Almada, L.L.; Couch, F.; Wetmore, C.; di Magliano, M.P.; Fernandez-Zapico, M.E. Loss of the Transcription Factor GLI1 Identifies a Signaling Network in the Tumor Microenvironment Mediating KRAS Oncogene-Induced Transformation. J. Biol. Chem. 2013, 288, 11786. [CrossRef] [PubMed]

142. De Reyniès, A.; Javelaud, D.; Elarouci, N.; Marsaud, V.; Gilbert, C.; Mauviel, A. Large-Scale Pan-Cancer Analysis Reveals Broad Prognostic Association between TGF- $\beta$ Ligands, Not Hedgehog, and GLI1/2 Expression in Tumors. Sci. Rep. 2020, $10,14491$. [CrossRef] 
143. Abe, Y.; Tanaka, N. The Hedgehog Signaling Networks in Lung Cancer: The Mechanisms and Roles in Tumor Progression and Implications for Cancer Therapy. Biomed Res. Int. 2016, 2016, 7969286. [CrossRef] [PubMed]

144. Dennler, S.; André, J.; Verrechia, F.; Mauviel, A. Cloning of the Human GLI2 Promoter: Transcriptional Activation by Transforming Growth Factor- $\beta$ via SMAD3/ $\beta$-Catenin Cooperation. J. Biol. Chem. 2009, 284, 31523-31531. [CrossRef]

145. Kim, J.-H.; Shin, H.S.; Lee, S.H.; Lee, I.; Lee, Y.S.; Park, J.C.; Kim, Y.J.; Chung, J.B.; Lee, Y.C. Contrasting Activity of Hedgehog and Wnt Pathways According to Gastric Cancer Cell Differentiation: Relevance of Crosstalk Mechanisms. Cancer Sci. 2010, 101, 328-335. [CrossRef]

146. Das, S.; Samant, R.S.; Shevde, L.A. Nonclassical Activation of Hedgehog Signaling Enhances Multidrug Resistance and Makes Cancer Cells Refractory to Smoothened-Targeting Hedgehog Inhibition. J. Biol. Chem. 2013, 288, 11824-11833. [CrossRef]

147. Atwood, S.X.; Li, M.; Lee, A.; Tang, J.Y.; Oro, A.E. GLI Activation by Atypical Protein Kinase C $\iota / \lambda$ Regulates the Growth of Basal Cell Carcinomas. Nature 2013, 494, 484-488. [CrossRef]

148. Goel, H.L.; Underwood, J.M.; Nickerson, J.A.; Hsieh, C.-C.; Languino, L.R. B1 Integrins Mediate Cell Proliferation in ThreeDimensional Cultures by Regulating Expression of the Sonic Hedgehog Effector Protein, GLI1. J. Cell. Physiol. 2010, $224,210$. [CrossRef] [PubMed]

149. Axelson, M.; Liu, K.; Jiang, X.; He, K.; Wang, J.; Zhao, H.; Kufrin, D.; Palmby, T.; Dong, Z.; Russell, A.M.; et al. U.S. Food and Drug Administration Approval: Vismodegib for Recurrent, Locally Advanced, or Metastatic Basal Cell Carcinoma. Clin. Cancer Res. 2013, 19, 2289-2293. [CrossRef]

150. Casey, D.; Demko, S.; Shord, S.; Zhao, H.; Chen, H.; He, K.; Putman, A.; Helms, W.; Keegan, P.; Pazdur, R. FDA Approval Summary: Sonidegib for Locally Advanced Basal Cell Carcinoma. Clin. Cancer Res. 2017, 23, 2377-2381. [CrossRef]

151. Jamieson, C.; Martinelli, G.; Papayannidis, C.; Cortes, J.E. Hedgehog Pathway Inhibitors: A New Therapeutic Class for the Treatment of Acute Myeloid Leukemia. Blood Cancer Discov. 2020, 1, 134-145. [CrossRef]

152. Cortes, J.E.; Dombret, H.; Merchant, A.; Tauchi, T.; Dirienzo, C.G.; Sleight, B.; Zhang, X.; Leip, E.P.; Shaik, N.; Bell, T.; et al. Glasdegib plus Intensive/Nonintensive Chemotherapy in Untreated Acute Myeloid Leukemia: BRIGHT AML 1019 Phase III Trials. Futur. Oncol. 2019, 15, 3531-3545. [CrossRef] [PubMed]

153. Ally, M.S.; Ransohoff, K.; Sarin, K.; Atwood, S.X.; Rezaee, M.; Bailey-Healy, I.; Kim, J.; Beachy, P.A.; Chang, A.L.S.; Oro, A.; et al. Effects of Combined Treatment With Arsenic Trioxide and Itraconazole in Patients With Refractory Metastatic Basal Cell Carcinoma. JAMA Dermatol. 2016, 152, 452. [CrossRef] [PubMed]

154. Xie, H.; Paradise, B.D.; Ma, W.W.; Fernandez-Zapico, M.E. Recent Advances in the Clinical Targeting of Hedgehog/GLI Signaling in Cancer. Cells 2019, 8, 394. [CrossRef] [PubMed]

155. Couban, S.; Benevolo, G.; Donnellan, W.; Cultrera, J.; Koschmieder, S.; Verstovsek, S.; Hooper, G.; Hertig, C.; Tandon, M.; Dimier, N.; et al. A Phase Ib Study to Assess the Efficacy and Safety of Vismodegib in Combination with Ruxolitinib in Patients with Intermediate- or High-Risk Myelofibrosis 11 Medical and Health Sciences 1103 Clinical Sciences 11 Medical and Health Sciences 1102 Cardiorespiratory Medicine and Haematology. J. Hematol. Oncol. 2018, 11, 122.

156. Bixby, D.; Noppeney, R.; Lin, T.L.; Cortes, J.; Krauter, J.; Yee, K.; Medeiros, B.C.; Krämer, A.; Assouline, S.; Fiedler, W.; et al. Safety and Efficacy of Vismodegib in Relapsed/Refractory Acute Myeloid Leukaemia: Results of a Phase Ib Trial. Br. J. Haematol. 2019, 185, 595-598. [CrossRef]

157. McCleary-Wheeler, A.L.; Carr, R.M.; Palmer, S.R.; Smyrk, T.C.; Allred, J.B.; Almada, L.L.; Tolosa, E.J.; Lamberti, M.J.; Marks, D.L.; Borad, M.J.; et al. Phase 1 Trial of Vismodegib and Erlotinib Combination in Metastatic Pancreatic Cancer. Pancreatology 2020, 20, 101-109. [CrossRef]

158. Carr, R.M.; Duma, N.; McCleary-Wheeler, A.L.; Almada, L.L.; Marks, D.L.; Graham, R.P.; Smyrk, T.C.; Lowe, V.; Borad, M.J.; Kim, G.; et al. Targeting of the Hedgehog/GLI and MTOR Pathways in Advanced Pancreatic Cancer, a Phase 1 Trial of Vismodegib and Sirolimus Combination. Pancreatology 2020, 20, 1115-1122. [CrossRef]

159. De Jesus-Acosta, A.; Sugar, E.A.; O’Dwyer, P.J.; Ramanathan, R.K.; Von Hoff, D.D.; Rasheed, Z.; Zheng, L.; Begum, A.; Anders, R.; Maitra, A.; et al. Phase 2 Study of Vismodegib, a Hedgehog Inhibitor, Combined with Gemcitabine and Nab-Paclitaxel in Patients with Untreated Metastatic Pancreatic Adenocarcinoma. Br. J. Cancer 2020, 122, 498-505. [CrossRef]

160. Dréno, B.; Kunstfeld, R.; Hauschild, A.; Fosko, S.; Zloty, D.; Labeille, B.; Grob, J.J.; Puig, S.; Gilberg, F.; Bergström, D.; et al. Two Intermittent Vismodegib Dosing Regimens in Patients with Multiple Basal-Cell Carcinomas (MIKIE): A Randomised, Regimen-Controlled, Double-Blind, Phase 2 Trial. Lancet Oncol. 2017, 18, 404-412. [CrossRef]

161. Mortier, L.; Bertrand, N.; Basset-Seguin, N.; Saiag, P.; Dupuy, A.; Dalac-Rat, S.; Guillot, B.; Templier, C.; Desmedt, E.; Duhamel, A.; et al. Vismodegib in Neoadjuvant Treatment of Locally Advanced Basal Cell Carcinoma: First Results of a Multicenter, Open-Label, Phase 2 Trial (VISMONEO Study). J. Clin. Oncol. 2018, 36, 9509. [CrossRef]

162. Sekulic, A.; Migden, M.R.; Basset-Seguin, N.; Garbe, C.; Gesierich, A.; Lao, C.D.; Miller, C.; Mortier, L.; Murrell, D.F.; Hamid, O; ; et al. Long-Term Safety and Efficacy of Vismodegib in Patients with Advanced Basal Cell Carcinoma: Final Update of the Pivotal ERIVANCE BCC Study. BMC Cancer 2017, 17, 332. [CrossRef] [PubMed]

163. Fosko, S.W.; Chu, M.B.; Armbrecht, E.; Galperin, T.; Potts, G.A.; Mattox, A.; Kurta, A.; Polito, K.; Slutsky, J.B.; Burkemper, N.M.; et al. Efficacy, Rate of Tumor Response, and Safety of a Short Course (12-24 Weeks) of Oral Vismodegib in Various Histologic Subtypes (Infiltrative, Nodular, and Superficial) of High-Risk or Locally Advanced Basal Cell Carcinoma, in an Open-Label, Prospective Case Series Clinical Trial. J. Am. Acad. Dermatol. 2020, 82, 946-954. 
164. Basset-Seguin, N.; Hauschild, A.; Grob, J.-J.; Kunstfeld, R.; Dréno, B.; Mortier, L.; Ascierto, P.A.; Licitra, L.; Dutriaux, C.; Thomas, L.; et al. Vismodegib in Patients with Advanced Basal Cell Carcinoma (STEVIE): A Pre-Planned Interim Analysis of an International, Open-Label Trial. Lancet Oncol. 2015, 16, 729-736. [CrossRef]

165. Bossi, P.; Peris, K.; Calzavara-Pinton, P.; Queirolo, P.; Alfieri, S.; Palla, M.; Rossi, M.T.; Spagnolo, F.; Tambone, S.; Astolfi, C.; et al. Cohort Analysis of Safety and Efficacy of Vismodegib in Italian Patients from the Phase II, Multicenter STEVIE Study. Futur. Oncol. 2020, 16, 1091-1100. [CrossRef] [PubMed]

166. Basset-Séguin, N.; Hauschild, A.; Kunstfeld, R.; Grob, J.; Dréno, B.; Mortier, L.; Ascierto, P.A.; Licitra, L.; Dutriaux, C.; Thomas, L.; et al. Vismodegib in Patients with Advanced Basal Cell Carcinoma: Primary Analysis of STEVIE, an International, Open-Label Trial. Eur. J. Cancer 2017, 86, 334-348. [CrossRef]

167. Ben Ishai, M.; Tiosano, A.; Fenig, E.; Ben Simon, G.; Yassur, I. Outcomes of Vismodegib for Periocular Locally Advanced Basal Cell Carcinoma from an Open-Label Trial. JAMA Ophthalmol. 2020, 138, 749-755. [CrossRef]

168. Tibes, R.; Kosiorek, H.E.; Dueck, A.; Palmer, J.; Slack, J.L.; Knight, E.A.; Hashmi, S.K.; Bogenberger, J.M.; Zblewski, D.; Hogan, W.J.; et al. Phase I/IB Study of Azacitidine and Hedgehog Pathway Inhibition with Sonidegib (LDE225) in Myeloid Malignancies. Blood 2017, 130, 2629.

169. Buadi, F.K.; Lacy, M.Q.; Dispenzieri, A.; Perez, G.; Gertz, M.A.; Kapoor, P.; Hayman, S.R.; Dingli, D.; Go, R.S.; Fonder, A.; et al. Phase 2 Trial of LDE225 and Lenalidomide Maintenance Post Autologous Stem Cell Transplant for Multiple Myeloma. Blood 2019, 134, 1905. [CrossRef]

170. Gupta, V.; Wolleschak, D.; Hasselbalch, H.; Vannucchi, A.M.; Koschmieder, S.; Cervantes, F.; Li, Y.; Dong, T.; Wroclawska, M.; Bharathy, S.; et al. Safety and Efficacy of the Combination of Sonidegib and Ruxolitinib in Myelofibrosis: A Phase 1b/2 Dose-Finding Study. Blood Adv. 2020, 4, 3063-3071. [CrossRef]

171. Sallman, D.A.; Komrokji, R.S.; Sweet, K.L.; Mo, Q.; McGraw, K.L.; Duong, V.H.; Zhang, L.; Nardelli, L.A.; Padron, E.; List, A.F.; et al. A Phase 2 Trial of the Oral Smoothened Inhibitor Glasdegib in Refractory Myelodysplastic Syndromes (MDS). Leuk. Res. 2019, 81, 56-61. [CrossRef]

172. Minami, Y.; Minami, H.; Miyamoto, T.; Yoshimoto, G.; Kobayashi, Y.; Munakata, W.; Onishi, Y.; Kobayashi, M.; Ikuta, M.; Chan, G.; et al. Phase I Study of Glasdegib (PF-04449913), an Oral Smoothened Inhibitor, in Japanese Patients with Select Hematologic Malignancies. Cancer Sci. 2017, 108, 1628-1633. [CrossRef] [PubMed]

173. Ottmann, O.G.; Stegelmann, F.; Breccia, M.; Steegmann, J.L.; Olavarria, E.; Aimone, P.; Lipton, J.H. Smoothened Inhibitor Erismodegib Combined with Nilotinib in Patients with Chronic Myeloid Leukemia Resistant/Intolerant to at Least One Prior Tyrosine Kinase Inhibitor: A Phase 1b Study. Leuk. Lymphoma 2021, 62, 739-742. [CrossRef] [PubMed]

174. Kieran, M.W.; Chisholm, J.; Casanova, M.; Brandes, A.A.; Aerts, I.; Bouffet, E.; Bailey, S.; Leary, S.; Macdonald, T.J.; Mechinaud, F.; et al. Phase i Study of Oral Sonidegib (LDE225) in Pediatric Brain and Solid Tumors and a Phase II Study in Children and Adults with Relapsed Medulloblastoma. Neuro-Oncology 2017, 19, 1542-1552. [CrossRef] [PubMed]

175. Dummer, R.; Lear, J.T.; Guminski, A.; Leow, L.J.; Squittieri, N.; Migden, M. Efficacy of Sonidegib in Histologic Subtypes of Advanced Basal Cell Carcinoma: Results from the Final Analysis of the Randomized Phase 2 Basal Cell Carcinoma Outcomes With LDE225 Treatment (BOLT) Trial at 42 Months. J. Am. Acad. Dermatol. 2020, 84, 1162-1164. [CrossRef] [PubMed]

176. Lear, J.T.; Hauschild, A.; Stockfleth, E.; Squittieri, N.; Basset-Seguin, N.; Dummer, R. Efficacy and Safety of Sonidegib in Adult Patients with Nevoid Basal Cell Carcinoma Syndrome (Gorlin Syndrome): Results from a Phase 2, Double-Blind, Randomized Trial. Clin. Cosmet. Investig. Dermatol. 2020, 13, 117-121. [CrossRef]

177. Lee, K.; Molenaar, R.J.; Klaassen, R.; Bijlsma, M.F.; Weterman, M.J.; Richel, D.J.; Wymenga, M.; van Laarhoven, H.W.M.; Wilmink, J.W. A Phase I Study of LDE225 in Combination with Gemcitabine and Nab-Paclitaxel in Patients with Metastasized Pancreatic Cancer. Ann. Oncol. 2017, 28, v260. [CrossRef]

178. Pijnappel, E.N.; Klaassen, R.; van der Lee, K.S.; Pleunis - van Empel, M.; Richel, D.; Legdeur, M.; Nederveen, A.; van Laarhoven, H.W.M.; Wilmink, H.W. Phase I/II Study of LDE225 in Combination with Gemcitabine and Nab-Paclitaxel in Patients with Metastatic Pancreatic Cancer. Ann. Oncol. 2019, 30, v265. [CrossRef]

179. Ruiz-Borrego, M.; Jimenez, B.; Antolín, S.; García-Saenz, J.A.; Corral, J.; Jerez, Y.; Trigo, J.; Urruticoechea, A.; Colom, H.; Gonzalo, N.; et al. A Phase Ib Study of Sonidegib (LDE225), an Oral Small Molecule Inhibitor of Smoothened or Hedgehog Pathway, in Combination with Docetaxel in Triple Negative Advanced Breast Cancer Patients: GEICAM/2012-12 (EDALINE) Study. Invest. New Drugs 2019, 37, 98-108. [CrossRef]

180. Ross, A.E.; Hughes, R.M.; Glavaris, S.; Ghabili, K.; He, P.; Anders, N.M.; Harb, R.; Tosoian, J.J.; Marchionni, L.; Schaeffer, E.M.; et al. Pharmacodynamic and Pharmacokinetic Neoadjuvant Study of Hedgehog Pathway Inhibitor Sonidegib (LDE-225) in Men with High-Risk Localized Prostate Cancer Undergoing Prostatectomy. Oncotarget 2017, 8, 104182-104192. [CrossRef]

181. Gerds, A.T.; Tauchi, T.; Ritchie, E.; Deininger, M.; Jamieson, C.; Mesa, R.; Heaney, M.; Komatsu, N.; Minami, H.; Su, Y.; et al. Phase 1/2 Trial of Glasdegib in Patients with Primary or Secondary Myelofibrosis Previously Treated with Ruxolitinib. Leuk. Res. 2019, 79, 38-44. [CrossRef] [PubMed]

182. Savona, M.R.; Pollyea, D.A.; Stock, W.; Oehler, V.G.; Schroeder, M.A.; Lancet, J.; McCloskey, J.; Kantarjian, H.M.; Ma, W.W.; Naveed Shaik, M.; et al. Phase Ib Study of Glasdegib, a Hedgehog Pathway Inhibitor, in Combination with Standard Chemotherapy in Patients with AML or High-Risk MDS. Clin. Cancer Res. 2018, 24, 2294-2303. [CrossRef] 
183. Heuser, M.; Smith, B.D.; Fiedler, W.; Sekeres, M.A.; Montesinos, P.; Leber, B.; Merchant, A.; Papayannidis, C.; Pérez-Simón, J.A.; Hoang, C.J.; et al. Clinical Benefit of Glasdegib plus Low-Dose Cytarabine in Patients with de Novo and Secondary Acute Myeloid Leukemia: Long-Term Analysis of a Phase II Randomized Trial. Ann. Hematol. 2021, 100, 1181-1194. [CrossRef]

184. Smith, B.D.; Papayannidis, C.; Heuser, M.; Montesinos, P.; Sekeres, M.A.; Oriol, A.; Schiller, G.J.; Candoni, A.; Jamieson, C.H.; Hoang, C.J.; et al. Low-Dose Cytarabine with or without Glasdegib in Newly Diagnosed Patients with Acute Myeloid Leukemia: Long-Term Analysis of a Phase 2 Randomized Trial. J. Clin. Oncol. 2019, 37, 7010. [CrossRef]

185. Cortes, J.E.; Douglas Smith, B.; Wang, E.S.; Merchant, A.; Oehler, V.G.; Arellano, M.; DeAngelo, D.J.; Pollyea, D.A.; Sekeres, M.A.; Robak, T.; et al. Glasdegib in Combination with Cytarabine and Daunorubicin in Patients with AML or High-Risk MDS: Phase 2 Study Results. Am. J. Hematol. 2018, 93, 1301-1310. [CrossRef]

186. Richards, D.A.; Stephenson, J.; Wolpin, B.M.; Becerra, C.; Hamm, J.T.; Messersmith, W.A.; Devens, S.; Cushing, J.; Schmalbach, T.; Fuchs, C.S. A Phase Ib Trial of IPI-926, a Hedgehog Pathway Inhibitor, plus Gemcitabine in Patients with Metastatic Pancreatic Cancer. J. Clin. Oncol. 2012, 30, 213. [CrossRef]

187. Epstein, E.H.; Lear, J.; Saldanha, G.; Tang, J.Y.; Harwood, C. Hedgehog Pathway Inhibition by Topical Patidegib to Reduce BCC Burden in Patients with Basal Cell Nevus (Gorlin) Syndrome. J. Clin. Oncol. 2018, 36, e21626. [CrossRef]

188. Ueno, H.; Kondo, S.; Yoshikawa, S.; Inoue, K.; Andre, V.; Tajimi, M.; Murakami, H. A Phase I and Pharmacokinetic Study of Taladegib, a Smoothened Inhibitor, in Japanese Patients with Advanced Solid Tumors. Invest. New Drugs 2018, 36, 647-656. [CrossRef]

189. Glasspool, R.M.; Blagden, S.P.; Lockley, M.; Paul, J.; Hopkins, C.; Thomson, F.; Brown, J.; Fernandes, R.; Douglas, N.; Pou, C.; et al. A Phase I Trial of the Oral Hedgehog Inhibitor Taladegib (LY2940680) in Combination with Weekly Paclitaxel in Patients with Advanced, Solid Tumours. J. Clin. Oncol. 2017, 35, 2594. [CrossRef]

190. Bendell, J.; Andre, V.; Ho, A.; Kudchadkar, R.; Migden, M.; Infante, J.; Tiu, R.V.; Pitou, C.; Tucker, T.; Brail, L.; et al. Phase i Study of Ly2940680, a Smo Antagonist, in Patients with Advanced Cancer Including Treatment-Naïve and Previously Treated Basal Cell Carcinoma. Clin. Cancer Res. 2018, 24, 2082-2091. [CrossRef]

191. Nakamoto, Y.; Tsubamoto, H.; Sawazaki, M.; Kakuno, A.; Sonoda, T. A Phase II Study of S-1, Oxaliplatin, and Nab-Paclitaxel, and Itraconazole Aimed at Conversion Surgery for Advanced and Recurrent Gastric Cancer. J. Clin. Oncol. 2019, 37, 4026. [CrossRef]

192. Lee, M.; Hong, H.; Kim, W.; Zhang, L.; Friedlander, T.W.; Fong, L.; Lin, A.M.; Small, E.J.; Wei, X.X.; Rodvelt, T.J.; et al. Itraconazole as a Noncastrating Treatment for Biochemically Recurrent Prostate Cancer: A Phase 2 Study. Clin. Genitourin. Cancer 2019, 17, e92-e96. [CrossRef] [PubMed]

193. Madariaga, A.; Marastoni, S.; Colombo, I.; Mandilaras, V.; Cabanero, M.; Bruce, J.; Garg, S.; Wang, L.; Gill, S.; Dhani, N.C.; et al. Phase I/II Trial Assessing Hydroxychloroquine and Itraconazole in Women with Advanced Platinum-Resistant Epithelial Ovarian Cancer (EOC) (HYDRA-01). J. Clin. Oncol. 2020, 38, 6049. [CrossRef]

194. Sekulic, A.; Migden, M.R.; Oro, A.E.; Dirix, L.; Lewis, K.D.; Hainsworth, J.D.; Solomon, J.A.; Yoo, S.; Arron, S.T.; Friedlander, P.A.; et al. Efficacy and Safety of Vismodegib in Advanced Basal-Cell Carcinoma. N. Engl. J. Med. 2012, 366, 2171-2179. [CrossRef]

195. Migden, M.R.; Guminski, A.; Gutzmer, R.; Dirix, L.; Lewis, K.D.; Combemale, P.; Herd, R.M.; Kudchadkar, R.; Trefzer, U.; Gogov, S.; et al. Treatment with Two Different Doses of Sonidegib in Patients with Locally Advanced or Metastatic Basal Cell Carcinoma (BOLT): A Multicentre, Randomised, Double-Blind Phase 2 Trial. Lancet Oncol. 2015, 16, 716-728. [CrossRef]

196. Menyhárt, O.; Győrffy, B. Principles of Tumorigenesis and Emerging Molecular Drivers of SHH-Activated Medulloblastomas. Ann. Clin. Transl. Neurol. 2019, 6, 990-1005. [CrossRef] [PubMed]

197. Li, Y.; Song, Q.; Day, B.W. Phase I and Phase II Sonidegib and Vismodegib Clinical Trials for the Treatment of Paediatric and Adult MB Patients: A Systemic Review and Meta-Analysis. Acta Neuropathol. Commun. 2019, 7, 123. [CrossRef] [PubMed]

198. Ko, A.H.; LoConte, N.; Tempero, M.A.; Walker, E.J.; Kelley, R.K.; Lewis, S.; Chang, W.-C.; Kantoff, E.; Vannier, M.W.; Catenacci, D.V.; et al. A Phase I Study of FOLFIRINOX Plus IPI-926, a Hedgehog Pathway Inhibitor, for Advanced Pancreatic Adenocarcinoma. Pancreas 2016, 45, 370. [CrossRef] [PubMed]

199. Cohen, D.J.; Christos, P.J.; Kindler, H.L.; Catenacci, D.V.T.; Bekaii-Saab, T.B.; Tahiri, S.; Janjigian, Y.Y.; Gibson, M.K.; Chan, E.; Rajdev, L.; et al. Vismodegib (V), a Hedgehog (HH) Pathway Inhibitor, Combined with FOLFOX for First-Line Therapy of Patients (Pts) with Advanced Gastric and Gastroesophageal Junction (GEJ) Carcinoma: A New York Cancer Consortium Led Phase II Randomized Study. J. Clin. Oncol. 2013, 31, 4011. [CrossRef]

200. Yoon, C.; Park, D.J.; Schmidt, B.; Thomas, N.J.; Lee, H.J.; Kim, T.S.; Janjigian, Y.Y.; Cohen, D.J.; Yoon, S.S. CD44 Expression Denotes a Subpopulation of Gastric Cancer Cells in Which Hedgehog Signaling Promotes Chemotherapy Resistance. Clin. Cancer Res. 2014, 20, 3974-3988. [CrossRef]

201. Pietanza, M.C.; Litvak, A.M.; Varghese, A.M.; Krug, L.M.; Fleisher, M.; Teitcher, J.B.; Holodny, A.I.; Sima, C.S.; Woo, K.M.; Ng, K.K.; et al. A Phase I Trial of the Hedgehog Inhibitor, Sonidegib (LDE225), in Combination with Etoposide and Cisplatin for the Initial Treatment of Extensive Stage Small Cell Lung Cancer. Lung Cancer 2016, 99, 23. [CrossRef]

202. Hanna, N.; Bunn, P.A.; Langer, C.; Einhorn, L.; Guthrie, T.; Beck, T.; Ansari, R.; Ellis, P.; Byrne, M.; Morrison, M.; et al. Randomized Phase III Trial Comparing Irinotecan/Cisplatin with Etoposide/Cisplatin in Patients with Previously Untreated Extensive-Stage Disease Small-Cell Lime Cancer. J. Clin. Oncol. 2006, 24, 2038-2043. [CrossRef] [PubMed]

203. Lara, P.N., Jr.; Natale, R.; Crowley, J.; Lenz, H.J.; Redman, M.W.; Carleton, J.E.; Jett, J.; Langer, C.J.; Kuebler, J.P.; Dakhil, S.R.; et al. Phase III Trial of Irinotecan/Cisplatin Compared With Etoposide/Cisplatin in Extensive-Stage Small-Cell Lung Cancer: Clinical and Pharmacogenomic Results From SWOG S0124. J. Clin. Oncol. 2009, 27, 2530. [CrossRef] [PubMed] 
204. Kuehn, J.; Espinoza-Sanchez, N.A.; Teixeira, F.C.O.B.; Pavão, M.S.G.; Kiesel, L.; Győrffy, B.; Greve, B.; Götte, M. Prognostic Significance of Hedgehog Signaling Network-Related Gene Expression in Breast Cancer Patients. J. Cell. Biochem. 2021, 122, 577-597. [CrossRef] [PubMed]

205. Wang, B.; Yu, T.; Hu, Y.; Xiang, M.; Peng, H.; Lin, Y.; Han, L.; Zhang, L. Prognostic Role of Gli1 Expression in Breast Cancer: A Meta-Analysis. Oncotarget 2017, 8, 81088. [CrossRef] [PubMed]

206. Im, S.; Choi, H.J.; Yoo, C.; Jung, J.-H.; Jeon, Y.-W.; Suh, Y.J.; Kang, C.S. Hedgehog Related Protein Expression in Breast Cancer: Gli-2 Is Associated with Poor Overall Survival. Korean J. Pathol. 2013, 47, 116. [CrossRef]

207. Ten Haaf, A.; Bektas, N.; von Serenyi, S.; Losen, I.; Arweiler, E.C.; Hartmann, A.; Knüchel, R.; Dahl, E. Expression of the Glioma-Associated Oncogene Homolog (GLI) 1 in Human Breast Cancer Is Associated with Unfavourable Overall Survival. BMC Cancer 2009, 9, 298. [CrossRef]

208. Cheng, J.; Gao, J.; Tao, K. Prognostic Role of Gli1 Expression in Solid Malignancies: A Meta-Analysis. Sci. Rep. 2016, 6, 22184. [CrossRef]

209. Richtig, G.; Aigelsreiter, A.M.; Asslaber, M.; Weiland, T.; Pichler, M.; Eberhard, K.; Sygulla, S.; Schauer, S.; Hoefler, G.; Aigelsreiter, A. Hedgehog Pathway Proteins SMO and GLI Expression as Prognostic Markers in Head and Neck Squamous Cell Carcinoma. Histopathology 2019, 75, 118. [CrossRef]

210. Li, R.; Liu, Z.; Chen, Y.; Hu, X.; Peng, X. GLI1 Expression in Pancreatic Ductal Adenocarcinoma Correlates the Clinical Significance and Prognosis: A Meta-Analysis. Medicine 2020, 99, e20950. [CrossRef]

211. Liao, X.; Siu, M.K.Y.; Au, C.W.H.; Wong, E.S.Y.; Chan, H.Y.; Ip, P.P.C.; Ngan, H.Y.S.; Cheung, A.N.Y. Aberrant Activation of Hedgehog Signaling Pathway in Ovarian Cancers: Effect on Prognosis, Cell Invasion and Differentiation. Carcinogenesis 2009, 30, 131-140. [CrossRef] [PubMed]

212. Zhao, H.; Li, N.; Pang, Y.; Zhao, J.; Wu, X. Gli Affects the Stemness and Prognosis of Epithelial Ovarian Cancer via Homeobox Protein NANOG. Mol. Med. Rep. 2021, 23, 128. [CrossRef] [PubMed]

213. Ciucci, A.; De Stefano, I.; Vellone, V.G.; Lisi, L.; Bottoni, C.; Scambia, G.; Zannoni, G.F.; Gallo, D. Expression of the GliomaAssociated Oncogene Homolog 1 (Gli1) in Advanced Serous Ovarian Cancer Is Associated with Unfavorable Overall Survival. PLOS ONE 2013, 8, e60145.

214. Rossi, M.; Magnoni, L.; Miracco, C.; Mori, E.; Tosi, P.; Pirtoli, L.; Tini, P.; Oliveri, G.; Cosci, E.; Bakker, A. $\beta$-Catenin and Gli1 Are Prognostic Markers in Glioblastoma. Cancer Biol. Ther. 2011, 753, 753-761. [CrossRef]

215. Lv, L.; Yang, Z.; Ma, T.; Xuan, Y. Gli1, a Potential Cancer Stem Cell Marker, Is Strongly Associated with Prognosis in Prostate Cancer. Int. J. Clin. Exp. Pathol. 2018, 11, 4957.

216. Xu, M.; Li, X.; Liu, T.; Leng, A.; Zhang, G. Prognostic Value of Hedgehog Signaling Pathway in Patients with Colon Cancer. Med. Oncol. 2011, 29, 1010-1016. [CrossRef]

217. Ding, Y.L.; Zhou, Y.; Xiang, L.; Ji, Z.P.; Luo, Z. hong Expression of Glioma-Associated Oncogene Homolog 1 Is Associated with Invasion and Postoperative Liver Metastasis in Colon Cancer. Int. J. Med. Sci. 2012, 9, 334-338. [CrossRef]

218. Lu, L.; Wu, M.; Zhao, F.; Fu, W.; Li, W.; Li, X.; Liu, T. Prognostic and Clinicopathological Value of Gli-1 Expression in Gastric Cancer: A Meta-Analysis. Oncotarget 2016, 7, 69087. [CrossRef]

219. Qi, W.; Yang, Z.; Feng, Y.; Li, H.; Che, N.; Liu, L.; Xuan, Y. Gli1 Regulates Stemness Characteristics in Gastric Adenocarcinoma. Diagn. Pathol. 2020, 15, 60. [CrossRef]

220. Shao, X.; Kuai, X.; Pang, Z.; Zhang, L.; Wu, L.; Xu, L.; Zhou, C. Correlation of Gli1 and HER2 Expression in Gastric Cancer: Identification of Novel Target. Sci. Rep. 2018, 8, 397. [CrossRef]

221. Buczkowicz, P.; Ma, J.; Hawkins, C. GLI2 Is a Potential Therapeutic Target in Pediatric Medulloblastoma. J. Neuropathol. Exp. Neurol. 2011, 70, 430-437. [CrossRef]

222. Ha, Y.-S.; Yun, S.-J.; Kim, Y.-J.; Lee, S.-C.; Kim, W.-J. Utility of Smo as a Prognostic Marker for Human Bladder Tumors. Korean J. Urol. 2007, 48, 997-1003. [CrossRef]

223. Tu, Y.; Niu, M.; Xie, P.; Yue, C.; Liu, N.; Qi, Z.; Gao, S.; Liu, H.; Shi, Q.; Yu, R.; et al. Smoothened Is a Poor Prognosis Factor and a Potential Therapeutic Target in Glioma. Sci. Rep. 2017, 7, 42630. [CrossRef] [PubMed]

224. Tu, Y.; Chen, Z.; Zhao, P.; Sun, G.; Bao, Z.; Chao, H.; Fan, L.; Li, C.; You, Y.; Qu, Y.; et al. Smoothened Promotes Glioblastoma Radiation Resistance Via Activating USP3-Mediated Claspin Deubiquitination. Clin. Cancer Res. 2020, 26, 1749-1762. [CrossRef] [PubMed]

225. Li, H.; Lui, N.; Cheng, T.; Tseng, H.-H.K.; Yue, D.; Giroux-Leprieur, E.; Do, H.T.; Sheng, Q.; Jin, J.Q.; Luh, T.W.; et al. Gli as a Novel Therapeutic Target in Malignant Pleural Mesothelioma. PLoS ONE 2013, 8, e57346. [CrossRef] [PubMed]

226. Boetto, J.; Bielle, F.; Sanson, M.; Peyre, M.; Kalamarides, M. SMO Mutation Status Defines a Distinct and Frequent Molecular Subgroup in Olfactory Groove Meningiomas. Neuro-Oncology 2017, 19, 345-351.

227. Jin, M.Z.; Jin, W.L. The Updated Landscape of Tumor Microenvironment and Drug Repurposing. Signal Transduct. Target. Ther. 2020, 5, 166. [CrossRef]

228. Gupta, S.; Takebe, N.; LoRusso, P. Targeting the Hedgehog Pathway in Cancer. Ther. Adv. Med. Oncol. 2010, 2, 237. [CrossRef]

229. Tang, J.Y.; Mackay-Wiggan, J.M.; Aszterbaum, M.; Yauch, R.L.; Lindgren, J.; Chang, K.; Coppola, C.; Chanana, A.M.; Marji, J.; Bickers, D.R.; et al. Inhibiting the Hedgehog Pathway in Patients with the Basal-Cell Nevus Syndrome. N. Engl. J. Med. 2012, 366, 2180-2188. [CrossRef] 
230. Rodon, J.; Tawbi, H.A.; Thomas, A.L.; Stoller, R.G.; Turtschi, C.P.; Baselga, J.; Sarantopoulos, J.; Mahalingam, D.; Shou, Y.; Moles, M.A.; et al. A Phase I, Multicenter, Open-Label, First-in-Human, Dose-Escalation Study of the Oral Smoothened Inhibitor Sonidegib (LDE225) in Patients with Advanced Solid Tumors. Clin. Cancer Res. 2014, 20, 1900-1909. [CrossRef] [PubMed]

231. Italiano, A.; Le Cesne, A.; Bellera, C.; Piperno-Neumann, S.; Duffaud, F.; Penel, N.; Cassier, P.; Domont, J.; Takebe, N.; Kind, M.; et al. GDC-0449 in Patients with Advanced Chondrosarcomas: A French Sarcoma Group/US and French National Cancer Institute Single-Arm Phase II Collaborative Study. Ann. Oncol. 2013, 24, 2922. [CrossRef] [PubMed]

232. Ishii, T.; Shimizu, Y.; Nakashima, K.; Kondo, S.; Ogawa, K.; Sasaki, S.; Matsui, H. Inhibition Mechanism Exploration of Investigational Drug TAK-441 as Inhibitor against Vismodegib-Resistant Smoothened Mutant. Eur. J. Pharmacol. 2014, 723, 305-313. [CrossRef]

233. Bender, M.H.; Hipskind, P.A.; Capen, A.R.; Cockman, M.; Credille, K.M.; Gao, H.; Bastian, J.A.; Clay, J.M.; Lobb, K.L.; Sall, D.J.; et al. Abstract 2819: Identification and Characterization of a Novel Smoothened Antagonist for the Treatment of Cancer with Deregulated Hedgehog Signaling. Cancer Res. 2011, 71, 2819.

234. Tu, J.; Li, J.J.; Song, L.T.; Zhai, H.L.; Wang, J.; Zhang, X.Y. Molecular Modeling Study on Resistance of WT/D473H SMO to Antagonists LDE-225 and LEQ-506. Pharmacol. Res. 2017, 129, 491-499. [CrossRef]

235. Jäger, T.; Ocker, M.; Kiesslich, T.; Neureiter, E.; Neureiter, D. Expert Opinion on Investigational Drugs Thoughts on Investigational Hedgehog Pathway Inhibitors for the Treatment of Cancer Thoughts on Investigational Hedgehog Pathway Inhibitors for the Treatment of Cancer. Expert Opin. Investig. Drugs 2016, 26, 133-136. [CrossRef]

236. Li, Q.; Zhao, H.; Zhang, X.; Lang, H.; Yu, K. Novel-Smoothened Inhibitors for Therapeutic Targeting of Naïve and Drug-Resistant Hedgehog Pathway-Driven Cancers. Acta Pharmacol. Sin. 2019, 40, 257. [CrossRef]

237. Hoch, L.; Faure, H.; Roudaut, H.; Schoenfelder, A.; Mann, A.; Girard, N.; Bihannic, L.; Ayrault, O.; Petricci, E.; Taddei, M.; et al. MRT-92 Inhibits Hedgehog Signaling by Blocking Overlapping Binding Sites in the Transmembrane Domain of the Smoothened Receptor. FASEB J. 2015, 29, 1817-1829. [CrossRef] [PubMed]

238. Li, B.; Flaveny, C.A.; Giambelli, C.; Fei, D.L.; Han, L.; Hang, B.I.; Bai, F.; Pei, X.-H.; Nose, V.; Burlingame, O.; et al. Repurposing the FDA-Approved Pinworm Drug Pyrvinium as a Novel Chemotherapeutic Agent for Intestinal Polyposis. PLoS ONE 2014, 9, e101969. [CrossRef] [PubMed]

239. Carpenter, R.L.; Lo, H.W. Identification, Functional Characterization, and Pathobiological Significance of GLI1 Isoforms in Human Cancers. Vitam. Horm. 2012, 88, 115-140. [PubMed]

240. Calcaterra, A.; Iovine, V.; Botta, B.; Quaglio, D.; D’Acquarica, I.; Ciogli, A.; Iazzetti, A.; Alfonsi, R.; Severini, L.L.; Infante, P.; et al. Chemical, Computational and Functional Insights into the Chemical Stability of the Hedgehog Pathway Inhibitor GANT61. J. Enzym. Inhib. Med. Chem. 2018, 33, 349. [CrossRef]

241. Zhang, R.; Ma, J.; Avery, J.T.; Sambandam, V.; Nguyen, T.H.; Xu, B.; Suto, M.J.; Boohaker, R.J. GLI1 Inhibitor SRI-38832 Attenuates Chemotherapeutic Resistance by Downregulating NBS1 Transcription in BRAFV600E Colorectal Cancer. Front. Oncol. 2020, 10, 241. [CrossRef]

242. Hyman, J.M.; Firestone, A.J.; Heine, V.M.; Zhao, Y.; Ocasio, C.A.; Han, K.; Sun, M.; Rack, P.G.; Sinha, S.; Wu, J.J.; et al. SmallMolecule Inhibitors Reveal Multiple Strategies for Hedgehog Pathway Blockade. Proc. Natl. Acad. Sci. USA 2009, 106, 14132-14137. [CrossRef]

243. Xu, Y.; Chenna, V.; Hu, C.; Sun, H.-X.; Khan, M.; Bai, H.; Yang, X.-R.; Zhu, Q.-F.; Sun, Y.-F.; Maitra, A.; et al. Polymeric Nanoparticle-Encapsulated Hedgehog Pathway Inhibitor HPI-1 (NanoHHI) Inhibits Systemic Metastases in an Orthotopic Model of Human Hepatocellular Carcinoma. Clin. Cancer Res. 2012, 18, 1291-1302. [CrossRef] [PubMed]

244. Severini, L.L.; Ghirga, F.; Bufalieri, F.; Quaglio, D.; Infante, P.; Marcotullio, L. Di The SHH/GLI Signaling Pathway: A Therapeutic Target for Medulloblastoma. Expert Opin. Ther. Targets 2020, 24, 1159-1181.

245. Bariwal, J.; Kumar, V.; Dong, Y.; Mahato, R.I. Design of Hedgehog Pathway Inhibitors for Cancer Treatment. Med. Res. Rev. 2019, 39, 1137. [CrossRef] [PubMed]

246. Infante, P.; Mori, M.; Alfonsi, R.; Ghirga, F.; Aiello, F.; Toscano, S.; Ingallina, C.; Siler, M.; Cucchi, D.; Po, A.; et al. Gli1/DNA Interaction Is a Druggable Target for Hedgehog-Dependent Tumors. EMBO J. 2015, 34, 200. [CrossRef] [PubMed]

247. Infante, P.; Alfonsi, R.; Botta, B.; Mori, M.; Di Marcotullio, L. Targeting GLI Factors to Inhibit the Hedgehog Pathway. Trends Pharmacol. Sci. 2015, 36, 547-558. [CrossRef]

248. Justilien, V.; Walsh, M.P.; Ali, S.A.; Thompson, E.A.; Murray, N.R.; Fields, A.P. The PRKCI and SOX2 Oncogenes Are Co-Amplified and Cooperate to Activate Hedgehog Signaling in Lung Squamous Cell Carcinoma. Cancer Cell 2014, 25, 139. [CrossRef] [PubMed]

249. Tang, J.Y.; Ally, M.S.; Chanana, A.M.; Mackay-Wiggan, J.M.; Aszterbaum, M.; Lindgren, J.A.; Ulerio, G.; Rezaee, M.R.; Gildengorin, G.; Marji, J.; et al. Inhibition of the Hedgehog Pathway in Patients with Basal-Cell Nevus Syndrome: Final Results from the Multicentre, Randomised, Double-Blind, Placebo-Controlled, Phase 2 Trial. Lancet Oncol. 2016, 17, 1720-1731. [CrossRef]

250. Huang, X.B.; Shi, Y.; Wang, C.S.; Wang, X.D.; Cheng, J.; Che, F.F. Synergistic Inhibitory Effect of Arsenic Trioxide Combined with Itraconazole on Hedgehog Pathway of Multiple Myeloma NCI-H929 Cells. Zhongguo Shi Yan Xue Ye Xue Za Zhi 2016, 24, 1459-1465.

251. Zhang, Z.; Zhang, R.; Hao, C.; Pei, X.; Li, J.; Wang, L. GANT61 and Valproic Acid Synergistically Inhibited Multiple Myeloma Cell Proliferation via Hedgehog Signaling Pathway. Med. Sci. Monit. 2020, 26, e920541-1. [CrossRef] 
252. Berardozzi, S.; Bernardi, F.; Infante, P.; Ingallina, C.; Toscano, S.; De Paolis, E.; Alfonsi, R.; Caimano, M.; Botta, B.; Mori, M.; et al. Synergistic Inhibition of the Hedgehog Pathway by Newly Designed Smo and Gli Antagonists Bearing the Isoflavone Scaffold. Eur. J. Med. Chem. 2018, 156, 554-562. [CrossRef] [PubMed]

253. Bureta, C.; Saitoh, Y.; Tokumoto, H.; Sasaki, H.; Maeda, S.; Nagano, S.; Komiya, S.; Taniguchi, N.; Setoguchi, T. Synergistic Effect of Arsenic Trioxide, Vismodegib and Temozolomide on Glioblastoma. Oncol. Rep. 2019, 41, 3404-3412. [CrossRef] [PubMed]

254. Pan, D.; Li, Y.; Li, Z.; Wang, Y.; Wang, P.; Liang, Y. Gli Inhibitor GANT61 Causes Apoptosis in Myeloid Leukemia Cells and Acts in Synergy with Rapamycin. Leuk. Res. 2012, 36, 742-748. [CrossRef] [PubMed]

255. Cai, X.; Yu, K.; Zhang, L.; Li, Y.; Li, Q.; Yang, Z.; Shen, T.; Duan, L.; Xiong, W.; Wang, W. Synergistic Inhibition of Colon Carcinoma Cell Growth by Hedgehog-Gli1 Inhibitor Arsenic Trioxide and Phosphoinositide 3-Kinase Inhibitor LY294002. Onco Targets Ther. 2015, 8, 877. [PubMed]

256. Hou, X.; Chen, X.; Zhang, P.; Fan, Y.; Ma, A.; Pang, T.; Song, Z.; Jin, Y.; Hao, W.; Liu, F.; et al. Inhibition of Hedgehog Signaling by GANT58 Induces Apoptosis and Shows Synergistic Antitumor Activity with AKT Inhibitor in Acute T Cell Leukemia Cells. Biochimie 2014, 101, 50-59. [CrossRef]

257. Eckerdt, F.; Clymer, J.; Bell, J.B.; Beauchamp, E.M.; Blyth, G.T.; Goldman, S.; Platanias, L.C. Pharmacological MTOR Targeting Enhances the Antineoplastic Effects of Selective PI3K $\alpha$ Inhibition in Medulloblastoma. Sci. Rep. 2019, 9, 12822. [CrossRef]

258. Bai, X.Y.; Zhang, X.C.; Yang, S.Q.; An, S.J.; Chen, Z.H.; Su, J.; Xie, Z.; Gou, L.Y.; Wu, Y.L. Blockade of Hedgehog Signaling Synergistically Increases Sensitivity to Epidermal Growth Factor Receptor Tyrosine Kinase Inhibitors in Non-Small-Cell Lung Cancer Cell Lines. PLoS ONE 2016, 11, e0149370.

259. Sternberg, C.; Gruber, W.; Eberl, M.; Tesanovic, S.; Stadler, M.; Elmer, D.P.; Schlederer, M.; Grund, S.; Roos, S.; Wolff, F.; et al. Synergistic Cross-Talk of Hedgehog and Interleukin-6 Signaling Drives Growth of Basal Cell Carcinoma. Int. J. Cancer 2018, 143, 2943-2954. [CrossRef] 